Chaudhary, A. and K. J. Gutzwiller. 2020. Within-scale and cross-scale interaction effects of temperature and human socioeconomic conditions on avian abundance. Avian Conservation and Ecology 15(2):8. https://doi.org/10.5751/ACE-01622-150208

Copyright (C) 2020 by the author(s). Published here under license by the Resilience Alliance.

Research Paper

\title{
Within-scale and cross-scale interaction effects of temperature and human socioeconomic conditions on avian abundance
}

\author{
Anand Chaudhary ${ }^{1}$ and Kevin J. Gutzwiller ${ }^{1,2}$ \\ ${ }^{1}$ The Institute of Ecological, Earth, and Environmental Sciences, Baylor University, Waco, TX, USA, ${ }^{2}$ Department of Biology, \\ Baylor University, Waco, TX, USA
}

\begin{abstract}
The interactive effects of climate and human socioeconomic factors on biodiversity in the Anthropocene may be studied most effectively from a social-ecological perspective. Climate can affect avian abundance, and socioeconomics may affect the human propensity to contribute to conservation. Yet, little is known about how these two factors interact to affect species. We assessed the relative influence of within-scale (landscape) and cross-scale (region-landscape) interaction effects of breeding-season temperature and four socioeconomic variables (percent female, percent college educated, median age, and median income) on the relative abundance of eight forest bird species in the Eastern Temperate Forest Ecoregion of North America. We used negative binomial regression to model relative abundance over three years. Akaike's Information Criterion for small sample sizes (AICc) was used to rank a set of nine a priori models for each combination of species and socioeconomic variable. Of the 32 best-supported models, seven included informative within-scale interactions and three additional models included informative cross-scale interactions, indicating that the relationships between species' relative abundance and socioeconomic variables varied for different levels of temperature. Our results suggest that interactions were generally less influential than were climate, socioeconomic, and habitat variables. Distinct responses to interactions were not evident between habitat groups or between wintering groups. Interactions between human socioeconomic variables and breeding-season temperature at different spatial scales can affect forest bird abundance in species-specific ways. Ignoring the effects of interactions on broad-scale patterns of avian abundance may result in misleading interpretations about additive effects and, consequently, ineffective use of limited conservation resources.
\end{abstract}

\section{Effets interactifs dans l'échelle et inter-échelles entre la température et les conditions socioéconomiques humaines sur l'abondance de la faune aviaire}

RÉSUMÉ. Les effets interactifs du climat et des facteurs socioéconomiques humains sur la biodiversité au cours de la période Anthropocène peuvent être étudiés particulièrement efficacement du point de vue socio-écologique. Le climat peut affecter l'abondance de la faune aviaire et les aspects socioéconomiques peuvent influer sur la propension humaine à contribuer à la conservation. Pourtant, on ne sait que peu de choses sur la manière dont ces deux facteurs interagissent pour affecter les espèces. Nous avons évalué l'influence relative des effets des interactions dans l'échelle (paysage) et horst-échelle (région-paysage) de la température pendant la saison de reproduction et de quatre variables socioéconomiques (pourcentage de femmes, pourcentage de diplômés universitaires, âge moyen et revenu médian) sur l'abondance relative de huit espèces d'oiseaux forestiers dans l'écorégion forestière tempérée de l'Est de l'Amérique du Nord. Nous avons utilisé la régression binomiale négative pour modéliser l'abondance relative sur trois ans. Le critère d'information d'Akaike pour les échantillons de petite taille (AICc) a été utilisé pour classer une série de neuf modèles a priori pour chaque combinaison d'espèce et de variable socioéconomique. Sur les 32 modèles les mieux étayés, sept comprenaient des interactions dans l'échelle informatives et trois modèles supplémentaire incluaient des interactions inter-échelles informatives, ce qui indique que les relations entre l'abondance relative des espèces et les variables socioéconomiques variaient selon les niveaux de température; Nos résultats suggèrent que ces interactions étaient généralement moins influentes que les variables climatiques, socioéconomiques et liées à l'habitat. Les différences entre les réponses n'étaient pas évidentes entre les groupes d'habitat ni entre les groupes d'hivernage. Les interactions entre les variables socioéconomiques humaines et la température pendant la saison de reproduction sur différentes échelles spatiales peuvent affecter l'abondance des oiseaux forestiers de manière spécifique aux différentes espèces. Ignorer les effets des interactions des modèles larges d'abondance aviaire pourrait aboutir à des interprétations trompeuses au sujet des effets cumulés et en conséquence, de l'utilisation inefficace de ressources de conservation limitées.

Key Words: forest edge; forest interior; human socioeconomics; mean daily maximum temperature; Nearctic wintering; Neotropical wintering 


\section{INTRODUCTION}

Hierarchy theory implies that regional- and landscape-scale drivers of change may not operate independently of each other (Turner et al. 2001), and the processes at one scale may constrain patterns and processes at another scale (Turner et al. 2001, Peters et al. 2007). Only by investigating interactive effects can we reach a clear understanding of how these drivers affect responses at the focal scale (Cash and Moser 2000).

Interactions occur when the influence of one explanatory variable on the response variable differs with the level of another explanatory variable. Within-scale interactions (WSIs) occur when these interacting variables are operating at the same spatial scale, whereas cross-scale interactions (CSIs) occur when the variables are operating at different spatial scales (Soranno et al. 2014). Identification of such interactions can help ecologists decipher mechanisms from observed patterns (McMahon and Diez 2007), and knowledge of interactions can be important in conservation, yet little is known about how interactions affect ecological responses (Soranno et al. 2014).

Most multiscale research on bird-environment relationships has focused on analyzing variables as additive (main) effects (Battin and Lawler 2006) and not on interactions. A thorough literature search indicated that studies involving birds have examined WSI effects of habitat, weather, and climate (e.g., Mantyka-Pringle et al. 2012, Cox et al. 2013, Ferger et al. 2017), and we are aware of one CSI study involving birds that focused on the effects of habitat variables (Vergara and Armesto 2009). But because of the anthropogenic nature of the drivers of environmental change, much can be gained by studying ecological relationships from a social-ecological perspective (Collins et al. 2011), and WSI and CSI effects of climate and socioeconomic factors on birds have not been examined separately or together.

Climate refers to long-term ( $\geq 20$ years) meteorological averages, whereas weather refers to shorter term meteorological patterns (Reside et al. 2010). Climate can affect trends in bird abundances across sites, regions, and entire ranges (Brotons and Jiguet 2010, Illán et al. 2014). Even a small $\left(\sim 2{ }^{\circ} \mathrm{C}\right)$ change in average temperature can affect food availability and thus avian breeding success (Sanz et al. 2003). A landscape with favorable temperatures may have more resources (i.e., food and vegetation) for a species and result in higher dispersal of the species into and within a landscape. However, if the region surrounding the landscape has a less-favorable temperature, there may be fewer individuals in the region to disperse into the landscape. Regional climate may therefore affect landscape-scale avian population densities (Anders and Post 2006).

The socioeconomics of local human populations also can affect avian species (Lerman and Warren 2011). Tens of millions of American bird enthusiasts spend about four billion dollars annually on bird food and an additional billion dollars annually on feeders, bird houses, nest boxes, and bird baths (U.S. Department of Interior et al. 2014, 2018). These expenditures on food, feeders, and nest boxes are conservation-related because some bird species are likely to benefit from the supplemental food, nest sites, and water. This information indicates that population income has the potential to have an important effect on bird abundance. In addition, older aged, female, higher income, and college-educated Americans participate in birding more often than do those who are not in these categories (Carver 2013), and conservation support from these groups may be important as well. For these reasons, we were interested in how these four socioeconomic variables may interact with climate variables to influence forest-bird abundance.

If human populations belonging to specific socioeconomic categories can, through their direct (e.g., bird feeders) and indirect (e.g., home ownership and backyard vegetation) choices affect food and habitat availability for birds, these socioeconomic characteristics also may affect avian abundance in their neighborhoods and surrounding landscapes. Women are more involved in birding around their homes than are men (Cooper and Smith 2010), and women start birding at a significantly older age $($ mean $=32$ years $)$ than do men $($ mean $=23$ years; Moore et al. 2008). Birdwatchers are four times more likely to exhibit proenvironmental behavior such as donating money to conservation, supporting habitat management, and participating in environmental groups than are people who are not involved in wildlife-related recreation (Cooper et al. 2015). Human populations that associate with the natural environment tend to participate in activities that support nature (Mayer and Frantz 2004), and human populations engaged in activities that support nature (e.g., bird feeding) are more likely to take action to conserve birds in their backyards (Dayer et al. 2019). Groups involved in birdwatching (older people, wealthier households, more-educated people, and older women; Cooper and Smith 2010, Carver 2013) and bird feeding (older people and women) have a higher propensity to contribute to local bird conservation (Cooper et al. 2015, Dayer et al. 2019). Furthermore, age, income, and education can affect whether a person lives in rented or owner-occupied housing (U.S. Census Bureau 2013). Income and home ownership are important predictors of vegetation cover in residential yards (Boone et al. 2010), and the amount and type of vegetation cover in yards may affect resources available for birds (Narango et al. 2018).

Effects of climate and socioeconomic conditions have considerable potential to differ between groups of birds based on their habitat associations (forest interior or edge) and wintering location (Nearctic or Neotropical region). During the breeding season, forest-interior species are unlikely to occupy forest edges, whereas forest-edge species use the perimeter of the forest, adjacent fields, and clearings within forests (Freemark and Collins 1992). Because of their affinity to open areas with low canopy cover, forest-edge species may be subjected to higher temperatures than may forest-interior species. We used zoogeographical regions (Cox 2001) to define Nearctic-wintering species as those that are resident or that migrate short distances to winter within the Nearctic region, and Neotropical-wintering species as those that use the Neotropical region during winter. In addition to stressors on the breeding grounds, long-distance migrants such as Neotropical-wintering species face stressors during extensive migrations (Newton 2006), are affected by various impacts on their wintering grounds (Sæther and Engen 2010), and may therefore be more vulnerable to climate and human socioeconomic conditions than may Nearctic-wintering species. Since the North American Breeding Bird Survey (BBS) began in 1966, forest (Robbins et al. 1989, Sauer and Link 2011) and Neotropical migrant species (Robbins et al. 1989, Sauer et al. 2017) have exhibited declines across the eastern United States. We 
studied eight species as examples of how WSIs and CSIs may affect the abundance of forest-interior or forest-edge species and Nearctic- or Neotropical-wintering species that breed in this region. We used our results for these small sets of species to provide initial information about patterns that may be important to consider in subsequent analyses involving larger numbers of species.

Our focal climate variable was the 30 -year mean daily maximum temperature during the breeding season. Environmental temperature can affect human spending (Murray et al. 2010) and altruistic behaviors (Van de Vliert et al. 2004). If breeding-season temperature (temperature hereafter) alters the effects of socioeconomic variables on birds, there is potential for WSIs and CSIs involving these variables to affect avian abundance. Consider, for example, a scenario involving temperature and age. Older-aged human populations participate more often in bird feeding (Lepczyk et al. 2012, Dayer et al. 2019), and people are more likely to put out bird feeders when temperatures are colder (Dayer et al. 2019), such as during winter (Lepczyk et al. 2004). Investment in backyard bird feeders may thus be more common in areas with cooler breeding seasons and older aged populations, and less common in areas with warmer breeding seasons and younger aged populations. For these reasons, temperature and age have the potential to interact within or across scales to affect a species' abundance. Conceivably, temperature also may influence conservation-associated behavior in human populations that are wealthier, that have a higher percent of females $\geq 30$ years old, or that have a higher percent of college-educated individuals differently than it influences behavior in populations that are not in these categories. If so, such differences may result in WSI and CSI effects of temperature and socioeconomic factors on avian abundance.

One of our overarching goals was to identify potential influences of WSIs and CSIs involving temperature and socioeconomic factors on broad-scale patterns of avian abundance. To do so effectively, we studied these various effects while accounting for environmental variables (e.g., weather and land cover) already known to affect bird populations. Our second overarching goal was to provide results that can be used to help steer subsequent research on patterns (relationships) and associated underlying processes. Discernment of patterns is a necessary first step for identifying important relationships and setting the stage for follow-up studies of related mechanisms.

For this initial pattern assessment, we conducted a comparative analysis of the effects of WSIs, CSIs, their component additive (main) effects, weather variables, and habitat variables by addressing three questions. First, was there evidence that avian abundance was associated with WSIs and CSIs involving temperature and socioeconomic variables? Second, were the relative influences of WSIs and CSIs higher than those for the additive effects of temperature and socioeconomic variables, or higher than those for habitat and weather variables? And third, were there differences in associations with WSIs, CSIs, or temperature and socioeconomic variables between habitat groups (interior vs. edge species) and between wintering groups (Nearctic-wintering vs. Neotropical-wintering species) that warranted further investigation? These significant but understudied issues have important ramifications for broad-scale avian conservation.

\section{METHODS}

\section{Study area}

The study area (Fig. 1) lies within the Eastern Temperate Forest Ecoregion, a U.S. Environmental Protection Agency (EPA) Level I ecoregion in the eastern United States (Commission for Environmental Cooperation 1997, Omernik and Griffith 2014). This region's climate is generally warm and humid, but varies latitudinally and seasonally; the vegetation is primarily characterized by broadleaf deciduous and conifer forests (Commission for Environmental Cooperation 1997). Within this EPA Level I ecoregion, our study area occupied 14 EPA Level III ecoregions (Omernik and Griffith 2014). We used these 14 ecoregions because each contained at least 10 BBS routes that were active during the study period, and all of the regions were within the breeding ranges of all of our study species (BirdLife International and Handbook of the Birds of the World 2016; Appendix 1).

Fig. 1. Study area in the eastern United States consisting of 14 Environmental Protection Agency (EPA) Level III ecoregions within the breeding ranges of all eight study species.

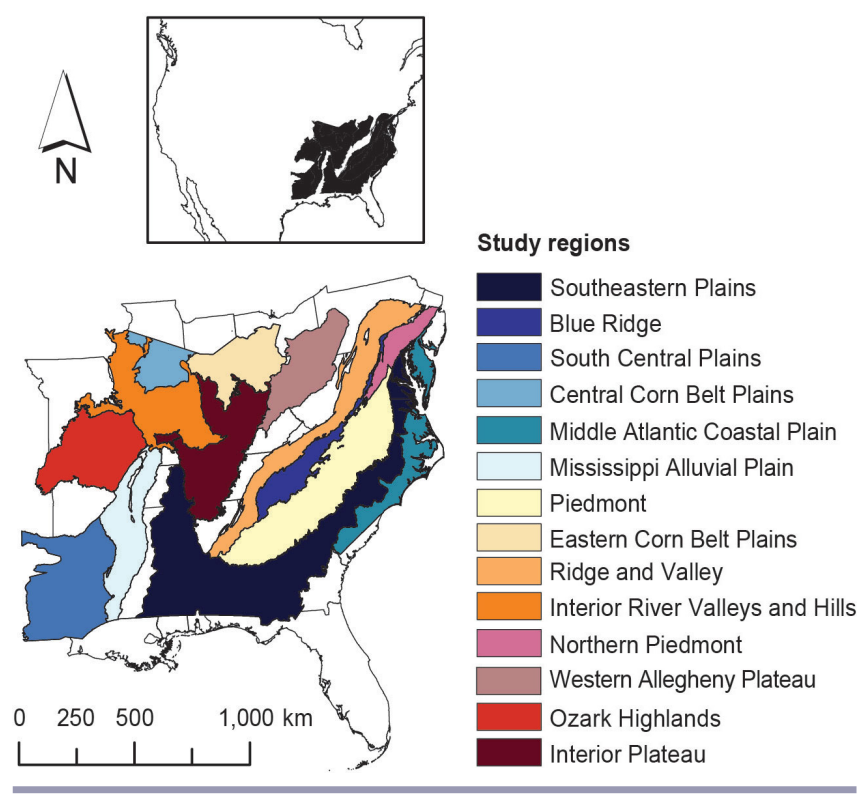

\section{Bird data}

We used data from BBS routes (Pardieck et al. 2016, Sauer et al. 2017) that were within the study ecoregions and had been run using standard BBS protocol and the single-observer method for three consecutive years (2010-2012). We compiled a list of species whose breeding ranges substantially overlapped large parts of the Eastern Temperate Forest Ecoregion. From this list, we chose as examples four forest-interior species and four forest-edge species, and each of these two groups included two Neotropical-wintering and two Nearctic-wintering species. The species' names, breedingseason habitat, wintering region, and the number of BBS routes used are in Table 1. A BBS route consists of 50 stops spaced 0.8 $\mathrm{km}$ apart, and at each stop the observer records all birds heard or seen during a 3-minute period (Sauer et al. 2013). For our study, the response variable (relative abundance) was calculated as the 
Table 1. Study species' names, breeding-season habitat, wintering region, and number of Breeding Bird Survey routes used.

\begin{tabular}{llll}
\hline \hline Common name & Scientific name & $\begin{array}{l}\text { Breeding-season } \\
\text { habitat }\end{array}$ & Wintering region \\
\hline Kentucky Warbler & Geothlypis formosa & Forest interior & Neotropical \\
Acadian Flycatcher & Empidonax virescens & Forest interior & Neotropical \\
Hairy Woodpecker & Picoides villosus & Forest interior & Nearctic \\
White-breasted Nuthatch & Sitta carolinensis & Forest interior & Nearctic \\
Yellow-breasted Chat & Icteria virens & Forest edge & Neotropical \\
Ruby-throated Hummingbird & Archilochus colubris & Forest edge & Neotropical \\
Northern Mockingbird & Mimus polyglottos & Forest edge & Nearctic \\
Brown-headed Cowbird & Molothrus ater & Forest edge & Nearctic \\
\hline
\end{tabular}

total number of individuals of a species detected on a BBS route during the 3-year study period (2010-2012).

\section{Candidate explanatory variables}

The landscape- and regional-scale mean daily maximum temperature of the breeding season, four landscape-scale socioeconomic variables, and the WSIs and CSIs involving temperature and socioeconomic variables were the focal explanatory variables (Table 2; Appendix 1). Landscape-scale variables were measured within species-specific buffers established around each BBS route; a species' median natal dispersal distance was used to define buffer size (Gutzwiller et al. 2015; Appendix 1). Regional-scale variables were measured within each Level III EPA ecoregion. As covariates, we also considered 11 landscape-and regional-scale explanatory variables to control for factors that may have affected avian relative abundance and that may have been associated with our focal explanatory variables (Table 2). To control for potential sources of variation in BBS data, five additional covariates were used: mean day of the year, area within $400 \mathrm{~m}$ of a route, number of years of assistant use, number of years involving first-time observers, and number of stops with excessive noise (Table 2). The rationale for using these covariates was explained in Appendix 1.

We used PRISM data (PRISM Climate Group 2016) to compute landscape- and regional-scale 30-year (1981-2010) mean daily maximum temperature (LndMaxTemp and RegMaxTemp) for the breeding season (May-July). LndMaxTemp values were binned into 14 groups, equal to the number of study regions (Appendix 1). Area-weighted averages (Appendix 1) of the percentage of the population that was female and $\geq 30$ years old (PercFemale), the percentage of the human population $\geq 25$ years old with $\geq 4$ years of college (PercColleg), median age (MedianAge), and median income (MedianInc) were the landscape-scale socioeconomic variables. These variables were derived from American Community Survey data for the 5-year period, 2009-2013 (U.S. Census Bureau 2015; Appendix 1).

We calculated percent cover for deciduous forest, mixed forest, and developed land from the 2011 National Land Cover Data (NLCD; Homer et al. 2015) using FRAGSTATS v4.2.1 (McGarigal et al. 2012). The four types of 2011 NLCD developed land-cover classes (21 [developed, open space], 22 [low-intensity developed], 23 [medium-intensity developed], and 24 [highintensity developed]) were combined in ArcGIS 10.1 (Environmental Systems Research Institute 2012) to measure percent cover for developed land. Weather involves short-term $(<$ 20 years) meteorological patterns (Reside et al. 2010), and threeyear averages for two weather variables (minimum temperature of the two coldest months, and precipitation during the spring; Table 2) were obtained from the PRISM Climate Group (2016).

\section{Statistical analyses}

Statistical analyses were carried out using various functions in the $\mathrm{R}$ base package version 3.6.1 (R Core Team 2019) except where stated otherwise below and in Appendix 1. All explanatory variables were standardized by subtracting the mean from each observation and then dividing by one standard deviation. For all eight species, we provided Kendall's tau $b$ correlation matrices (Appendix 2) for all of the explanatory variables used in the analyses. This correlation coefficient was provided because some of the variables (regional-scale) had many tied observations (Xu et al. 2013). Histograms (Appendix 1, Fig. A1.1) and scatterplots (Appendix 1, Fig. A1.2) for the set of routes used for the Rubythroated Hummingbird (Archilochus colubris) were provided to illustrate the frequency and geographic distributions of the four socioeconomic variables, and Pearson $(r)$ correlation matrices for the socioeconomic variables and geographic coordinates are provided in Appendix 1. This species was used because it had the largest number of observations ( $n=390$ routes) among the eight species in the analysis. The histograms, scatterplots, and correlations for the socioeconomic variables for the remaining seven species (not provided) were very similar because many of the BBS routes used were the same among species.

We fitted negative binomial (NB) regression models using $\mathrm{R}$ package MASS (Venables and Ripley 2002) for all eight species because the relative abundance values (counts) followed a negative binomial distribution. Model fitting was carried out in two stages. In the first stage we identified covariates (from among the 16 nonfocal explanatory variables) that individually were associated with at least $10 \%$ of the variation (Pearson 1993, Gutzwiller et al. 2015) in a species' relative abundance. To identify these variables for each species, each individual candidate covariate was regressed against relative abundance. $R^{2}{ }_{\text {COR }}$ values (squared correlation between actual and fitted values; Cameron and Trivedi 2013) $\geq$ $10 \%$ were used to identify covariates for a base model. We used the $\mathrm{R}$ package car (Fox and Weisberg 2011) to compute variance inflation factors (VIFs) for each covariate in the base model (Table 3). Covariates with VIFs $\geq 3$ (Zuur et al. 2010) were removed one at a time until all variables in the base model had VIFs $<3$ (Appendix 1). Steps taken in this stage reduced multicollinearity and the risk of spurious results associated with using a larger 
Table 2. Definitions and summary statistics for candidate explanatory variables in statistical analyses.

\begin{tabular}{|c|c|c|c|c|}
\hline Variable & Definition & $\operatorname{Mean}^{\dagger}$ & Range $^{\dagger}$ & Variable scale \\
\hline RegMaxTemp & $\begin{array}{l}\text { 30-year (1981-2010) mean daily maximum temperature }\left({ }^{\circ} \mathrm{C}\right) \text { for the breeding } \\
\text { season (May-July) }\end{array}$ & 28.3 & $25.9-31.4$ & Regional \\
\hline RegSprPrec & Precipitation (mm) during the spring (March and April 2010-2012) & 108.3 & $81.5-136.8$ & Regional \\
\hline RegWinTemp & $\begin{array}{l}\text { Daily minimum temperature }\left({ }^{\circ} \mathrm{C}\right) \text { of the two coldest months (Dec 2009, Jan } \\
\text { 2010, Dec 2010, Jan 2011, Dec 2011, Jan 2012) }\end{array}$ & -3.2 & $-7.3-1.5$ & Regional \\
\hline RegPercDev & Percent of developed land & 10.2 & $5.4-26.0$ & Regional \\
\hline RegPercDec & Percent of deciduous forest & 29.4 & $1.3-72.3$ & Regional \\
\hline RegPercMix & Percent of mixed forest & 2.4 & $0.0-6.8$ & Regional \\
\hline RegArea & Area (thousands of $\mathrm{km}^{2}$ ) of EPA III ecoregion & 106.6 & $29.2-302.1$ & Regional \\
\hline PercFemale & Percent of population that was female and $\geq 30$ years old & 33.2 & $22.0-43.0$ & Landscape \\
\hline PercColleg & Percent of population $\geq 25$ years old with $\geq 4$ years of college & 11.0 & $2.47-45.0$ & Landscape \\
\hline MedianAge & Median age (years) of population & 42.9 & $30.5-53.2$ & Landscape \\
\hline MedianInc & Median income (thousands of U.S. dollars) of population & 47.4 & $21.9-142.1$ & Landscape \\
\hline LndMaxTemp & $\begin{array}{l}\text { 30-year (1981-2010) mean daily maximum temperature }\left({ }^{\circ} \mathrm{C}\right) \text { for the breeding } \\
\text { season (May-July) }\end{array}$ & 28.6 & $22.4-32.3$ & Landscape \\
\hline LndSprPrec & Precipitation (mm) during the spring (March and April 2010-2012) & 106.6 & $62.5-192.9$ & Landscape \\
\hline LndWinTemp & $\begin{array}{l}\text { Daily minimum temperature }\left({ }^{\circ} \mathrm{C}\right) \text { of the two coldest months (Dec 2009, Jan } \\
\text { 2010, Dec 2010, Jan 2011, Dec 2011, Jan 2012) }\end{array}$ & -2.7 & $-8.7-4.1$ & Landscape \\
\hline LndPercDev & Percent of developed land & 8.3 & $2.3-68.7$ & Landscape \\
\hline LndPercDec & Percent of deciduous forest & 30.1 & $0.0-90.0$ & Landscape \\
\hline LndPercMix & Percent of mixed forest & 2.9 & $0.0-23.5$ & Landscape \\
\hline IntRegTemFem & Interaction $($ RegMaxTemp $\times$ PercFemale $)$ & 951.0 & $679.9-1266.0$ & Cross-scale \\
\hline IntRegTemColl & Interaction (RegMaxTemp $\times$ PercColleg) & 313.3 & $74.9-1213.0$ & Cross-scale \\
\hline IntRegTemAge & Interaction (RegMaxTemp $\times$ MedianAge) & 1229.5 & $895.6-1610.0$ & Cross-scale \\
\hline IntRegTemInc & Interaction (RegMaxTemp $\times$ MedianInc) & 1352.1 & $671.7-3841.0$ & Cross-scale \\
\hline IntLndTemFem & Interaction (LndMaxTemp $\times$ PercFemale $)$ & 947.9 & $691.0-1308.0$ & Within-scale \\
\hline IntLndTemColl & Interaction (LndMaxTemp $\times$ PercColleg) & 311.7 & $74.3-1244.0$ & Within-scale \\
\hline IntLndTemAge & Interaction (LndMaxTemp $\times$ MedianAge) & 1225.0 & $882.0-1618.0$ & Within-scale \\
\hline IntLndTemInc & Interaction (LndMaxTemp $\times$ MedianInc) & 1344.1 & $674.6-3938.0$ & Within-scale \\
\hline MnDayYear & Mean day of the year of the BBS survey $(2010-2012)$ & 160.5 & 139.3-186.7 & BBS Route \\
\hline Buff $400 \mathrm{~m}$ & Area $\left(\mathrm{km}^{2}\right)$ of $400 \mathrm{~m}$ buffer around BBS route & 32.8 & $15.0-53.9$ & BBS Route \\
\hline AssistUse & Assistant use (number of years) during BBS survey (2010-2012) & 0.9 & $0.0-3.0$ & BBS Route \\
\hline FirstObs & $\begin{array}{l}\text { Number of years first-time observer was used to run the BBS route (2010 } \\
2012 \text { ) }\end{array}$ & 0.1 & $0.0-2.0$ & BBS Route \\
\hline Noise & Total number of BBS route stops (2010-2012) with excessive noise & 6.9 & $0-57$ & $\begin{array}{l}\text { Stops along BBS } \\
\text { Route }\end{array}$ \\
\hline
\end{tabular}

number of potential variables in the second (model-selection) stage of the analyses. All covariates selected in stage one were included as base variables in stage two of the analyses.

In the second stage, we compared nine competing models (Table 3) separately for each combination of the eight species and four socioeconomic variables; this process involved assessment of 32 sets of models. Models within a set were compared using Akaike's Information Criterion adjusted for small sample size $\left(\mathrm{AIC}_{\mathrm{c}}\right.$; Burnham and Anderson 2002), and $\mathrm{AIC}_{\mathrm{c}}$ values were calculated and ranked using R package MuMIn (Barton 2018). For each of the 32 model sets, the model with the lowest $\mathrm{AIC}_{\mathrm{c}}$ value (bestsupported model) was interpreted (Burnham and Anderson 2002).

If spatial autocorrelation was detected in the residuals of the bestsupported model, spatial eigenvectors that reduced Moran's I for the residuals were added to the model one at a time until the absolute value of Moran's $I$ for the model's residuals was $\leq 0.1$ for all distance classes (Gutzwiller et al. 2015; Appendix 1). Standard techniques (Appendix 1) were used to confirm that all statistical assumptions of the analyses were met. We used methods in Hilbe (2014) to confirm that NB models were better suited for our data than were Poisson models. To characterize the amount of variation in the response variable that was associated with explanatory variables, we computed $R^{2}{ }_{\mathrm{COR}}$ for the best-supported models.

Assessment of interaction effects and relative effect sizes of variables was integral to addressing our research questions. We used the general approach of assessing the difference in fit between a full and a reduced model (Neter et al. 1989) instead of using the sum of weights (SW; Burnham and Anderson 2002). Specifically, we computed the change in $\mathrm{AIC}_{\mathrm{c}}\left(\Delta \mathrm{AIC}_{\mathrm{c}}\right)$ between the best-supported model and the reduced model in which the variable of interest was removed (Coppes et al. 2017). Within a model, a variable with a larger $\triangle \mathrm{AIC}_{\mathrm{c}}$ value was more influential than was a variable with a smaller $\Delta \mathrm{AIC}_{\mathrm{c}}$ because removing the former resulted in more degradation of model fit than did removing the latter. A negative $\Delta \mathrm{AIC}_{\mathrm{c}}$ value indicated that the reduced model had a better fit than did the best-supported model, implying that the associated variable was not influential. 
Table 3. Set of nine competing models used for each combination of species and socioeconomic variable.

\begin{tabular}{|c|c|}
\hline Model name & Explanatory variables $^{\dagger}$ \\
\hline Intercept only & None \\
\hline Base & Covariates selected in the first stage of the analysis \\
\hline Additive with landscape temperature & Base variables $^{\ddagger}+$ socioeconomic variable ${ }^{\S}+$ landscape temperature \\
\hline Additive with regional temperature & Base variables + socioeconomic variable + regional temperature \\
\hline Additive with both temperatures & Base variables + socioeconomic variable + landscape temperature + regional temperature \\
\hline Within-scale interaction & Base variables + socioeconomic variable $\times$ landscape temperature \\
\hline Cross-scale interaction & Base variables + socioeconomic variable $\times$ regional temperature \\
\hline Both interactions & Socioeconomic variable $\times$ landscape temperature + socioeconomic variable $\times$ regional temperature \\
\hline Global & $\begin{array}{l}\text { Base variables }+ \text { socioeconomic variable } \times \text { landscape temperature }+ \text { socioeconomic variable } \times \text { regional } \\
\text { temperature }\end{array}$ \\
\hline \multicolumn{2}{|c|}{$\begin{array}{l}\text { All models included an intercept term. For three species (Kentucky Warbler Geothlypis formosa, Ruby-throated Hummingbird Archilochus colubris, and } \\
\text { Brown-headed Cowbird Molothrus ater) no covariates (base variables) were found to be useful in the first stage of the analysis. Consequently, for these } \\
\text { species there were no differences between the Base model and the Intercept-only model, and no differences between the Global model and the Both- } \\
\text { interactions model. } \\
{ }^{7} \text { Base variables = covariates in the Base model. Within a species, the base variables were identical for all sets of competing models. } \\
{ }^{5} \text { There were four sets of competing models for each species; each set involved only one of the four socioeconomic variables (percent female, percent college, } \\
\text { median age, or median income). } \\
\text { 'For brevity, the interaction terms signify both the additive (main) effects and the cross-product of the additive effects. }\end{array}$} \\
\hline
\end{tabular}

Model weights $\left(w_{i}\right)$ from $\mathrm{AIC}_{\mathrm{c}}$-based model selection (Burnham and Anderson 2002) have often been used to estimate the relative influence of explanatory variables in regression models. But when variable influence is assessed using the $\mathrm{SW}$, interactions can inflate the $S W$ values associated with the explanatory variables involved in the interactions (Galipaud et al. 2014 and references therein). In addition, the SW has been found to be a poor measure of the relative influence of a variable (Galipaud et al. 2014) because SW values reflect the relative influence of models, or perhaps the occurrence of a variable among multiple models, but not the relative contribution of a variable in a given model (Cade 2015). SW values also can indicate levels of variable influence that are not consistent with the magnitudes of regression estimates or how much the variables contributed to maximizing model likelihoods (Cade 2015).

We computed $85 \%$ confidence intervals for regression coefficients because they are more consistent with $\mathrm{AIC}_{\mathrm{c}}$-based model selection (Arnold 2010) than are other (e.g., 90\% or 95\%) confidence intervals. If a confidence interval for a regression coefficient did not include zero, the variable was considered to be informative (Josefsson et al. 2018). We calculated VIFs to identify the degree of association among explanatory variables in the best-supported model. To help interpret the statistical results for the bestsupported models when VIFs were $\geq 3$, we followed advice from the literature. Specifically, high VIFs between nonfocal variables are not considered a problem because they do not affect the interpretation of the focal variables (Wooldridge 2003). And if focal explanatory variables with high VIFs are informative, high VIFs do not affect conclusions about the effects of those variables (Allison 1999, 2012).

A leave-one-out algorithm (Harrell 2001) was used to crossvalidate each best-supported model; we compared the mean absolute error (MAE) values for the best-supported model (fitted) to the MAE for the cross-validated model. Additional details about statistical analyses and figure production are in Appendix 1.

\section{RESULTS}

\section{Evidence for WSIs and CSIs involving temperature and socioeconomic variables}

A best-supported model was identified for each of 32 model sets ( 8 species $\times 4$ socioeconomic variables per species). For each combination of species and socioeconomic variable (i.e., each set of nine models) separately, two interactions (one WSI and one CSI; Table 2) were studied. Of the 32 best-supported models (Table 4; supporting statistics in Appendix 1, Tables A1.1 and A1.2), 12 contained interactions ( 9 WSIs and 3 CSIs), relative abundances for 5 of the 8 species were associated with informative interactions (Table 5; Appendix 1, Table A1.2), and 10 interaction effects were informative ( $85 \%$ CI did not include zero). To illustrate how a species' relative abundance may have been associated with variables involved in interactions, we considered in some detail a WSI involving the Yellow-breasted Chat (Icteria virens; Table 5). Relative abundance of the Yellow-breasted Chat (forest-edge species) was associated with the WSI involving landscape-scale 30-year (1981-2010) mean daily maximum breeding-season temperature (LndMaxTemp) and median income of the population (MedianInc). Yellow-breasted Chat relative abundance was greater in landscapes with higher LndMaxTemp; increasing MedianInc had a positive effect on relative abundance in the landscapes with the highest LndMaxTemp values and a negative effect on relative abundance in the remaining landscapes (Fig. 2).

\section{Relative influence of interactions versus other variables}

An individual socioeconomic variable (e.g., MedianInc) and its interaction with temperature were candidate variables in a maximum of eight sets of competing models (one set for each species), whereas the other variables considered were candidate variables in all 32 sets of competing models. We therefore calculated the occurrence of variables in the best-supported models as a percentage of possible best-supported models in which the variables could have potentially occurred. Within the 
Table 4. Best-supported and second-best-supported models for each species and socioeconomic variable. See Table 1 for scientific names.

\begin{tabular}{|c|c|c|c|c|}
\hline Species & $\begin{array}{l}\text { Socioeconomic } \\
\text { variable }\end{array}$ & Best-supported model $^{\dagger}$ & $\begin{array}{c}\mathrm{AIC}_{\mathrm{c}} \\
\text { difference }\end{array}$ & Second-best-supported model ${ }^{\dagger}$ \\
\hline \multirow[t]{4}{*}{ Kentucky Warbler } & Percent female & Additive with landscape temperature & 0.07 & Intercept only \\
\hline & Percent college & Within-scale interaction & 5.70 & Cross-scale interaction \\
\hline & Median age & Within-scale interaction & 2.54 & Additive with both temperatures \\
\hline & Median income & Within-scale interaction & 9.13 & Cross-scale interaction \\
\hline \multirow[t]{4}{*}{ Acadian Flycatcher } & Percent female & Additive with regional temperature & 2.02 & Cross-scale interaction \\
\hline & Percent college & Additive with regional temperature & 7.01 & Additive with landscape temperature \\
\hline & Median age & Additive with regional temperature & 6.91 & Additive with landscape temperature \\
\hline & Median income & Additive with regional temperature & 2.07 & Cross-scale interaction \\
\hline \multirow[t]{4}{*}{ Hairy Woodpecker } & Percent female & Within-scale interaction & 1.50 & Additive with both temperatures \\
\hline & Percent college & Additive with landscape temperature & 2.11 & Additive with regional temperature \\
\hline & Median age & Additive with landscape temperature & 1.52 & Base \\
\hline & Median income & Within-scale interaction & 1.10 & Additive with landscape temperature \\
\hline \multirow[t]{4}{*}{ White-breasted Nuthatch } & Percent female & Additive with both temperatures & 0.13 & Additive with landscape temperature \\
\hline & Percent college & Additive with both temperatures & 3.30 & Additive with regional temperature \\
\hline & Median age & Additive with both temperatures & 0.24 & Additive with landscape temperature \\
\hline & Median income & Additive with both temperatures & 0.98 & Additive with regional temperature \\
\hline \multirow[t]{4}{*}{ Yellow-breasted Chat } & Percent female & Additive with landscape temperature & 34.09 & Both interactions \\
\hline & Percent college & Within-scale interaction & 6.91 & Both interactions \\
\hline & Median age & Within-scale interaction & 0.40 & Additive with landscape temperature \\
\hline & Median income & Within-scale interaction & 7.95 & Both interactions \\
\hline Ruby-throated & Percent female & Additive with landscape temperature & 1.17 & Additive with regional temperature \\
\hline \multirow[t]{3}{*}{ Hummingbird } & Percent college & Additive with landscape temperature & 2.05 & Additive with both temperatures \\
\hline & Median age & Additive with landscape temperature & 0.72 & Additive with regional temperature \\
\hline & Median income & Within-scale interaction & 7.52 & Additive with landscape temperature \\
\hline \multirow[t]{4}{*}{ Northern Mockingbird } & Percent female & Additive with landscape temperature & 1.34 & Base \\
\hline & Percent college & Additive with landscape temperature & 1.67 & Additive with regional temperature \\
\hline & Median age & Additive with landscape temperature & 3.30 & Additive with regional temperature \\
\hline & Median income & Additive with landscape temperature & 0.71 & Additive with regional temperature \\
\hline \multirow[t]{4}{*}{ Brown-headed Cowbird } & Percent female & Cross-scale interaction & 1.88 & Within-scale interaction \\
\hline & Percent college & Intercept only & 5.58 & Additive with both temperatures \\
\hline & Median age & Cross-scale interaction & 3.06 & Within-scale interaction \\
\hline & Median income & Cross-scale interaction & 3.32 & Within-scale interaction \\
\hline
\end{tabular}

context of a best-supported model, variables with positive $\Delta \mathrm{AIC}_{\mathrm{c}}$ values were considered to be influential. On the basis of information in Table 6, the occurrence of influential CSIs associated with the four socioeconomic variables in the bestsupported models was $0 \%$ for CSIs involving percentage of the population $\geq 25$ years old with $\geq 4$ years of college (PercColleg) and $13 \%$ for CSIs involving the remaining three socioeconomic variables. Occurrence of influential WSIs ranged from $0 \%$ for WSIs involving median age of the population (MedianAge) to $50 \%$ for WSIs involving MedianInc. In contrast, the occurrences of influential additive effects of socioeconomic variables $(38 \%$ to $100 \%)$ and climate variables (16\% for 30-year mean daily maximum temperature during the breeding season at the regional scale [RegMaxTemp] and 50\% for LndMaxTemp) were higher in models. Only two covariates, landscape-scale percent of deciduous forest (LndPercDec) and landscape-scale daily minimum temperature of the two coldest months (LndWinTemp), were in the best-supported models for more than one species.
The relative influence of interactions varied among species and with the types of variables involved in the interaction. Among the 12 best-supported models with interaction effects, the relative influences (based on $\triangle \mathrm{AIC}_{\mathrm{c}}$ values) of interactions were less than were those for the additive effects of LndMaxTemp and RegMaxTemp in 10 models, and less than were those for the additive effects of socioeconomic variables in 9 models (Table 6). Among socioeconomic variables, the influences of the additive and interactive effects of PercColleg and MedianInc were generally higher than were those for percent of the population that was female and $\geq 30$ years old (PercFemale) and MedianAge (Table 6). When present in the same best-supported models, interactions tended to be less influential than was LndPercDec (Hairy Woodpecker, Picoides villosus) and more influential than was LndWinTemp (Yellow-breasted Chat; Table 6). 
Table 5. Statistics for the best-supported model relating Yellow-breasted Chat (Icteria virens) relative abundance to landscape-scale 30-year mean daily maximum temperature for the breeding season, median income, and other explanatory variables. ${ }^{\dagger}$

\begin{tabular}{|c|c|c|c|c|c|}
\hline Explanatory variable ${ }^{\ddagger}$ & Coefficient & $\mathrm{SE}$ & $85 \%$ CI for coefficient & $\Delta \mathrm{AIC}_{\mathrm{c}}^{\S}$ & $\mathrm{VIF}^{\prime}$ \\
\hline Intercept & 2.50 & 0.06 & $2.41-2.59$ & & \\
\hline LndMaxTemp & 1.09 & 0.15 & $0.88-1.30$ & 57.21 & 7.0 \\
\hline MedianInc & -0.38 & 0.08 & $-0.50--0.26$ & 38.92 & 1.3 \\
\hline Spatial eigenvector 48 & -0.39 & 0.06 & $-0.49--0.29$ & 28.59 & 1.1 \\
\hline Spatial eigenvector 16 & 0.49 & 0.08 & $0.36-0.63$ & 28.22 & 1.4 \\
\hline Spatial eigenvector 11 & -0.26 & 0.05 & $-0.34--0.17$ & 16.93 & 1.1 \\
\hline Spatial eigenvector 18 & 0.24 & 0.06 & $0.15-0.32$ & 14.31 & 1.1 \\
\hline Spatial eigenvector 34 & 0.23 & 0.05 & $0.15-0.31$ & 13.95 & 1.1 \\
\hline IntLndTemInc & 0.38 & 0.09 & $0.24-0.52$ & 13.09 & 1.3 \\
\hline Spatial eigenvector 40 & 0.15 & 0.05 & $0.08-0.22$ & 7.09 & 1.0 \\
\hline Spatial eigenvector 10 & -0.15 & 0.05 & $-0.24--0.07$ & 5.46 & 1.1 \\
\hline LndPercDev & -0.26 & 0.10 & $-0.40--0.12$ & 4.59 & 1.3 \\
\hline Spatial eigenvector 37 & 0.16 & 0.05 & $0.07-0.24$ & 4.39 & 1.1 \\
\hline Spatial eigenvector4 & 0.10 & 0.05 & $0.03-0.18$ & 2.35 & 1.1 \\
\hline LndWinTemp & -0.26 & 0.16 & $-0.48--0.04$ & 0.69 & 8.8 \\
\hline RegPercMix & -0.03 & 0.07 & $-0.13-0.07$ & -2.00 & 1.8 \\
\hline
\end{tabular}

Fig. 2. Model-based prediction for the relative abundance of Yellow-breasted Chat (Icteria virens; number of individuals) in relation to a within-scale interaction involving landscape-scale mean daily maximum temperature during the breeding season (Temperature $\left[{ }^{\circ} \mathrm{C}\right]$ ) and landscape-scale median income of the population (Median income [1000s of U.S. dollars]). The figure was based on the best-supported model (Table 5) from among a set of nine competing models for this species.

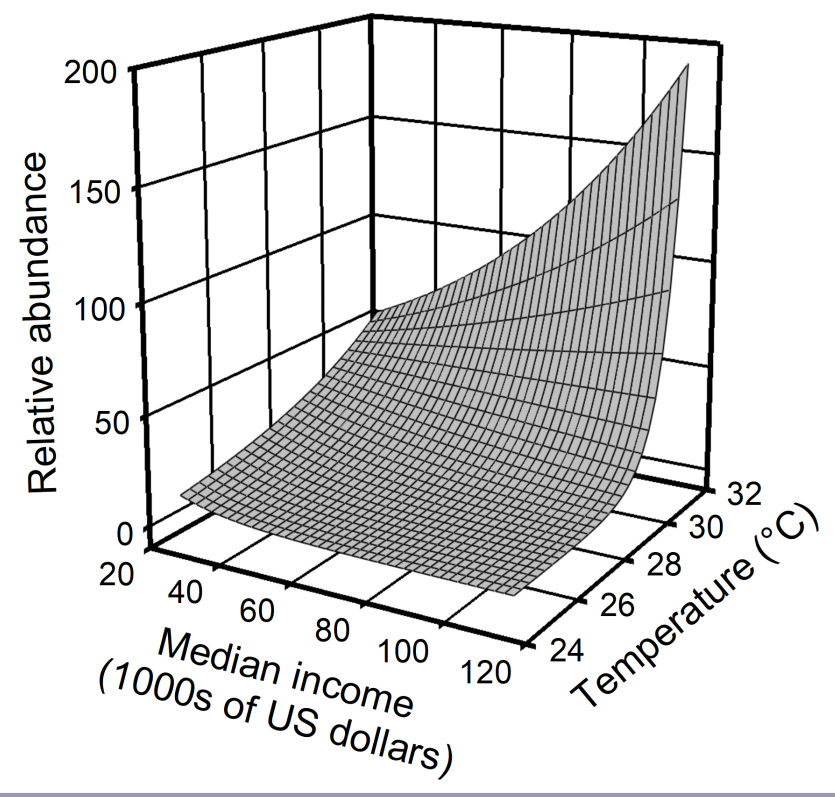

\section{Differences in associations with focal variables between habitat groups and between wintering groups}

There were no clear differences between forest-interior and forestedge species in the number of best-supported models with WSIs ( 5 vs. 4 models), with temperature and socioeconomic variables (11 vs. 8 models; Table 7), or in the relative influences of WSIs (Table 6). CSIs (three models) were only associated with the Brown-headed Cowbird (Molothrus ater; forest-edge, Nearcticwintering species). Furthermore, there were no clear differences in the additive associations of socioeconomic variables between the Neotropical-wintering and Nearctic-wintering groups (Table 6). LndMaxTemp was informative in more models (5 WSIs and 5 additive models) for Neotropical-wintering species than it was in models for Nearctic-wintering species (2 WSIs and 2 additive models). RegMaxTemp was informative in fewer CSIs (0) and more additive models (4) for Neotropical-wintering species than it was for Nearctic-wintering species (3 CSIs and 0 additive models; Table 5; Appendix 1, Table A1.2). Overall, the additive effects of temperature were more influential (higher $\Delta \mathrm{AIC}_{\mathrm{c}}$ ) on the relative abundance of Neotropical-wintering species than they were on the relative abundance of Nearctic-wintering species.

\section{DISCUSSION}

The explanatory abilities of our best-supported models varied considerably ( $R^{2}{ }_{\mathrm{COR}}$ range: $11.0-47.2 \%$; Appendix 1, Table A 1.2$)$, and the low $R_{\text {COR }}^{2}$ values $(<15 \%$ ) for some models (e.g., for Kentucky Warbler, Geothlypis formosa) imply that the factors considered by this study did not strongly affect some species' relative abundance. The low MAE values of most fitted models indicated a good fit, and fitted and cross-validated MAE values 
Table 6. Relative influence values $\left(\Delta \mathrm{AIC}_{\mathrm{c}}\right)$ for focal explanatory variables and common covariates in the best-supported models for each species and socioeconomic variable. ${ }^{\dagger}$

\begin{tabular}{|c|c|c|c|c|c|c|c|c|c|c|}
\hline \multirow[t]{2}{*}{ Species $^{\ddagger}$} & \multicolumn{4}{|c|}{ Socioeconomic variables ${ }^{\S}$} & \multirow[t]{2}{*}{ RegMaxTemp } & \multirow[t]{2}{*}{ LndMaxTemp } & \multirow[t]{2}{*}{ CSI } & \multirow[t]{2}{*}{ WSI } & \multirow[t]{2}{*}{ LndPercDec } & \multirow[t]{2}{*}{ LndWinTemp } \\
\hline & $\mathrm{PF}$ & $\mathrm{PC}$ & MA & MI & & & & & & \\
\hline \multirow{4}{*}{$\begin{array}{l}\text { Kentucky Warbler } \\
(\mathrm{I}, \mathrm{NT})\end{array}$} & 0.9 & $-\pi$ & - & - & - & 40.7 & - & - & - & - \\
\hline & - & 15.2 & - & - & - & 24.6 & - & 3.4 & - & - \\
\hline & - & - & -1.5 & - & - & 42.8 & - & -1.5 & - & - \\
\hline & - & - & - & 30.6 & - & 16.6 & - & 14.3 & - & - \\
\hline \multirow{4}{*}{$\begin{array}{l}\text { Acadian Flycatcher } \\
(\mathrm{I}, \mathrm{NT})\end{array}$} & -1.4 & - & - & - & 17.8 & - & - & - & 92.7 & - \\
\hline & - & -1.0 & - & - & 18.2 & - & - & - & 91.2 & - \\
\hline & - & - & 0.4 & - & 18.5 & - & - & - & 89.0 & - \\
\hline & - & - & - & 7.1 & 27.2 & - & - & - & 99.9 & - \\
\hline \multirow{4}{*}{$\begin{array}{l}\text { Yellow-breasted Chat } \\
(\mathrm{E}, \mathrm{NT})\end{array}$} & -2.1 & & - & - & - & 27.8 & - & - & - & 0.2 \\
\hline & - & 9.8 & - & - & - & 28.8 & - & 0.7 & - & -1.7 \\
\hline & - & - & -1.5 & - & - & 28.8 & - & -0.3 & - & -0.3 \\
\hline & - & - & - & 38.9 & - & 57.2 & - & 13.1 & - & 0.7 \\
\hline Ruby-throated & 1.0 & - & - & - & - & 10.2 & - & - & - & - \\
\hline \multirow[t]{3}{*}{ Hummingbird (E, NT) } & - & 19.1 & - & - & - & 18.3 & - & - & - & - \\
\hline & - & - & 1.8 & - & - & 7.1 & - & - & - & - \\
\hline & - & - & - & 19.3 & - & 17.4 & - & 9.9 & - & - \\
\hline \multirow{4}{*}{$\begin{array}{l}\text { Hairy Woodpecker } \\
\text { (I, NA) }\end{array}$} & -1.4 & - & - & - & - & 6.7 & - & 0.5 & 14.4 & - \\
\hline & - & -1.2 & - & - & - & 2.4 & - & - & 16.8 & - \\
\hline & - & - & -1.5 & - & - & 5.4 & - & - & 16.5 & - \\
\hline & - & - & - & 3.1 & & 3.4 & - & 2.7 & 12.4 & - \\
\hline White-breasted & -1.7 & - & - & - & -0.7 & -1.2 & - & - & 75.2 & - \\
\hline \multirow{3}{*}{ Nuthatch (I, NA) } & - & 21.8 & - & - & -0.2 & $-2.0 \mathrm{E}-02$ & - & - & 95.3 & - \\
\hline & - & - & -2.0 & - & -0.3 & -1.1 & - & - & 74.2 & - \\
\hline & - & - & - & 25.2 & -0.3 & -1.2 & - & - & 94.8 & - \\
\hline \multirow{4}{*}{$\begin{array}{l}\text { Northern Mockingbird } \\
\text { (E, NA) }\end{array}$} & -1.9 & - & - & - & - & -2.1 & - & - & 10.6 & 26.1 \\
\hline & - & 21.1 & - & - & - & -0.1 & - & - & 14.1 & 25.3 \\
\hline & - & - & 5.8 & - & - & -1.9 & - & - & 0.9 & 33.6 \\
\hline & - & - & - & 23.2 & - & -1.0 & - & - & 8.6 & 31.2 \\
\hline \multirow{4}{*}{$\begin{array}{l}\text { Brown-headed } \\
\text { Cowbird (E, NA) }\end{array}$} & 10.4 & - & - & - & 2.7 & - & 4.7 & - & - & - \\
\hline & $\ldots{ }^{\#}$ & $\ldots$ & $\ldots$ & $\ldots$ & $\ldots$ & $\ldots$ & $\ldots$ & $\ldots$ & $\ldots$ & $\ldots$ \\
\hline & - & - & 13.6 & - & 13.4 & - & 11.2 & - & - & - \\
\hline & - & - & - & 4.4 & -1.0 & - & 1.0 & - & - & - \\
\hline \multicolumn{11}{|c|}{ 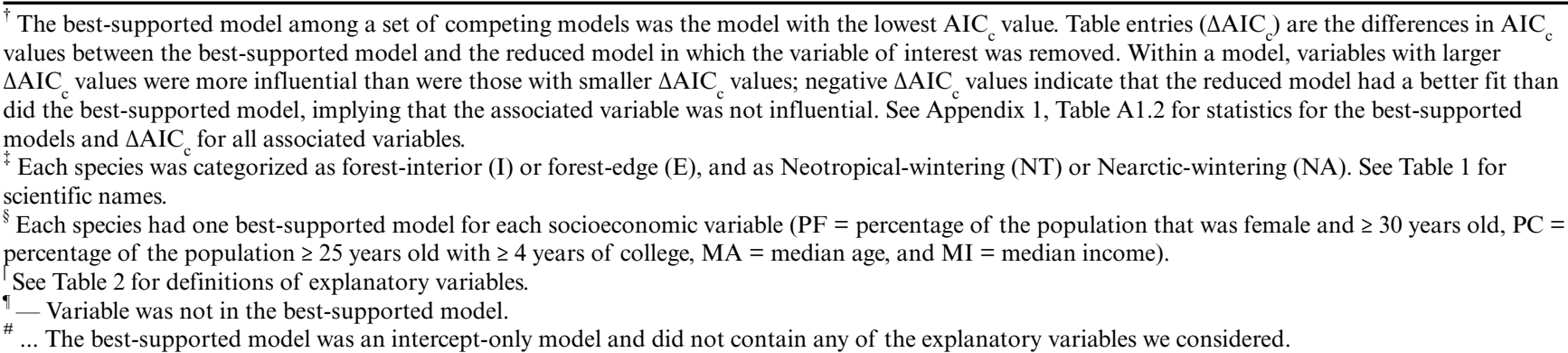 } \\
\hline
\end{tabular}

were similar in magnitude (Appendix 1, Table A1.2), indicating that our models generalized well to independent data. The low VIFs $(<3)$ for most of the variables (Table 5; Appendix 1, Table A1.2) suggested that individual explanatory variables in most models had largely independent effects on a species' relative abundance. In models for the Yellow-breasted Chat (Appendix 1, Table A1.2), our conclusion about the effects of focal climate variables with high VIFs $(>3)$ was not affected by collinearity because the variables' confidence intervals for the regression coefficients did not include 0 . In models for the Northern Mockingbird (Mimus polyglottos) and the White-breasted Nuthatch (Sitta carolinensis; Appendix 1, Table A1.2), focal climate variables with high VIFs had confidence intervals for the regression coefficients that included 0 . For these latter models, the collinearity prevented us from drawing clear conclusions about whether the focal climate variables were informative. The histograms for the socioeconomic variables indicated that there was ample variation in the data, and the scatterplots and Pearson correlations of socioeconomic variables against longitude and latitude implied that there were no strong geographical gradients in our socioeconomic data (Appendix 1). Kendall's tau b correlation matrices (Appendix 2) indicated that, apart from variables for which associations would be expected (e.g., between additive effects and their related interactions, and between some temperature variables) very few of the variables were strongly correlated with one another. 
Table 7. Types and numbers of best-supported models for the eight study species.

\begin{tabular}{|c|c|c|c|c|c|c|}
\hline \multirow[t]{2}{*}{$\overline{\text { Species }^{\dagger}}$} & \multicolumn{6}{|c|}{ Type of best-supported model ${ }^{\ddagger}$} \\
\hline & $\begin{array}{l}\text { Additive with both } \\
\text { temperatures }\end{array}$ & $\begin{array}{c}\text { Additive with } \\
\text { landscape temperature }\end{array}$ & $\begin{array}{l}\text { Additive with } \\
\text { regional temperature }\end{array}$ & $\begin{array}{l}\text { Within-scale } \\
\text { interaction }\end{array}$ & $\begin{array}{l}\text { Cross-scale } \\
\text { interaction }\end{array}$ & Intercept only \\
\hline $\begin{array}{l}\text { Kentucky Warbler } \\
\text { (I, NT) }\end{array}$ & $-\S$ & 1 & - & 3 & - & - \\
\hline $\begin{array}{l}\text { Acadian Flycatcher } \\
(\mathrm{I}, \mathrm{NT})\end{array}$ & - & - & 4 & - & - & - \\
\hline $\begin{array}{l}\text { Hairy Woodpecker } \\
\text { (I, NA) }\end{array}$ & - & 2 & - & 2 & - & - \\
\hline $\begin{array}{l}\text { White-breasted Nuthatch } \\
\text { (I, NA) }\end{array}$ & 4 & - & - & - & - & - \\
\hline $\begin{array}{l}\text { Yellow-breasted Chat } \\
(\mathrm{E}, \mathrm{NT})\end{array}$ & - & 1 & - & 3 & - & - \\
\hline $\begin{array}{l}\text { Ruby-throated } \\
\text { Hummingbird } \\
(\text { E, NT) }\end{array}$ & - & 3 & - & 1 & - & - \\
\hline $\begin{array}{l}\text { Northern Mockingbird } \\
\text { (E, NA) }\end{array}$ & - & 4 & - & - & - & - \\
\hline $\begin{array}{l}\text { Brown-headed Cowbird } \\
\text { (E, NA) }\end{array}$ & - & - & - & - & 3 & 1 \\
\hline \multicolumn{7}{|c|}{$\begin{array}{l}{ }^{7} \text { Each species was categorized as forest-interior (I) or forest-edge (E), and as Neotropical-wintering (NT) or Nearctic-wintering (NA). See Table } 1 \text { for all } \\
\text { scientific names. } \\
\text { The best-supported model among a set of competing models was the model with the lowest } \text { AIC }_{c} \text { value. There were } 32 \text { sets of competing models, one for } \\
\text { each combination of } 8 \text { species and } 4 \text { socioeconomic variables. Three model types (Base, Both interactions, and Global) were not selected as best-supported } \\
\text { models for any of the } 32 \text { sets of competing models. See Table } 3 \text { for definitions of names of competing models. } \\
\S \text { - None of the best-supported models for the species was of this type. }\end{array}$} \\
\hline
\end{tabular}

\section{Evidence for WSIs and CSIs involving temperature and socioeconomic variables}

Interactions between temperature and socioeconomic variables were present in more than one-third of the 32 best-supported models (4 models for each of 8 species), and most were informative. Interactions were not associated with the Acadian Flycatcher (Empidonax virescens), White-breasted Nuthatch, or the Northern Mockingbird and had low influence in some species' models (Table 6). The relative influence of interactions for other species (e.g., Kentucky Warbler $\Delta \mathrm{AIC}_{\mathrm{c}}=14.30$ and Brown-headed Cowbird $\triangle \mathrm{AIC}_{\mathrm{c}}=11.18$; Table 6 ) indicated, however, that not exploring WSIs and CSIs of temperature and socioeconomic variables on forest birds may miss information crucial for management decisions and lead to ineffective use of limited conservation resources.

To follow up on our Yellow-breasted Chat example, here we summarize one possible explanation (see additional details in Appendix 1) for the relationship between this species' relative abundance and the WSI involving LndMaxTemp and MedianInc (Fig. 2). Higher temperatures can lead to higher forest productivity (Raich et al. 2006) and more food for the Yellowbreasted Chat during the breeding season, which may have led to the progressively greater relative abundance of this species with higher LndMaxTemp (Fig. 2). The Yellow-breasted Chat's association with increasing MedianInc varied with LndMaxTemp (Fig. 2), and we hypothesize that this variation arose from the effect of maximum breeding-season temperature on human contributions to the conservation of natural places. Higher income populations are associated with proenvironmental behavior (Theodori and Luloff 2002), but such behavior may be affected by the amount of contact with nature (Schuttler et al.
2018). Environmental temperature can affect human behaviors (Van de Vliert et al. 2004), and we suggest that people in the warmest landscapes had less contact with nature (went out less often because of uncomfortably high temperatures), resulting in less contribution to the conservation of natural places. Landscapes with less support for conservation may have had less contiguous (more fragmented) forest and hence more edge habitat for the Yellow-breasted Chat; thus, in the warmest landscapes, relative abundance increased with increasing MedianInc (Fig. 2). But, as LndMaxTemp decreased, populations may have had increased contact with nature (went out more often), and increased proenvironmental behavior as MedianInc increased may have resulted in more contiguous forest and less edge habitat for the Yellow-breasted Chat. Consequently, as LndMaxTemp declined and MedianInc increased, less and less edge habitat may have been available, resulting in lower Yellow-breasted Chat relative abundance (Fig. 2).

\section{Relative influence of interactions versus other variables}

Environmental factors such as habitat and food are important in the regulation of bird populations (Newton 1991), and these factors are affected by climate (Crick 2004). Climate variables (RegMaxTemp, LndMaxTemp) had higher $\triangle \mathrm{AIC}_{\mathrm{c}}$ values than did the interactions, implying that additive climate effects had a greater influence on avian abundance. The greater relative influences of socioeconomic variables and LndPercDec compared to interactions (Table 6) suggest that the interactions involving temperature and landscape-scale human socioeconomic factors we studied were influential in some cases but were not as influential for forest birds overall as were the additive effects of socioeconomic, climate (LndMaxTemp, RegMaxTemp), and 
habitat variables. Yet, the greater relative influence of interactions compared to the relative influence of either the climate or the socioeconomic variable in some models (Table 6) underscores the need to consider interactions.

Generally, PercColleg and MedianInc had higher relative influences (Table 6) than did PercFemale and MedianAge, perhaps because education (positive relationship in three of five models) and income (positive relationship in all models) can dictate home ownership (Gyourko and Linneman 1997) and vegetation composition of backyards and neighborhoods (Melles 2005), and vegetation composition of yards can influence food availability for birds (Narango et al. 2018). In addition, households with higher education and income participate more actively in community groups (Matarrita-Cascante and Luloff 2008), including grassroots environmental movements (Weber 2000), and thus may contribute more to decisions that affect natural bird habitats at the landscape-scale. Appendix 1 contains additional discussion of the effects of LndPercDec and LndWinTemp on avian abundance.

\section{Differences in associations with focal variables between habitat groups and between wintering groups}

We considered eight species as examples of forest-interior, forestedge, Nearctic-wintering, and Neotropical-wintering groups of birds. Our findings that models for only one species included associations with CSIs, and that the relative influence of WSIs did not differ greatly between habitat groups or wintering groups, suggest that responses to interactions may be species-specific rather than group-specific (see Cox et al. 2013). These results emphasize the need to assess the influence of interactions on individual species, and not necessarily groups of species that share a habitat or wintering region.

Galitsky and Lawler (2015) found that avian species' responses to environmental factors at different scales were group-specific. Our results suggest that the response of breeding forest birds in the eastern United States to temperature may have been groupspecific, with Nearctic-wintering species being less associated with climate than were Neotropical-wintering species. Nearcticwintering species may have to cope with colder winter temperatures than may Neotropical-wintering species. Compared to Neotropical-wintering species, Nearctic-wintering species that breed in our study area may have developed greater capacity to tolerate a wider range of temperatures. Hence, in the eastern United States, Nearctic-wintering forest bird species may be less sensitive to temperature overall compared to Neotropicalwintering forest bird species.

\section{Implications for management and research}

Recognizing the limitations of single-scale analyses, landscape ecologists have advocated for hierarchical multiscale studies (Turner et al. 2001, Cushman and McGarigal 2002). The present study involving WSI and CSI effects of social-ecological conditions on avian abundance is to our knowledge the first of its kind. We demonstrated that avian abundance was associated with both WSIs and CSIs, and that these interactions can be more influential for some species than can additive influences of the interacting variables alone. For example, influences of a WSI was greater than the influence of PercFemale for the best-supported Hairy Woodpecker model, and the influences of CSIs were greater than the influences of RegMaxTemp for two best-supported Brown-headed Cowbird models (Table 6). We also found that different habitat and wintering groups of species were similarly susceptible to such interaction effects. If either landscape- or regional-scale variables exacerbate or ameliorate the effects of other variables, results of studies that do not consider interactions may be misleading. Factors already known to strongly influence a species of conservation concern may be good starting points for managers and researchers interested in incorporating WSIs and CSIs into analyses to improve conservation outcomes. Managers also may be interested in direct and indirect responses of species to human population demographics. For example, wealthier communities in some regions may have vegetation structure with lower value for native bird species (Loss et al. 2009), whereas in other regions native plants in backyard vegetation in wealthy communities may be vital habitat for birds (Warren et al. 2019).

Results that document important effects of social-ecological factors, and lack thereof, are essential for characterizing the full range of conditions that affect avian abundance. Based on our findings involving interactions, additional research on the ways in which climate, education, age, gender, and income affect avian abundance is warranted. The observed associations with socioeconomic variables appear to arise because of these variables' effects on bird habitat and food. For example, females are associated more with contributing money to conservation (Cooper et al. 2015).

The broad-scale nature of our study enabled us to identify patterns involving interactions of climate and human socioeconomics. At present, the lack of fine-scale data on relevant factors (e.g., backyard habitats, bird baths, bird feeders, expenditures on conservation, and conservation-friendly decisions by local committees) across large areas makes it difficult to discern the mechanisms involved. Fine-scale data for food, habitat, and other factors for birds may become available in the near future with new technologies or wider use of available technologies like light detection and ranging (LiDAR) imagery, for example. LiDAR currently has an approximate horizontal resolution as good as $0.5 \mathrm{~m}$ (Chang 2008) and vertical resolution as good as $0.1 \mathrm{~m}$ (Bradbury et al. 2005), and these resolutions are likely to improve in the future. Therefore, LiDAR imagery may enable assessment of backyard vegetation, presence of bird baths, or other fine-scale variables across large geographic areas. Such data hold promise for helping to disentangle the drivers of the patterns we uncovered.

For a broader assessment of the prevalence and effect size of interactions involving climate and socioeconomic factors, researchers need to consider a greater diversity of species in the analyses. The models for the species whose abundance was associated with interactions can be viewed as working hypotheses about such effects, and follow-up analyses with new data can be used to test hypotheses about the processes that underlie the patterns we observed. Grouping species based on their functional traits (Galitsky and Lawler 2015) rather than habitat groups may reveal group-specific responses not identified by the present study. Interactions can be nonlinear, include feedbacks, involve thresholds (Peters et al. 2004, Liu et al. 2007, Raffa et al. 2008, 
Soranno et al. 2014), and may have legacy effects, and identifying such patterns and their underlying mechanisms constitutes an important research frontier for avian ecologists and conservationists.

Responses to this article can be read online at: http://www.ace-eco.org/issues/responses.php/1622

\section{Acknowledgments:}

We thank S. Alexander, T. A. Pinney, J.-J. Song, J. D. White, and J. C. Yelderman for advice about this research and an early draft of the paper; $B . S$. Cade for information on statistical modeling and response-surface plotting; T. Arnold, L. Bosco, and J.-J. Song for statistical information; F. Eigenbrod, B. J. Payne, and B. Rimal for recommendations that improved the manuscript; and BirdLife International for species distribution maps. We are grateful to Baylor University for funding.

\section{LITERATURE CITED}

Allison, P. D. 1999. Multiple regression: a primer. Pine Forge, Thousand Oaks, California, USA.

Allison, P. D. 2012. When can you safely ignore multicollinearity? Statistical Horizons, 10 September. [online] URL: https:// statisticalhorizons.com/multicollinearity

Anders, A. D., and E. Post. 2006. Distribution-wide effects of climate on population densities of a declining migratory landbird. Journal of Animal Ecology 75:221-227. https://doi.org/10.1111/ j.1365-2656.2006.01034.x

Arnold, T. W. 2010. Uninformative parameters and model selection using Akaike's Information Criterion. Journal of Wildife Management 74:1175-1178. https://doi.org/10.2193/2009-367

Bartoń, K. 2018. Multi-model inference. R package version 1.40.4. [online] URL: https://CRAN.R-project.org/package=MuMIn

Battin, J., and J. J. Lawler. 2006. Cross-scale correlations and the design and analysis of avian habitat selection studies. Condor 108:59-70. https://doi.org/10.1650/0010-5422(2006)108[0059:CCATDA] 2.0.CO;2

BirdLife International, and Handbook of the Birds of the World. 2016. Bird species distribution maps of the world. Version 6.0. BirdLife International, Cambridge, UK. [online] URL: http:// datazone.birdlife.org/species/requestdis

Boone, C. G., M. L. Cadenasso, J. M. Grove, K. Schwarz, and G. L. Buckley. 2010. Landscape, vegetation characteristics, and group identity in an urban and suburban watershed: why the 60 s matter. Urban Ecosystems 13:255-271. https://doi.org/10.1007/ s11252-009-0118-7

Bradbury, R. B., R. A. Hill, D. C. Mason, S. A. Hinsley, J. D. Wilson, H. Balzter, G. Q. A. Anderson, M. J. Whittingham, I. J. Davenport, and P. E. Bellamy. 2005. Modelling relationships between birds and vegetation structure using airborne LiDAR data: a review with case studies from agricultural and woodland environments. Ibis 147:443-452. https://doi.org/10.1111/ j.1474-919x.2005.00438.x
Brotons, L., and F. Jiguet. 2010. Bird communities and climate change. Pages 275-294 in A. P. Møller, W. Fiedler, and P. Berthold, editors. Effects of climate change on birds. Oxford University Press, Oxford, UK.

Burnham, K. P., and D. R. Anderson. 2002. Model selection and multimodel inference: a practical information-theoretic approach. Second edition. Springer, New York, New York, USA.

Cade, B. S. 2015. Model averaging and muddled multimodel inferences. Ecology 96:2370-2382. https://doi.org/10.1890/14-1639.1

Cameron, A. C., and P. K. Trivedi. 2013. Regression analysis of count data. Second edition. Cambridge University Press, New York, USA.

Carver, E. 2013. Birding in the United States: a demographic and economic analysis. Addendum to the 2011 National Survey of Fishing, Hunting, and Wildlife-Associated Recreation. U.S. Fish and Wildlife Service, Arlington, Virginia, USA.

Cash, D. W., and S. C. Moser. 2000. Linking global and local scales: designing dynamic assessment and management processes. Global Environmental Change 10:109-120. https://doi.org/10.1016/ S0959-3780(00)00017-0

Chang, K.-T. 2008. Introduction to geographic information systems. Tata McGraw-Hill, New Delhi, India.

Collins, S. L., S. R. Carpenter, S. M. Swinton, D. E. Orenstein, D. L. Childers, T. L. Gragson, N. B. Grimm, J. M. Grove, S. L. Harlan, J. P. Kaye, A. K. Knapp, G. P. Kofinas, J. J. Magnuson, W. H. McDowell, J. M. Melack, L. A. Ogden, G. P. Robertson, M. D. Smith, and A. C. Whitmer. 2011. An integrated conceptual framework for long-term social-ecological research. Frontiers in Ecology and the Environment 9:351-357 https://doi.org/10.1890/100068

Commission for Environmental Cooperation 1997. Ecological regions of North America: toward a common perspective. Commission for Environmental Cooperation, Montreal, Quebec, Canada. [online] URL: http://www3.cec.org/islandora/en/ item/1701-ecological-regions-north-america-toward-common-perspective/

Cooper, C., L. Larson, A. Dayer, R. Stedman, and D. Decker. 2015. Are wildlife recreationists conservationists? Linking hunting, birdwatching, and pro-environmental behavior. Journal of Wildlife Management 79:446-457. https://doi.org/10.1002/ jwmg.855

Cooper, C. B., and J. A. Smith. 2010. Gender patterns in birdrelated recreation in the USA and UK. Ecology and Society 15 (4):4. https://doi.org/10.5751/ES-03603-150404

Coppes, J., J. Ehrlacher, D. Thiel, R. Suchant, and V. Braunisch. 2017. Outdoor recreation causes effective habitat reduction in capercaillie Tetrao urogallus: a major threat for geographically restricted populations. Journal of Avian Biology 48:1583-1594. https://doi.org/10.1111/jav.01239

Cox, B. 2001. The biogeographic regions reconsidered. Journal of Biogeography 28:511-523. https://doi.org/10.1046/j.1365-2699.2001.00566. $\mathrm{x}$

Cox, W. A., F. R. Thompson III, J. L. Reidy, and J. Faaborg. 2013. Temperature can interact with landscape factors to affect songbird productivity. Global Change Biology 19:1064-1074. https://doi.org/10.1111/gcb.12117 
Crick, H. Q. P. 2004. The impact of climate change on birds. Ibis 146:48-56. https://doi.org/10.1111/j.1474-919X.2004.00327.x

Cushman, S. A., and K. McGarigal. 2002. Hierarchical, multiscale decomposition of species-environment relationships. Landscape Ecology 17:637-646. https://doi.org/10.1023/A:1021571603605

Dayer, A. A., C. Rosenblatt, D. N. Bonter, H. Faulkner, R. J. Hall, W. M. Hochachka, T. B. Phillips, and D. M. Hawley. 2019. Observations at backyard bird feeders influence the emotions and actions of people that feed birds. People and Nature 1:138-151. https://doi.org/10.1002/pan3.17

Environmental Systems Research Institute (ESRI). 2012. ArcGIS Desktop 10.1. ESRI, Redlands, California, USA.

Ferger, S. W., M. K. Peters, T. Appelhans, F. Detsch, A. Hemp, T. Nauss, I. Otte, K. Böhning-Gaese, and M. Schleuning. 2017. Synergistic effects of climate and land use on avian beta-diversity. Diversity and Distributions 23:1246-1255. https://doi.org/10.1111/ ddi. 12615

Fox, J., and S. Weisberg. 2011. An $R$ companion to applied regression. Second edition. SAGE, Thousand Oaks, California, USA.

Freemark, K. E., and B. Collins. 1992. Landscape ecology of birds breeding in temperate forest fragments. Pages 443-454 in J. M. I. Hagan and D. W. Johnston, editors. Ecology and conservation of Neotropical migrant landbirds. Smithsonian Institution, Washington, D.C., USA.

Galipaud, M., M. A. F. Gillingham, M. David, and F.-X. Dechaume-Moncharmont. 2014. Ecologists overestimate the importance of predictor variables in model averaging: a plea for cautious interpretations. Methods in Ecology and Evolution 5:983-991. https://doi.org/10.1111/2041-210X.12251

Galitsky, C., and J. J. Lawler. 2015. Relative influence of local and landscape factors on bird communities vary by species and functional group. Landscape Ecology 30:287-299. https://doi. org/10.1007/s10980-014-0138-4

Gutzwiller, K. J., S. K. Riffell, and C. H. Flather. 2015. Avian abundance thresholds, human-altered landscapes, and the challenge of assemblage-level conservation. Landscape Ecology 30:2095-2110. https://doi.org/10.1007/s10980-015-0233-1

Gyourko, J., and P. Linneman. 1997. The changing influences of education, income, family structure, and race on homeownership by age over time. Journal of Housing Research 8:1-25.

Harrell Jr., F. E. 2001. Regression modeling strategies: with applications to linear models, logistic regression, and survival analysis. Springer, New York, New York, USA. https://doi. org/10.1007/978-1-4757-3462-1

Hilbe, J. M. 2014. Modeling count data. Cambridge University Press, New York, New York, USA.

Homer, C. G., J. A. Dewitz, L. Yang, S. Jin, P. Danielson, G. Xian, J. Coulston, N. D. Herold, J. D. Wickham, and K. Megwon. 2015. Completion of the 2011 National Land Cover Database for the conterminous United States-representing a decade of land cover change information. Photogrammetric Engineering and Remote Sensing 81:345-354.
Illán, J. G., C. D. Thomas, J. A. Jones, W.-K. Wong, S. M. Shirley, and M. G. Betts. 2014. Precipitation and winter temperature predict long-term range-scale abundance changes in Western North American birds. Global Change Biology 20:3351-3364. https://doi.org/10.1111/gcb.12642

Josefsson, J., T. Pärt, Å. Berg, A. M. Lokhorst, and S. Eggers. 2018. Landscape context and farm uptake limit effects of bird conservation in the Swedish Volunteer \& Farmer Alliance. Journal of Applied Ecology 55:2719-2730. https://doi.org/10.1111/1365-2664.13184

Lepczyk, C. A., A. G. Mertig, and J. Liu. 2004. Assessing landowner activities related to birds across rural-to-urban landscapes. Environmental Management 33:110-125. https://doi. org/10.1007/s00267-003-0036-Z

Lepczyk, C. A., P. S. Warren, L. Machabee, A. P. Kinzig, and A. G. Mertig. 2012. Who feeds the birds? A comparison across regions. Pages 267-284 in C. A. Lepczyk and P. S. Warren, editors. Urban bird ecology and conservation. University of California Press, Berkeley, California, USA. https://doi.org/10.1525/ california/9780520273092.003.0017

Lerman, S. B., and P. S. Warren. 2011. The conservation value of residential yards: linking birds and people. Ecological Applications 21:1327-1339. https://doi.org/10.1890/10-0423.1

Liu, J., T. Dietz, S. R. Carpenter, M. Alberti, C. Folke, E. Moran, A. N. Pell, P. Deadman, T. Kratz, J. Lubchenco, E. Ostrom, Z. Ouyang, W. Provencher, C. L. Redman, S. H. Schneider, and W. W. Taylor. 2007. Complexity of coupled human and natural systems. Science 317:1513-1516. https://doi.org/10.1126/science.1144004

Loss, S. R., M. O. Ruiz, and J. D. Brawn. 2009. Relationships between avian diversity, neighborhood age, income, and environmental characteristics of an urban landscape. Biological Conservation 142:2578-2585. https://doi.org/10.1016/j.biocon.2009.06.004

Mantyka-Pringle, C. S., T. G. Martin, and J. R. Rhodes. 2012. Interactions between climate and habitat loss effects on biodiversity: a systematic review and meta-analysis. Global Change Biology 18:1239-1252. https://doi.org/10.1111/ j.1365-2486.2011.02593.X

Matarrita-Cascante, D., and A. E. Luloff. 2008. Profiling participative residents in Western communities. Rural Sociology 73:44-61. https://doi.org/10.1526/003601108783575899

Mayer, F. S., and C. M. Frantz. 2004. The connectedness to nature scale: a measure of individuals' feeling in community with nature. Journal of Environmental Psychology 24:503-515. https://doi. org/10.1016/j.jenvp.2004.10.001

McGarigal, K., S. A. Cushman, and E. Ene. 2012. FRAGSTATS: Spatial pattern analysis program for categorical and continuous maps. University of Massachusetts, Amherst, Massachusetts, USA.

McMahon, S. M., and J. M. Diez. 2007. Scales of association: hierarchical linear models and the measurement of ecological systems. Ecology Letters 10:437-452. https://doi.org/10.1111/ j.1461-0248.2007.01036.x

Melles, S. J. 2005. Urban bird diversity as an indicator of human social diversity and economic inequality in Vancouver, British Columbia. Urban Habitats 3:25-48. 
Moore, R. L., D. Scott, and A. Moore. 2008. Gender-based differences in birdwatchers' participation and commitment. Human Dimensions of Wildlife 13:89-101. https://doi. org/10.1080/10871200701882525

Murray, K. B., F. Di Muro, A. Finn, and P. Popkowski Leszczyc. 2010. The effect of weather on consumer spending. Journal of Retailing and Consumer Services 17:512-520. https://doi. org/10.1016/j.jretconser.2010.08.006

Narango, D. L., D. W. Tallamy, and P. P. Marra. 2018. Nonnative plants reduce population growth of an insectivorous bird. Proceedings of the National Academy of Sciences of the United States of America 115:11549-11554. https://doi.org/10.1073/ pnas. 1809259115

Neter, J., W. Wasserman, and M. H. Kutner. 1989. Applied linear regression models. Second edition. Irwin Inc., Homewood, Illinois, USA.

Newton, I. 1991. Concluding remarks. Pages 637-654 in C. M. Perrins, J.-D. Lebreton, and G. J. M. Hirons, editors. Bird population studies: relevance to conservation and management. Oxford University Press, Oxford, UK.

Newton, I. 2006. Can conditions experienced during migration limit the population levels of birds? Journal of Ornithology 147:146-166. https://doi.org/10.1007/s10336-006-0058-4

Omernik, J. M., and G. E. Griffith. 2014. Ecoregions of the conterminous United States: evolution of a hierarchical spatial framework. Environmental Management 54:1249-1266. https:// doi.org/10.1007/s00267-014-0364-1

Pardieck, K. L., D. J. Ziolkowski, M.-A. R. Hudson, and K. Campbell. 2016. North American Breeding Bird Survey dataset 1966 - 2015, version 2015.1. U.S. Geological Survey, Patuxent Wildlife Research Center, Laurel, Maryland, USA. [online] URL: http://www.pwrc.usgs.gov/BBS/RawData/

Pearson, S. M. 1993. The spatial extent and relative influence of landscape-level factors on wintering bird populations. Landscape Ecology 8:3-18. https://doi.org/10.1007/BF00129863

Peters, D. P. C., B. T. Bestelmeyer, and M. G. Turner. 2007. Crossscale interactions and changing pattern-process relationships: consequences for system dynamics. Ecosystems 10:790-796. https://doi.org/10.1007/s10021-007-9055-6

Peters, D. P. C., R. A. Pielke, B. T. Bestelmeyer, C. D. Allen, S. Munson-McGee, and K. M. Havstad. 2004. Cross-scale interactions, nonlinearities, and forecasting catastrophic events. Proceedings of the National Academy of Sciences of the United States of America 101:15130-15135. https://doi.org/10.1073/ pnas.0403822101

PRISM Climate Group. 2016. Climate Data. PRISM Climate Group, Oregon State University, Corvallis, Oregon, USA. [online] URL: http://www.prism.oregonstate.edu/

R Core Team. 2019. R: A language and environment for statistical computing. version 3.6.1. $\mathrm{R}$ Foundation for Statistical Computing, Vienna, Austria. [online] URL: https://www.rproject.org/
Raffa, K. F., B. H. Aukema, B. J. Bentz, A. L. Carroll, J. A. Hicke, M. G. Turner, and W. H. Romme. 2008. Cross-scale drivers of natural disturbances prone to anthropogenic amplification: the dynamics of bark beetle eruptions. BioScience 58:501-517. https:// doi.org/10.1641/B580607

Raich, J. W., A. E. Russell, K. Kitayama, W. J. Parton, and P. M. Vitousek. 2006. Temperature influences carbon accumulation in moist tropical forests. Ecology 87:76-87. https://doi.org/10.1890/05-0023

Reside, A. E., J. J. VanDerWal, A. S. Kutt, and G. C. Perkins. 2010. Weather, not climate, defines distributions of vagile bird species. PLoS ONE 5:e13569. https://doi.org/10.1371/journal. pone. 0013569

Robbins, C. S., J. R. Sauer, R. S. Greenberg, and S. Droege. 1989. Population declines in North American birds that migrate to the Neotropics. Proceedings of the National Academy of Sciences of the United States of America 86:7658-7662. https://doi. org/10.1073/pnas.86.19.7658

Sæther, B.-E., and S. Engen. 2010. Population consequences of climate change. Pages 191-211 in A. P. Møller, W. Fiedler, and P. Berthold, editors. Effects of climate change on birds. Oxford University Press, Oxford, UK.

Sanz, J. J., J. Potti, J. Moreno, S. Merino, and O. Frías. 2003. Climate change and fitness components of a migratory bird breeding in the Mediterranean region. Global Change Biology 9:461-472. https://doi.org/10.1046/j.1365-2486.2003.00575.x

Sauer, J. R., and W. A. Link. 2011. Analysis of the North American Breeding Bird Survey using hierarchical models. Auk 128:87-98. https://doi.org/10.1525/auk.2010.09220

Sauer, J. R., W. A. Link, J. E. Fallon, K. L. Pardieck, and D. J. Ziolkowski. 2013. The North American Breeding Bird Survey 1966-2011: summary analysis and species accounts. North American Fauna 79:1-32. https://doi.org/10.3996/nafa.79.0001

Sauer, J. R., D. K. Niven, J. E. Hines, D. J. Ziolkowski, K. L. Pardieck, J. E. Fallon, and W. A. Link. 2017. The North American Breeding Bird Survey, results and analysis 1966-2015. Version 2.07.2017. U.S. Geological Survey Patuxent Wildlife Research Center, Laurel, Maryland, USA.

Schuttler, S. G., A. E. Sorensen, R. C. Jordan, C. Cooper, and A. Shwartz. 2018. Bridging the nature gap: can citizen science reverse the extinction of experience? Frontiers in Ecology and the Environment 16:405-411. https://doi.org/10.1002/fee.1826

Soranno, P. A., K. S. Cheruvelil, E. G. Bissell, M. T. Bremigan, J. A. Downing, C. E. Fergus, C. T. Filstrup, E. N. Henry, N. R. Lottig, E. H. Stanley, C. A. Stow, P.-N. Tan, T. Wagner, and K. E. Webster. 2014. Cross-scale interactions: quantifying multiscaled cause-effect relationships in macrosystems. Frontiers in Ecology and the Environment 12:65-73. https://doi.org/10.1890/120366

Theodori, G. L., and A. E. Luloff. 2002. Position on environmental issues and engagement in proenvironmental behaviors. Society \& Natural Resources 15:471-482. https://doi. org/10.1080/08941920290069128

Turner, M. G., R. H. Gardner, and R. V. O'Neill. 2001. Landscape ecology in theory and practice: pattern and process. Springer, New York, New York, USA. 
U.S. Census Bureau. 2013. American Housing Survey for the United States: 2011. U.S. Government Printing Office, Washington, D.C., USA.

U.S. Census Bureau. 2015. 2009-13 American Community Survey 5-year estimates. U.S. Census Bureau, Washington, D.C., USA. [online] URL: https://www.census.gov/programs-surveys/acs/ data/summary-file.2013.html

U.S. Department of Interior, U.S. Fish and Wildlife Service, and U.S. Department of Commerce. 2014. 2011 National Survey of Fishing, Hunting, and Wildlife-Associated Recreation. U.S. Fish and Wildlife Service, Washington, D.C., USA.

U.S. Department of Interior, U.S. Fish and Wildlife Service, U.S. Department of Commerce, and U.S. Census Bureau. 2018. 2016 National Survey of Fishing, Hunting, and Wildlife-Associated Recreation. U.S. Fish and Wildlife Service, Washington, D.C., USA.

Van de Vliert, E., X. Huang, and P. M. Parker. 2004. Do colder and hotter climates make richer societies more, but poorer societies less, happy and altruistic? Journal of Environmental Psychology 24:17-30. https://doi.org/10.1016/S0272-4944(03) 00021-5

Venables, W. N., and B. D. Ripley. 2002. Modern applied statistics with $S$. Fourth edition. Springer, New York, New York, USA. https://doi.org/10.1007/978-0-387-21706-2

Vergara, P. M., and J. J. Armesto. 2009. Responses of Chilean forest birds to anthropogenic habitat fragmentation across spatial scales. Landscape Ecology 24:25-38. https://doi.org/10.1007/ s10980-008-9275-y

Warren, P. S., S. B. Lerman, R. Andrade, K. L. Larson, and H. L. Bateman. 2019. The more things change: species losses detected in Phoenix despite stability in bird-socioeconomic relationships. Ecosphere 10:e02624. https://doi.org/10.1002/ecs2.2624

Weber, E. P. 2000. A new vanguard for the environment: grassroots ecosystem management as a new environmental movement. Society \& Natural Resources 13:237-259. https://doi. org/10.1080/089419200279081

Wooldridge, J. M. 2003. Introductory econometrics: a modern approach. Second edition. South-Western, Mason, Ohio, USA.

Xu, W., Y. Hou, Y. S. Hung, and Y. Zou. 2013. A comparative analysis of Spearman's rho and Kendall's tau in normal and contaminated normal models. Signal Processing 93:261-276. https://doi.org/10.1016/j.sigpro.2012.08.005

Zuur, A. F., E. N. Ieno, and C. S. Elphick. 2010. A protocol for data exploration to avoid common statistical problems. Methods in Ecology and Evolution 1:3-14. https://doi.org/10.1111/ j.2041-210X.2009.00001.x

Editor-in-Chief: Alexander L.Bond Subject Editor: Andrew J.Campomizzi

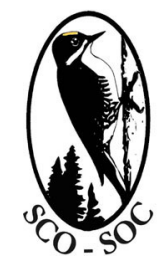

Sponsored by the Society of Canadian Ornithologists and Birds Canada

Parrainée par la Société des ornithologistes du Canada et Oiseaux Canada

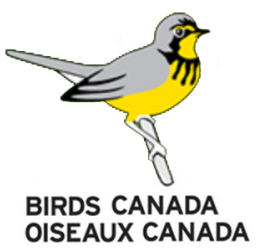


Appendix 1. Information about the study area, buffer sizes, explanatory variables, statistical analyses, how the interaction figure was produced, the within-scale interaction for the Yellowbreasted Chat, influential covariates, histograms and scatterplots for socioeconomic variables, and tables of statistics for $\mathrm{AIC}_{\mathrm{c}}$-based model selection and the best-supported regression models.

\section{Study area}

Our study area was within the Eastern Temperate Forest Ecoregion, which is a U.S.

Environmental Protection Agency (EPA) Level I ecoregion in the eastern United States (Commission for Environmental Cooperation 1997, Omernik and Griffith 2014). Each Level III ecoregion is a distinct ecological division of the Level I and II ecoregions and presents opportunities for unique management strategies based on its physical and biological characteristics (Commission for Environmental Cooperation 1997). Each EPA Level I ecoregion is divided into several Level II ecoregions, and each Level II ecoregion is further divided into several Level III ecoregions. Our study area fell within four EPA Level II ecoregions (Central USA Plains, Southeastern USA Plains, Ozark Ouachita-Appalachian Forests, and Mississippi Alluvial and Southeast USA Costal Plains) and two to six EPA Level III ecoregions within the EPA Level II ecoregions.

Central Corn Belt Plains and Eastern Corn Belt Plains were two Level III ecoregions within the Central USA Plains Ecoregion; both are now mostly covered by agriculture (U.S. Environmental Protection Agency 2017a). The Central Corn Belt Plains Ecoregion once was mostly prairie intermixed with oak-hickory (Quercus spp. - Carya spp.) forests. The Eastern Corn Belt Plains was once dominated by beech (Fagus spp.) forests and elm-ash (Ulmus spp. - Fraxinus spp.) swamp forests (U.S. Environmental Protection Agency 2017a).

Six EPA Level III ecoregions (Northern Piedmont, Interior River Valleys and Hills, Interior Plateau, Piedmont, Southeastern Plains, and South Central Plains) were from within the Southeastern USA Plains Ecoregion. The vegetation of the Northern Piedmont Ecoregion includes oak forest, but now it is mostly covered by agriculture. Large parts of the Interior River Valleys and Hills Ecoregion are under agriculture (cropland and pasture), but valley slopes have mixed oak and oak-hickory forests, and lower elevations have bottomland deciduous forests and swamp forests. The Interior Plateau Ecoregion is primarily oak-hickory forest, with some prairie and glades. The Piedmont Ecoregion vegetation is primarily composed of pine (Pinus spp.) and hardwood; this region is rapidly being converted to urban and suburban areas. The Southeastern Plains Ecoregion has longleaf pine ( $P$. palustris) forests, mixed forests, and agriculture. More than half of the South Central Plains Ecoregion is forest, and the ecoregion is populated mostly by loblolly (P. taeda) and shortleaf (P. echinata) pine plantations (U.S. Environmental Protection Agency 2017a).

Four EPA Level III ecoregions (Ridge and Valley, Western Allegheny Plateau, Blue Ridge, and Ozark Highlands) were from within the Ozark Ouachita-Appalachian Forests Ecoregion. Approximately half of the Ridge and Valley Ecoregion is under forest cover. Most of the Western Allegheny Plateau Ecoregion is under agriculture, but remaining forests are mainly 
mixed mesophytic and oak. The Blue Ridge Ecoregion consists of ridges, plateaus, and mountainous areas with forested slopes; most of the forests are composed of oak and northern hardwoods, but some spruce-fir (Picea spp. - Abies spp.) forests occur at higher elevations. The Ozark Highlands Ecoregion is generally forested with oak, but mixed forest of oak and pine also is present (U.S. Environmental Protection Agency 2017a).

Middle Atlantic Coastal Plain and Mississippi Alluvial Plain were the two EPA Level III Ecoregions within the Mississippi Alluvial and Southeast USA Costal Plains Ecoregion. The forest in the Middle Atlantic Coastal Plain Ecoregion consists mostly of loblolly and shortleaf pine. The forest in the Mississippi Alluvial Plain Ecoregion consists primarily of bottomland deciduous forest; much of this forest has now been converted to agriculture (U.S. Environmental Protection Agency 2017a).

Because we only included parts of the 14 EPA Level III ecoregions that were within the breeding ranges (BirdLife International and Handbook of the Birds of the World 2016) of all 8 study species, some edges of ecoregions in Fig.1 (in main text) appear as straight lines. GIS layers for the EPA ecoregions were obtained from the EPA (U.S. Environmental Protection Agency 2017a).

\section{Calculation of median natal dispersal distances and buffer sizes}

For each species, we calculated a median natal dispersal distance based on a species' general diet and its average body size (Sutherland et al. 2000). The dispersal distances (km) were: Kentucky Warbler (Geothlypis formosa, 2.6), Acadian Flycatcher (Empidonax virescens, 2.4), Hairy Woodpecker (Picoides villosus, 1.3), White-breasted Nuthatch (Sitta carolinensis, 1.0), Yellowbreasted Chat (Icteria virens, 1.1), Ruby-throated Hummingbird (Archilochus colubris, 0.8), Northern Mockingbird (Mimus polyglottos, 1.2), and Brown-headed Cowbird (Molothrus ater, 1.2). We used this distance to define the spatial extent of the landscape for each species (Gutzwiller et al. 2015) and created a landscape sampling buffer that extended this distance from both sides of a Breeding Bird Survey (BBS) route.

A species-specific landscape buffer based on the median natal dispersal distance was created around the boundaries of each EPA Level III ecoregion; shapefiles of ecoregions were obtained from the U.S. Environmental Protection Agency (2017b). To ensure that the landscape-scale measurements around a route did not involve information from more than one EPA Level III ecoregion, no routes that intersected the buffer along an ecoregion boundary were used in the analysis.

\section{Rationale for nonfocal explanatory variables (candidate covariates)}

Effects of several variables were studied at both the regional and landscape scales because the regional- and landscape-scale measures of variables we considered had the potential to affect avian abundance along the BBS routes. Nonfocal explanatory variables were included as candidate base variables to control for variables that had the potential to be associated with the 
focal explanatory variables, or to control for variation in abundance that was not of primary interest.

Precipitation during the spring (regional and landscape scales)

Weather conditions before the start of the breeding season can affect populations of many bird species (Sæther et al. 2004). Spring precipitation helps to establish soil moisture at the start of the growing season, and less spring precipitation can result in lower aboveground net primary productivity (Heisler-White et al. 2008). A decrease in net aboveground productivity may lead to a decrease in arthropod abundance (Kaspari et al. 2000, Kaspari 2001). There is a positive relationship between arthropod availability and abundance of individual forest bird species (Sillett et al. 2000, Jones et al. 2003). Given the connections between spring precipitation, vegetation growth, and arthropod availability, and the relationships between arthropod availability and avian abundance, precipitation during the spring has the potential to affect avian abundance.

Daily minimum temperature of the two coldest months (regional and landscape scales) Winter temperatures affect survival (Forsman and Mönkkönen 2003, Jones et al. 2003) and occupancy (Zuckerberg et al. 2011) of overwintering birds and summer productivity of habitat (Illán et al. 2014). Winter temperatures significantly affect abundances of terrestrial breeding bird species (Howard et al. 2015), and warmer winters have been associated with a higher abundance of individual resident breeding bird species (Jones et al. 2003). Hence, the minimum temperature of the two coldest months can potentially affect avian abundance.

Percent area covered by developed land (regional and landscape scales) Participation in birding-related activities varies with income (Carver 2009). Higher home densities can result in higher incidences of generalist bird species and lower incidences of specialist bird species (Fraterrigo and Wiens 2005), and therefore affect the abundance of the species we are studying. Potentially, values of the socioeconomic variables could be associated with the percentage of area covered by developed land. Including percentage of area covered by developed land in the analyses as a candidate covariate enabled us to control analytically for these effects, which were not of primary interest in our analysis. We used the $30-\mathrm{m}$ resolution 2011 National Land Cover Database land-cover class = 2 for developed land (MRLC 2016). Areas ranging from those with some construction but mostly vegetation (class 21 ) to $100 \%$ impervious surface (class 24) were included in developed land (MRLC 2016).

\section{Percent area covered by forest types (regional and landscape scales)}

To assess correlations between variables, we used Kendall's tau $b$ when there were many tied observations (Xu et al. 2013) (i.e., regional-scale data) and Pearson's correlation coefficient ( $r$ ) when the data had few tied observations. A preliminary analysis indicated that there were negative correlations between percent deciduous forest and percent evergreen forest at both the landscape $(r=-0.93)$ and regional scales $(\operatorname{tau} b=-0.59)$. At the landscape and regional scales, there were weak correlations between percent mixed forest and percent deciduous forest $(r=$ 0.06 , tau $b=0.35$, respectively) and between percent mixed forest and percent evergreen forest 
( $r=0.14$, tau $b=0.07$, respectively). We wanted to avoid using correlated variables in the same model. Because only a few of our species were associated with evergreen forest (Drapeau et al. 2000, Holmes and Sherry 2001, Billerman et al. 2020), and because of the pattern of correlations explained immediately above, we decided to include only percent deciduous forest and percent mixed forest as candidate covariates in our analysis.

Mean day of the year of BBS survey

BBSs are conducted during the breeding season, but the date of survey varies somewhat by route and year. Detectability of species may decline as the breeding season progresses because of concomitant declines in species' singing frequency (Sólymos et al. 2012), and this phenomenon could affect the recorded abundance for a species.

400-m buffer area around each BBS route

During a BBS, birds within approximately 400-m of the route are thought to be sampled by the observer (Sauer et al. 2003). However, BBS routes follow secondary roads and may not be a straight line. The total area sampled around a route may therefore vary due to the sinuosity of the route (Gutzwiller et al. 2015). This variation in area sampled could lead to variation in the number of birds detected per route and, consequently, in observed abundance. To control analytically for this potential source of variation associated with the area sampled, we used the area within $400 \mathrm{~m}$ of a BBS route as a candidate covariate in the statistical modeling.

\section{Area of landscapes and EPA Level III ecoregions}

Landscape-scale measurements were made within the buffers around each BBS route. The area of landscape depends on the median natal dispersal distance (Sutherland et al. 2000) of the species, length of the route, and the sinuosity of the route. Because the area of the landscape around each route varied, this variation could affect the observations of our landscape-scale weather variables (precipitation during the spring, and minimum temperature of the two coldest months). Specifically, larger areas may have a greater variety of possible values than may smaller areas. To control for the effect of differences in landscape area, we considered using landscape area as a covariate. However, we found that another covariate, the area of the $400 \mathrm{~m}$ buffer around a BBS route, was highly correlated ( $r=0.93$ to 0.99$)$ with the area of the landscape. Therefore, we did not use the area of the landscape as a candidate covariate to control for variation in size of the landscape sampled; the size of the $400 \mathrm{~m}$ buffer was sufficient for this purpose.

Because the areas of EPA Level III ecoregions vary in size, these areas may affect the variety of possible values of regional-scale climate and weather variables (daily maximum breeding-season temperature, precipitation during the spring, and daily minimum temperature of the two coldest months). Regional area was not correlated with landscape area (tau $b=0.12$ to 0.15 ) or with the size of the $400-\mathrm{m}$ buffer around each route ( $\operatorname{tau} b=0.09$ to 0.10 ). To control statistically for the effect of regional-scale area, we included the area of the region as a candidate covariate in the statistical modeling. 
Assistant use during a $B B S$

Many BBS routes are run using an assistant to help with activities like navigation and recording weather data (Downes et al. 2016), but the assistant does not count or record birds. The use of an assistant differs from the double-observer method because with the double-observer method there are two observers actively recording the birds and alternating as the primary and secondary observer (Nichols et al. 2000). When an observer approaches a survey location, birds nearby may flush away from the survey area or stop vocalizing (Buckland et al. 2008). The presence of an assistant may increase the level of disturbance and thus affect detection of birds during a single-observer bird survey. Effects of disturbance on birds could in turn affect observed abundance on a route. We analytically controlled for assistant use by using the number of years that a BBS route involved an assistant during 2010-2012 (0, 1, 2, or 3 years) as a candidate covariate in our models.

\section{First-time Observers}

We defined first-time observers as those who had not previously conducted a BBS survey. Firsttime observers on a BBS route may affect detection rates (Kendall et al. 1996), and this phenomenon could affect the recorded abundance for a species. We analytically controlled for first-time observer effects by using the number of years that a BBS route was run by a first-time observer during 2010-2012 (0,1,2, or 3 years) as a candidate covariate in our models.

\section{Excessive noise}

The BBS survey defines excessive noise as any constant ( $>45$ seconds) noise at any 1 of the 50 stops along a BBS route that affects the observer's ability to hear birds (U.S. Geological Survey Patuxent Wildlife Research Center and Canadian Wildlife Service 1998). The number of birds detected, and hence the recorded abundances of species, may be affected by excessive noise at stops along the BBS route. We used the total number of stops with excessive noise (2010-2012) as a candidate covariate to control analytically for the effect of excessive noise. Accounting for noise also may indirectly control for differences among observers in the ability to detect sounds in the presence of background noise. Because this ability can be lower in older observers, controlling for noise may help to control for observer differences associated with age.

\section{Calculation of weighted averages for socioeconomic variables}

The socioeconomic data came from the American Community Survey (U.S. Census Bureau 2015). A five-year estimate has the smallest sampling error and is the only estimate available for census blocks with populations $<20,000$ (U.S. Census Bureau 2009). Some of the census blocks in our study area had populations $<20,000$. Because our landscapes covered more than one census block group, we wanted to ensure that all estimates of the socioeconomic data we used were from the same period. Therefore, we used a five-year (2009-2013) estimate of the socioeconomic data for all the census blocks in our study. To calculate the area-weighted averages of the socioeconomic variables, we calculated the area of the landscape that overlapped each census block group (U.S. Census Bureau 2016). We multiplied this area by the value obtained from the American Community Survey for the census block group. We then summed the products and divided this sum by the total area of the landscape. For example, suppose a 
landscape had an area of $46 \mathrm{~km}^{2}$ and overlapped three census block groups. Inside the landscape, Block A had an area of $12 \mathrm{~km}^{2}$ and a median age of 22, Block B had an area of 28 $\mathrm{km}^{2}$ and a median age of 31 , and Block $\mathrm{C}$ had an area of $6 \mathrm{~km}^{2}$ and a median age of 41 . Our area-weighted average for median age for the landscape would be:

$$
\frac{(12 \times 22)+(28 \times 31)+(6 \times 41)}{46}=30.0 \text { years }
$$

\section{Calculation of precipitation during the spring months (regional and landscape scales)} Raster data of total precipitation (spatial resolution $=4 \mathrm{~km}$ ) during the months of March and April (2010-12) were obtained from the PRISM Climate Group (2016), and a raster dataset with the averages of total precipitation for the six months was created for the entire study area in ArcGIS 10.1 (ESRI 2012). To calculate the six-month average, we added the total precipitations for the six months and divided the sum by six. The zonal statistics tool in ArcGIS was used to calculate the average total precipitation during the spring within each landscape and within each EPA Level III ecoregion.

\section{Calculation of daily minimum temperature of the two coldest months (regional and landscape scales)}

Raster data of average daily minimum temperature (spatial resolution $=4 \mathrm{~km}$ ) of the months of December $(2009,2010$, and 2011) and January (2010, 2011, and 2012) were obtained from the PRISM Climate Group (2016), and a raster dataset with the averages for the six months was created for the entire study area in ArcGIS 10.1 (ESRI 2012). To calculate the six-month average, we added the average daily minimum temperatures for the six months and divided the sum by six. The zonal statistics tool in ArcGIS was used to calculate the average minimum temperature of the two coldest months within each landscape and within each EPA Level III ecoregion.

\section{Calculation of daily maximum breeding-season temperature (regional and landscape scales)}

Raster data of 30-year (1981-2010) average daily maximum temperature (spatial resolution $=$ $800 \mathrm{~m}$ ) for the months of May, June, and July were obtained from the PRISM Climate Group (2016), and a raster dataset with the average for the three months was created for the entire study area in ArcGIS 10.1 (ESRI 2012). To calculate the average, we added the average maximum daily temperature for the three months and divided the sum by three. The zonal statistics tool in ArcGIS was used to calculate the average maximum breeding-season temperature within each landscape and within each EPA Level III ecoregion.

\section{Binning of landscape temperature}

To avoid having widely different levels of power for detecting cross-scale and within-scale interactions, we designed the analyses so that the number of different values of landscape-scale mean daily maximum breeding-season temperature (LndMaxTemp) would be the same as the number of regional-scale mean daily maximum breeding-season temperatures (RegMaxTemp). 
There were 14 EPA level III regions (hence 14 RegMaxTemp values). Therefore, we binned the LndMaxTemp into 14 bins for all 8 species. To ensure that each bin had at least 10 observations, we used a slightly larger bin width for the bin containing the lowest temperatures; the actual number of observations in this first bin ranged from 16 to 19 for the 8 species. The remaining 13 bins were created by dividing the difference between the lowest LndMaxTemp not included in the first bin and the highest LndMaxTemp for all 8 species by 13. The difference in the highest LndMaxTemp observation among the eight species was $<0.04{ }^{\circ} \mathrm{C}$. The bin widths for all eight species were identical (first bin $=2.90^{\circ} \mathrm{C}$, remaining bins $=0.55^{\circ} \mathrm{C}$ ). We used the median of the LndMaxTemp values in a given bin as the LndMaxTemp value for the observations in that bin.

No binning of regional temperature was needed because we used the mean temperature of the EPA Level III ecoregion as the RegMaxTemp for all the observations within that region.

\section{Statistical analyses}

If spatial autocorrelation was detected in the residuals of the best-supported model (model with lowest AICc value among the set of competing models; see Table 3 in the main text), we added spatial eigenvectors to the model to remove the autocorrelation (Gutzwiller et al. 2015). We used the output from SAM 4.0's (Rangel et al. 2010) eigenvector-based spatial filtering module to identify which eigenvectors would reduce Moran's $I$ for the residuals. To decide which eigenvectors to include, we used $r^{2}$ values from the SAM 4.0 output to choose the spatial eigenvector that was most correlated with the response variable. Spatial eigenvectors were added one at a time, and residuals for the model with the added spatial eigenvector were checked for spatial autocorrelation. This process was continued until the absolute value of Moran's $I$ for all distance classes was $\leq 0.1$ (Gutzwiller et al. 2015).

We used techniques (Neter et al. 1989) involving residuals of the best-supported model to confirm that none of the variables in the model was informative in a different form (e.g., quadratic instead of linear). Standard procedures (Hilbe 2014) were used to make certain that the independence assumption of the NB model was met.

Variance Inflation Factors (VIF) can be used to measure collinearity between explanatory variables, and VIFs $\geq 3$ are considered to be high (Zuur et al. 2010). To reduce multicollinearity among covariates in the base model during the first stage of analyses, we removed covariates with VIF $\geq 3$ one at a time (by removing the variable with the highest VIF first) until all covariates in the base model had VIFs $<3$. If two covariates with VIFs $\geq 3$ had equal VIF values, the covariate associated with the lower $R^{2}$ COR was removed. VIFs also were calculated for the variables in the best-supported models, and most variables had VIFs $<3$ (Appendix 1, Table A1.2).

Mean Absolute Error (MAE) was calculated as the average magnitude of the prediction error. MAE for the best-supported model (fitted) was obtained using R package Metrics (Hamner and Frasco 2018). We used the leave-one-out method (Harrell 2001) and the function cv.glm in R package boot (Canty and Ripley 2017) to cross-validate each best-supported model. MAEs for 
the fitted and cross-validated models were reported in Appendix 1, Table A1.2. Lower values of MAE indicated a better fit (Chuang and Chang 2014).

The process of computing the changes in Akaike's Information Criterion corrected for small sample size $\left(\triangle \mathrm{AIC}_{\mathrm{c}}\right)$ as a measure of variable influence (Coppes et al. 2017) involved removing the variable of interest from the best-supported model and calculating the difference in $\mathrm{AIC}_{\mathrm{c}}$ between the reduced model and the best-supported model. To estimate the change in $\mathrm{AIC}_{\mathrm{c}}$ associated with an interaction effect (cross-product term) in a best-supported model, only the interaction effect was removed from the best-supported model. To estimate the change in $\mathrm{AIC}_{\mathrm{c}}$ associated with a main-effect variable involved in an interaction in a best-supported model, both the main effect and the associated interaction effect were removed from the best-supported model.

\section{Creation of the within-scale interaction figure}

First, using the ranges of the two variables involved in the interaction and the observed average values of all other variables in the best-supported model, a dataset with 1000 observations was created in $\mathrm{R}$ ( $\mathrm{R}$ Core Team 2019). We then used this dataset and the regression coefficients from the best-supported model to compute values for the predicted response surface (B. S. Cade, personal communication). Finally, the within-scale interaction figure (Fig. 2, in main text) was created by using SigmaPlot 14.0 (Systat Software, San Jose, CA) to plot the predicted relative abundance of Yellow-breasted Chat against landscape-scale mean daily maximum temperature during the breeding season and median income.

\section{Additional details about the within-scale interaction effect on the Yellow-breasted Chat} The relative abundance of the Yellow-breasted Chat increased with increasing LndMaxTemp; MedianInc was positively associated with relative abundance in the landscapes with the highest LndMaxTemp values and negatively associated with relative abundance in the landscapes with lower LndMaxTemp (Fig. 2, in main text). Higher temperatures are associated with higher forest productivity (Raich et al. 2006). Higher temperatures and productivity are associated with a greater abundance of insects (e.g., Kaspari 2001) - a crucial food for the Yellow-breasted Chat during the breeding season (Ehrlich et al. 1988) - which may have led to a gradual increase in the relative abundance of this species with increasing LndMaxTemp (Fig. 2). The Yellowbreasted Chat's association with increasing MedianInc varied with LndMaxTemp (Fig. 2), and we hypothesize that this variation arose from the effect of maximum breeding-season temperature on human contributions to the conservation of natural places.

Participation in wildlife watching near home and on trips away from home is greater with higher income (U.S. Department of Interior et al. 2018). Higher-income populations also are likely to be more involved in local environmental advisory bodies (Wellstead et al. 2003) and grassroots environmental movements (Weber 2000), and higher income is positively associated with proenvironmental behavior such as contributing time and money to conservation (Theodori and Luloff 2002). The desire to conserve biodiversity, however, may be affected by the level of contact with nature (Zhang et al. 2014, Soga et al. 2016, Schuttler et al. 2018). LndMaxTemp 
during the breeding season may have affected the degree of contact between nature and local populations, including those with higher MedianInc.

Environmental conditions such as temperature and sunlight can affect human behaviors (Van de Vliert et al. 2004, Murray et al. 2010). We suggest that in the warmest landscapes, the temperatures during the breeding season were often uncomfortably high, people there went out for wildlife watching less frequently and, because of less contact with nature, their contribution to the conservation of natural places was lower. We propose that as MedianInc increased in landscapes with higher LndMaxTemp (Fig. 2), there were fewer individuals in local decisionmaking bodies in those landscapes who had a desire to conserve nature (because uncomfortable temperatures resulted in less contact with nature), leading to fewer decisions that supported conservation. In landscapes with less support for conservation, there may have been less conservation of forests. Forests in such landscapes may have been more fragmented and provided more edge habitat for the Yellow-breasted Chat. This increase in relative abundance of the Yellow-breasted Chat in the warmest landscapes with increasing MedianInc (Fig. 2) may thus be a consequence of temperature affecting human behavior. But, as LndMaxTemp decreased, visits to natural places (contact with nature) may have increased, and as MedianInc increased, support for conservation (via individual activities or through decision-making bodies) may have increased, resulting in more contiguous forest. Consequently, as LndMaxTemp declined and MedianInc increased, less edge habitat may have been available for the Yellowbreasted Chat, resulting in a low relative abundance for the species (Fig. 2).

\section{Influences of landscape-scale percent of deciduous forest and landscape-scale minimum temperature of the two coldest months}

Landscape-scale percent of deciduous forest (LndPercDec) occurred in models of four species and had the highest $\triangle \mathrm{AIC}_{\mathrm{c}}$ among the variables considered for three forest-interior species (Acadian Flycatcher, Hairy Woodpecker, and White-breasted Nuthatch; Table 6 in the main text, Appendix 1, Table A1.2). The relative abundance of these species increased with LndPercDec, but the relative abundance of the Northern Mockingbird, a forest-edge species, declined with greater LndPercDec. The fact that LndPercDec was informative for the relative abundance of the three forest-interior species is consistent with findings (Smith et al. 2011) that the percentage of forest in the landscape was the most important variable for occurrence and richness of forest birds. The Northern Mockingbird is associated with forest edges and open areas with scattered shrubs and small trees (Freemark and Collins 1992, Farnsworth et al. 2020), and its decline in relative abundance with increasing LndPercDec (Appendix 1, Table A1.2) may be because more area in forest resulted in less habitat for this species.

Landscape-scale daily minimum temperature of the two coldest months (LndWinTemp) was the only weather variable that was informative for more than one species (Northern Mockingbird and Yellow-breasted Chat; Appendix 1, Table A1.2), and its relative influence ( $\triangle \mathrm{AIC}_{\mathrm{c}}$ ) was high in the models for Northern Mockingbird (Table 6 in the main text). Pre-breeding season weather can affect population size of many bird species (Sæther et al. 2004). The presence of informative pre-breeding season weather variables (e.g., LndWinTemp) in some species' best-supported 
models is consistent with this idea. The higher relative abundance of Northern Mockingbird with higher LndWinTemp in the present study supports findings that abundance of resident species is higher following warmer winters (Lemoine and Bohning-Gaese 2003, Jones et al. 2003). The decline in relative abundance of the Yellow-breasted Chat with warmer winters is consistent with findings (Lemoine and Bohning-Gaese 2003) that the number of individuals of long-distance migrants declines on the breeding grounds following warmer winters because resident birds benefit from milder winters and fewer resources are therefore available for migrants (Lemoine and Bohning-Gaese 2003).

\section{Frequency and geographic distributions for socioeconomic variables}

The conclusions drawn for the socioeconomic variables in the analyses (population that was female and $\geq 30$ years old [PercFemale], percent of the population $\geq 25$ years old with $\geq 4$ years of college [PercColleg], median age of the population [MedianAge], and median income of the population [MedianInc]) could potentially be misleading if there was little variation in the data. For example, if most of the median income observations had one value (e.g., 50,000 U.S. dollars) and only a few large or small values were driving the interaction observed in Fig. 2 (in the main text), the results of the study may not have meaningful implications. Fig. A1.1, based on data for the species with the largest number of observations (Ruby-throated Hummingbird, $n=390$ ), demonstrated that there was enough variation in the underlying socioeconomic data to justify the conclusions. The histograms of socioeconomic variables for the remaining seven species (not provided) were very similar because many of the BBS routes used were the same among species.

We assessed whether there were geographic patterns in the socioeconomic variables that might indicate potential confounding between these variables and broad-scale environmental conditions (e.g., temperature, precipitation, or the soil and forest types they influence). As general proxies for this set of conditions, we used each observation's longitude and latitude. Fig. A1.2 shows scatterplots for the four socioeconomic variables against longitude $\left({ }^{\circ} \mathrm{E}\right)$ and latitude $\left({ }^{\circ} \mathrm{N}\right)$ for the set of routes $(n=390)$ used for the Ruby-throated Hummingbird. Scatterplots for socioeconomic variables for the remaining seven species (not provided) were very similar because many of the BBS routes used were the same among species. The scatterplots indicate that there were no strong geographic gradients in the socioeconomic variables. Pearson correlation coefficients supported this conclusion. The Pearson correlations $(r)$ between Longitude $\left({ }^{\circ} \mathrm{E}\right)$ and the four socioeconomic variables were: PercFemale (0.189), PercColleg (0.271), MedianAge (0.074), and MedianInc (0.334). The Pearson correlations between Latitude $\left({ }^{\circ} \mathrm{N}\right)$ and the four socioeconomic variables were: PercFemale (0.061), PercColleg (0.297), MedianAge (0.194), and MedianInc (0.457). 

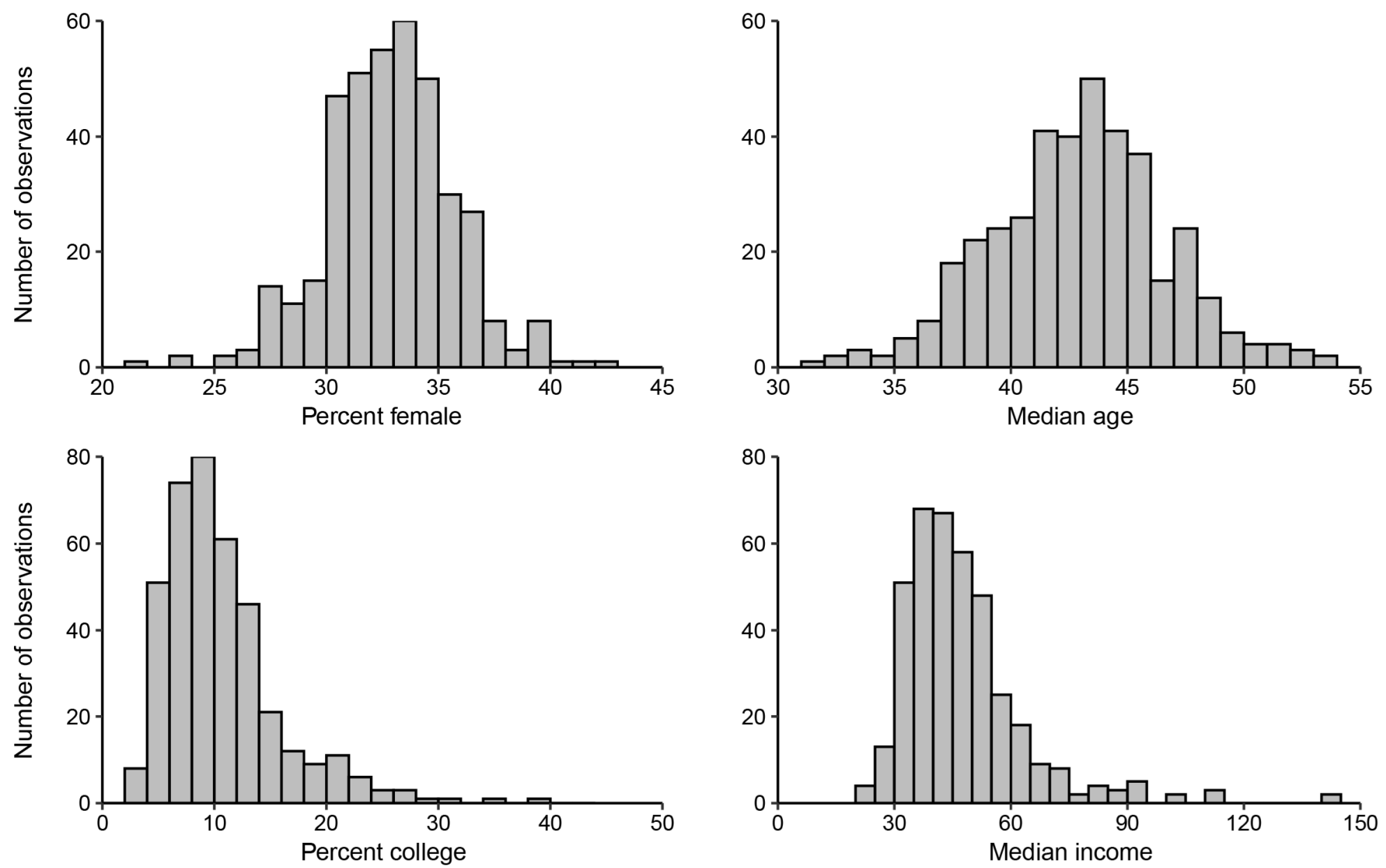

Fig. A1.1. Histograms for percent of the population that was female and $\geq 30$ years old (Percent female), median age (years) of the population, percent of the population $\geq 25$ years old with $\geq 4$ years of college (Percent college), and median income (thousands of U.S. dollars) of the population for the set of routes $(n=390)$ used for the Ruby-throated Hummingbird. This species was used to show these distributions because it had the largest number of observations (routes) among the eight species in the analysis. The histograms of socioeconomic variables for the remaining seven species (not provided) were very similar because many of the BBS routes used were the same among species. 

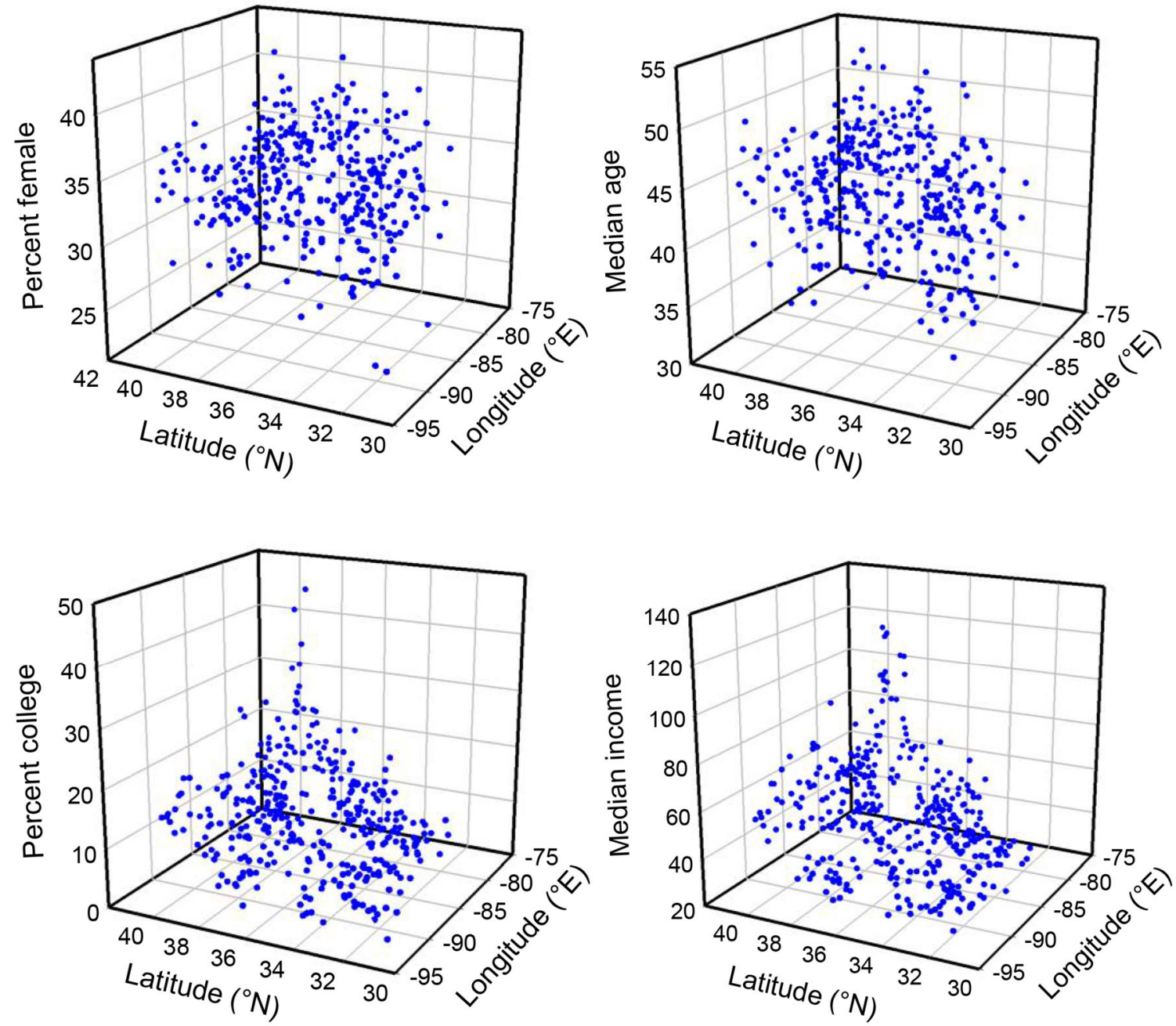

Fig. A1.2. Scatterplots for percent of the population that was female and $\geq 30$ years old (Percent female), median age (years) of the population, percent of the population $\geq 25$ years old with $\geq 4$ years of college (Percent college), and median income (thousands of U.S. dollars) of the population against longitude $\left({ }^{\circ} \mathrm{E}\right)$ and latitude $\left({ }^{\circ} \mathrm{N}\right)$ for the set of routes $(n=390)$ used for the Ruby-throated Hummingbird. This species was used to show these relationships because it had the largest number of observations (routes) among the eight species in the analysis. The scatterplots for socioeconomic variables for the remaining seven species (not provided) were very similar because many of the BBS routes used were the same among species. 
Table A1.1. Statistics for $\mathrm{AIC}_{\mathrm{c}}$-based model selection for each socioeconomic variable and species.

\begin{tabular}{|c|c|c|c|c|c|c|}
\hline $\begin{array}{l}\text { Socioeconomic } \\
\text { variable }\end{array}$ & Model $^{\dagger}$ & $K^{\ddagger}$ & $\begin{array}{l}\log \\
\text { likelihood }\end{array}$ & $\mathrm{AIC}_{\mathrm{c}}$ & $\begin{array}{c}\mathrm{AIC}_{\mathrm{c}} \\
\text { difference }\end{array}$ & $w_{\mathrm{i}}{ }^{\prime}$ \\
\hline \multirow[t]{20}{*}{ Percent female } & Kentucky Warbler & & & & & \\
\hline & Additive with landscape temperature & 4 & -713.22 & 1434.55 & 0.00 & 0.253 \\
\hline & Intercept only & 2 & -715.29 & 1434.62 & 0.07 & 0.245 \\
\hline & Additive with both temperatures & 5 & -712.34 & 1434.85 & 0.30 & 0.218 \\
\hline & Within-scale interaction & 5 & -712.98 & 1436.12 & 1.57 & 0.115 \\
\hline & Additive with regional temperature & 4 & -714.33 & 1436.78 & 2.23 & 0.083 \\
\hline & Both interactions & 7 & -711.63 & 1437.58 & 3.03 & 0.056 \\
\hline & Cross-scale interaction & 5 & -714.32 & 1438.81 & 4.26 & 0.030 \\
\hline & Acadian Flycatcher & & & & & \\
\hline & Additive with regional temperature & 5 & -1037.09 & 2084.34 & 0.00 & 0.518 \\
\hline & Additive with both temperatures & 6 & -1036.87 & 2085.98 & 1.65 & 0.228 \\
\hline & Cross-scale interaction & 6 & -1037.06 & 2086.36 & 2.02 & 0.188 \\
\hline & Global & 8 & -1036.58 & 2089.56 & 5.22 & 0.038 \\
\hline & Additive with landscape temperature & 5 & -1040.79 & 2091.75 & 7.41 & 0.013 \\
\hline & Base & 3 & -1043.05 & 2092.17 & 7.83 & 0.010 \\
\hline & Within-scale interaction & 6 & -1040.77 & 2093.79 & 9.45 & 0.005 \\
\hline & Both interactions & 7 & -1063.47 & 2141.27 & 56.93 & 0.000 \\
\hline & Intercept only & 2 & -1071.10 & 2146.24 & 61.90 & 0.000 \\
\hline & Hairy Woodpecker & & & & & \\
\hline & Within-scale interaction & 6 & -554.99 & 1122.20 & 0.00 & 0.335 \\
\hline
\end{tabular}


Additive with landscape temperature

Additive with both temperatures

Base

Global

Additive with regional temperature

Cross-scale interaction

Both interactions

Intercept only

White-breasted Nuthatch

Additive with both temperatures

Additive with landscape temperature

Global

Within-scale interaction

Base

Additive with regional temperature

Cross-scale interaction

Both interactions

Intercept only

Yellow-breasted Chat

Additive with landscape temperature

Within-scale interaction

Additive with both temperatures

Global

Both interactions

$\begin{array}{rrrrr}5 & -556.34 & 1122.84 & 0.63 & 0.244 \\ 6 & -555.74 & 1123.70 & 1.50 & 0.158 \\ 3 & -559.21 & 1124.49 & 2.29 & 0.107 \\ 8 & -554.23 & 1124.84 & 2.64 & 0.090 \\ 5 & -558.14 & 1126.44 & 4.24 & 0.040 \\ 6 & -557.54 & 1127.31 & 5.10 & 0.026 \\ 7 & -561.26 & 1136.81 & 14.61 & 0.000 \\ 2 & -578.63 & 1161.30 & 39.09 & 0.000\end{array}$

$\begin{array}{rrrrr}8 & -1004.69 & 2025.76 & 0.00 & 0.365 \\ 7 & -1005.80 & 2025.89 & 0.13 & 0.341 \\ 10 & -1003.60 & 2027.77 & 2.02 & 0.133 \\ 8 & -1005.71 & 2027.80 & 2.04 & 0.131 \\ 5 & -1010.54 & 2031.25 & 5.49 & 0.023 \\ 7 & -1010.36 & 2035.02 & 9.26 & 0.004 \\ 8 & -1009.63 & 2035.63 & 9.87 & 0.003 \\ 7 & -1055.10 & 2124.50 & 98.75 & 0.000 \\ 2 & -1115.17 & 2234.38 & 208.62 & 0.000\end{array}$

$\begin{array}{rrrrr}7 & -1452.98 & 2920.25 & 0.00 & 0.529 \\ 8 & -1452.82 & 2922.01 & 1.76 & 0.219 \\ 8 & -1452.88 & 2922.13 & 1.88 & 0.206 \\ 10 & -1452.27 & 2925.13 & 4.88 & 0.046 \\ 7 & -1470.02 & 2954.34 & 34.09 & 0.000\end{array}$


Additive with regional temperature

Cross-scale interaction

Base

Intercept only

Ruby-throated Hummingbird

Additive with landscape temperature

Additive with regional temperature

Within-scale interaction

Additive with both temperatures

Intercept only

Cross-scale interaction

Both interactions

Northern Mockingbird

Additive with landscape temperature

Within-scale interaction

Base

Additive with both temperatures

Additive with regional temperature

Global

Cross-scale interaction

Both interactions

Intercept only

$\begin{array}{rrrrr}7 & -1471.38 & 2957.06 & 36.81 & 0.000 \\ 8 & -1471.23 & 2958.84 & 38.59 & 0.000 \\ 5 & -1476.36 & 2962.88 & 42.63 & 0.000 \\ 2 & -1532.07 & 3068.16 & 147.92 & 0.000\end{array}$

$\begin{array}{lllll}4 & -817.04 & 1642.17 & 0.00 & 0.337\end{array}$

$\begin{array}{lllll}4 & -817.62 & 1643.34 & 1.17 & 0.188\end{array}$

$\begin{array}{lllll}5 & -816.89 & 1643.94 & 1.76 & 0.140\end{array}$

$\begin{array}{lllll}5 & -816.99 & 1644.14 & 1.96 & 0.126\end{array}$

$\begin{array}{lllll}2 & -820.16 & 1644.36 & 2.18 & 0.113\end{array}$

$\begin{array}{lllll}5 & -817.48 & 1645.12 & 2.94 & 0.077\end{array}$

$\begin{array}{lllll}7 & -816.81 & 1647.90 & 5.73 & 0.019\end{array}$

$\begin{array}{rrrrr}7 & -1905.61 & 3825.52 & 0.00 & 0.311 \\ 8 & -1904.80 & 3825.99 & 0.47 & 0.246 \\ 5 & -1908.35 & 3826.86 & 1.34 & 0.159 \\ 8 & -1905.41 & 3827.19 & 1.68 & 0.135 \\ 7 & -1907.25 & 3828.80 & 3.29 & 0.060 \\ 10 & -1904.36 & 3829.31 & 3.80 & 0.047 \\ 8 & -1906.56 & 3829.49 & 3.98 & 0.043 \\ 7 & -1927.12 & 3868.54 & 43.03 & 0.000 \\ 2 & -1967.48 & 3939.00 & 113.48 & 0.000\end{array}$


Brown-headed Cowbird

Cross-scale interaction

Within-scale interaction

Additive with regional temperature

Additive with landscape temperature

Both interactions

Additive with both temperatures

Intercept only

$\begin{array}{lllll}5 & -1722.63 & 3455.41 & 0.00 & 0.452 \\ 5 & -1723.57 & 3457.29 & 1.88 & 0.177 \\ 4 & -1724.99 & 3458.08 & 2.67 & 0.119 \\ 4 & -1724.99 & 3458.08 & 2.67 & 0.119 \\ 7 & -1722.31 & 3458.91 & 3.50 & 0.078 \\ 5 & -1724.96 & 3460.08 & 4.67 & 0.044 \\ 2 & -1729.42 & 3462.87 & 7.46 & 0.011\end{array}$

Percent college

Kentucky Warbler

Within-scale interaction

Both interactions

Cross-scale interaction

Additive with landscape temperature

Additive with both temperatures

Additive with regional temperature

Intercept only

$\begin{array}{rrrrr}5 & -698.82 & 1407.82 & 0.00 & 0.788 \\ 7 & -698.38 & 1411.08 & 3.27 & 0.154 \\ 5 & -701.67 & 1413.52 & 5.70 & 0.046 \\ 4 & -704.72 & 1417.56 & 9.74 & 0.006 \\ 5 & -704.05 & 1418.26 & 10.45 & 0.004 \\ 4 & -705.80 & 1419.71 & 11.89 & 0.002 \\ 2 & -715.29 & 1434.62 & 26.80 & 0.000\end{array}$

Acadian Flycatcher

Additive with regional temperature

Cross-scale interaction

Additive with both temperatures

Global

Additive with landscape temperature

Within-scale interaction

Base

$\begin{array}{lllll}5 & -1037.11 & 2084.38 & 0.00 & 0.368 \\ 6 & -1036.11 & 2084.46 & 0.08 & 0.354 \\ 6 & -1036.84 & 2085.93 & 1.54 & 0.170 \\ 8 & -1035.52 & 2087.45 & 3.07 & 0.079 \\ 5 & -1040.61 & 2091.39 & 7.01 & 0.011 \\ 6 & -1039.71 & 2091.66 & 7.28 & 0.010 \\ 3 & -1043.05 & 2092.17 & 7.79 & 0.008\end{array}$


Both interactions

Intercept only

Hairy Woodpecker

Additive with landscape temperature

Additive with both temperatures

Within-scale interaction

Additive with regional temperature

Cross-scale interaction

Global

Base

Both interactions

Intercept only

White-breasted Nuthatch

Additive with both temperatures

Additive with regional temperature

Additive with landscape temperature

Global

Cross-scale interaction

Within-scale interaction

Base

Both interactions

Intercept only

$\begin{array}{lllll}7 & -1061.19 & 2136.69 & 52.31 & 0.000 \\ 2 & -1071.10 & 2146.24 & 61.85 & 0.000\end{array}$

$\begin{array}{rrrrr}5 & -555.15 & 1120.46 & 0.00 & 0.308 \\ 6 & -554.29 & 1120.80 & 0.35 & 0.259 \\ 6 & -554.81 & 1121.83 & 1.38 & 0.155 \\ 5 & -556.21 & 1122.57 & 2.11 & 0.107 \\ 6 & -555.64 & 1123.50 & 3.05 & 0.067 \\ 8 & -553.62 & 1123.61 & 3.16 & 0.063 \\ 3 & -559.21 & 1124.49 & 4.03 & 0.041 \\ 7 & -563.37 & 1141.03 & 20.58 & 0.000 \\ 2 & -578.63 & 1161.30 & 40.84 & 0.000\end{array}$

$\begin{array}{rrrrr}8 & -992.99 & 2002.35 & 0.00 & 0.603 \\ 7 & -995.68 & 2005.65 & 3.30 & 0.116 \\ 7 & -995.83 & 2005.95 & 3.60 & 0.100 \\ 10 & -992.77 & 2006.12 & 3.77 & 0.092 \\ 8 & -995.41 & 2007.21 & 4.86 & 0.053 \\ 8 & -995.80 & 2007.97 & 5.62 & 0.036 \\ 5 & -1010.54 & 2031.25 & 28.90 & 0.000 \\ 7 & -1051.52 & 2117.33 & 114.99 & 0.000 \\ 2 & -1115.17 & 2234.38 & 232.03 & 0.000\end{array}$


Yellow-breasted Chat

Within-scale interaction

Global

Both interactions

Additive with landscape temperature

Additive with both temperatures

Cross-scale interaction

Additive with regional temperature

Base

Intercept only

Ruby-throated Hummingbird

Additive with landscape temperature

Within-scale interaction

Additive with both temperatures

Additive with regional temperature

Both interactions

Cross-scale interaction

Intercept only

$\begin{array}{rrrrr}8 & -1438.67 & 2893.72 & 0.00 & 0.815 \\ 10 & -1438.42 & 2897.42 & 3.69 & 0.129 \\ 7 & -1443.17 & 2900.63 & 6.91 & 0.026 \\ 7 & -1443.33 & 2900.95 & 7.23 & 0.022 \\ 8 & -1443.16 & 2902.69 & 8.97 & 0.009 \\ 8 & -1456.24 & 2928.87 & 35.15 & 0.000 \\ 7 & -1459.34 & 2932.97 & 39.25 & 0.000 \\ 5 & -1476.36 & 2962.88 & 69.16 & 0.000 \\ 2 & -1532.07 & 3068.16 & 174.44 & 0.000\end{array}$

Northern Mockingbird

Additive with landscape temperature

Additive with regional temperature

Within-scale interaction

Additive with both temperatures

Cross-scale interaction

$\begin{array}{rrrrr}4 & -811.32 & 1630.73 & 0.00 & 0.368 \\ 5 & -811.31 & 1632.79 & 2.05 & 0.132 \\ 5 & -810.59 & 1631.34 & 0.60 & 0.272 \\ 4 & -812.45 & 1633.01 & 2.27 & 0.118 \\ 7 & -810.05 & 1634.39 & 3.66 & 0.059 \\ 5 & -812.29 & 1634.74 & 4.00 & 0.050 \\ 2 & -820.16 & 1644.36 & 13.62 & 0.000\end{array}$

$\begin{array}{lllll}7 & -1902.14 & 3818.58 & 0.00 & 0.409 \\ 7 & -1902.98 & 3820.25 & 1.67 & 0.178 \\ 8 & -1902.02 & 3820.42 & 1.84 & 0.163 \\ 8 & -1902.12 & 3820.61 & 2.03 & 0.148 \\ 8 & -1902.97 & 3822.32 & 3.74 & 0.063\end{array}$




\author{
Global \\ Base \\ Both interactions \\ Intercept only
}

Brown-headed Cowbird

Intercept-only

Cross-scale interaction

Additive with regional temperature

Additive with landscape temperature

Within-scale interaction

Additive with both temperatures

Both interactions

\section{Kentucky Warbler}

Within-scale interaction

Additive with landscape temperature

Additive with both temperatures

Both interactions

Intercept only

Additive with regional temperature

Cross-scale interaction

Acadian Flycatcher

Additive with regional temperature

Cross-scale interaction

$\begin{array}{rrrrr}10 & -1901.54 & 3823.66 & 5.08 & 0.032 \\ 5 & -1908.35 & 3826.86 & 8.28 & 0.007 \\ 7 & -1919.19 & 3852.67 & 34.09 & 0.000 \\ 2 & -1967.48 & 3939.00 & 120.42 & 0.000\end{array}$

$\begin{array}{lllll}2 & -1729.42 & 3462.87 & 0.00 & 0.559 \\ 5 & -1727.77 & 3465.69 & 2.83 & 0.136 \\ 4 & -1729.15 & 3466.41 & 3.54 & 0.095 \\ 4 & -1729.16 & 3466.41 & 3.55 & 0.095 \\ 5 & -1728.68 & 3467.51 & 4.65 & 0.055 \\ 5 & -1729.15 & 3468.45 & 5.58 & 0.034 \\ 7 & -1727.36 & 3469.03 & 6.16 & 0.026\end{array}$

$\begin{array}{lllll}5 & -710.32 & 1430.81 & 0.00 & 0.408 \\ 4 & -712.05 & 1432.22 & 1.41 & 0.201 \\ 5 & -711.59 & 1433.35 & 2.54 & 0.115 \\ 7 & -709.52 & 1433.36 & 2.56 & 0.114 \\ 2 & -715.29 & 1434.62 & 3.81 & 0.061 \\ 4 & -713.26 & 1434.63 & 3.82 & 0.060 \\ 5 & -712.61 & 1435.39 & 4.58 & 0.041\end{array}$

$\begin{array}{lllll}5 & -1036.51 & 2083.19 & 0.00 & 0.433 \\ 6 & -1035.91 & 2084.06 & 0.87 & 0.280\end{array}$


Additive with both temperatures

Global

Additive with landscape temperature

Within-scale interaction

Base

Both interactions

Intercept only

Hairy Woodpecker

Additive with landscape temperature

Additive with both temperatures

Base

Within-scale interaction

Additive with regional temperature

Global

Cross-scale interaction

Both interactions

Intercept only

White-breasted Nuthatch

Additive with both temperatures

Additive with landscape temperature

Within-scale interaction

Global

Base

Cross-scale interaction

$\begin{array}{rrrrr}6 & -1036.39 & 2085.01 & 1.81 & 0.175 \\ 8 & -1034.98 & 2086.37 & 3.18 & 0.088 \\ 5 & -1039.97 & 2090.10 & 6.91 & 0.014 \\ 6 & -1039.81 & 2091.85 & 8.66 & 0.006 \\ 3 & -1043.05 & 2092.17 & 8.98 & 0.005 \\ 7 & -1061.04 & 2136.40 & 53.20 & 0.000 \\ 2 & -1071.10 & 2146.24 & 63.04 & 0.000\end{array}$

$\begin{array}{rrrrr}5 & -556.41 & 1122.97 & 0.00 & 0.350 \\ 6 & -555.84 & 1123.91 & 0.93 & 0.219 \\ 3 & -559.21 & 1124.49 & 1.52 & 0.164 \\ 6 & -556.31 & 1124.84 & 1.86 & 0.138 \\ 5 & -558.29 & 1126.74 & 3.77 & 0.053 \\ 8 & -555.25 & 1126.88 & 3.91 & 0.049 \\ 6 & -557.96 & 1128.13 & 5.16 & 0.026 \\ 7 & -562.74 & 1139.78 & 16.81 & 0.000 \\ 2 & -578.63 & 1161.30 & 38.32 & 0.000\end{array}$

$\begin{array}{rrrrr}8 & -1004.60 & 2025.58 & 0.00 & 0.357 \\ 7 & -1005.76 & 2025.82 & 0.24 & 0.317 \\ 8 & -1005.20 & 2026.78 & 1.20 & 0.197 \\ 10 & -1003.80 & 2028.17 & 2.59 & 0.098 \\ 5 & -1010.54 & 2031.25 & 5.66 & 0.021 \\ 8 & -1008.87 & 2034.11 & 8.53 & 0.005\end{array}$


Additive with regional temperature

Both interactions

Intercept only

Yellow-breasted Chat

Within-scale interaction

Additive with landscape temperature

Additive with both temperatures

Global

Both interactions

Additive with regional temperature

Cross-scale interaction

Base

Intercept only

Ruby-throated Hummingbird

Additive with landscape temperature Additive with regional temperature

Within-scale interaction

Additive with both temperatures

Cross-scale interaction

Both interactions

Intercept only

Northern Mockingbird

Additive with landscape temperature

$\begin{array}{rrrrr}7 & -1010.05 & 2034.39 & 8.81 & 0.004 \\ 7 & -1052.85 & 2119.99 & 94.40 & 0.000 \\ 2 & -1115.17 & 2234.38 & 208.79 & 0.000\end{array}$

$\begin{array}{lllll}8 & -1451.75 & 2919.88 & 0.00 & 0.423\end{array}$

$\begin{array}{lllll}7 & -1452.99 & 2920.28 & 0.40 & 0.346\end{array}$

$\begin{array}{lllll}8 & -1452.83 & 2922.05 & 2.17 & 0.143\end{array}$

$\begin{array}{lllll}10 & -1451.21 & 2923.01 & 3.12 & 0.089\end{array}$

$\begin{array}{lllll}7 & -1467.84 & 2949.97 & 30.09 & 0.000\end{array}$

$\begin{array}{lllll}7 & -1471.24 & 2956.77 & 36.88 & 0.000\end{array}$

$\begin{array}{lllll}8 & -1470.34 & 2957.07 & 37.18 & 0.000\end{array}$

$\begin{array}{lllll}5 & -1476.36 & 2962.88 & 43.00 & 0.000\end{array}$

$\begin{array}{lllll}2 & -1532.07 & 3068.16 & 148.28 & 0.000\end{array}$

$\begin{array}{rrrrr}4 & -815.18 & 1638.46 & 0 & 0.352 \\ 4 & -815.54 & 1639.18 & 0.72 & 0.246 \\ 5 & -815.13 & 1640.41 & 1.953 & 0.133 \\ 5 & -815.15 & 1640.46 & 1.994 & 0.130 \\ 5 & -815.39 & 1640.93 & 2.472 & 0.102 \\ 7 & -814.99 & 1644.28 & 5.815 & 0.019 \\ 2 & -820.16 & 1644.36 & 5.897 & 0.018\end{array}$

$\begin{array}{lllll}7 & -1903.65 & 3821.59 & 0.00 & 0.420\end{array}$ 
Within-scale interaction

Additive with both temperatures

Additive with regional temperature

Cross-scale interaction

Global

Base

Both interactions

Intercept only

\section{Brown-headed Cowbird}

Cross-scale interaction

Within-scale interaction

Both interactions

Intercept only

Additive with landscape temperature

Additive with regional temperature

Additive with both temperatures

\section{Kentucky Warbler}

Within-scale interaction

Both interactions

Cross-scale interaction

Additive with regional temperature

Additive with both temperatures

Additive with landscape temperature

Intercept only

$\begin{array}{rrrrr}8 & -1903.25 & 3822.87 & 1.28 & 0.221 \\ 8 & -1903.46 & 3823.30 & 1.70 & 0.179 \\ 7 & -1905.30 & 3824.89 & 3.30 & 0.081 \\ 8 & -1905.10 & 3826.59 & 5.00 & 0.035 \\ 10 & -1903.01 & 3826.61 & 5.02 & 0.034 \\ 5 & -1908.35 & 3826.86 & 5.26 & 0.030 \\ 7 & -1924.21 & 3862.72 & 41.13 & 0.000 \\ 2 & -1967.48 & 3939.00 & 117.41 & 0.000\end{array}$

$\begin{array}{lllll}5 & -1723.55 & 3457.26 & 0.00 & 0.684 \\ 5 & -1725.08 & 3460.33 & 3.06 & 0.148 \\ 7 & -1723.46 & 3461.22 & 3.96 & 0.095 \\ 2 & -1729.42 & 3462.87 & 5.60 & 0.042 \\ 4 & -1728.49 & 3465.08 & 7.82 & 0.014 \\ 4 & -1728.51 & 3465.13 & 7.86 & 0.013 \\ 5 & -1728.48 & 3467.11 & 9.85 & 0.005\end{array}$

$\begin{array}{rrrrr}5 & -697.79 & 1405.75 & 0.00 & 0.864 \\ 7 & -697.65 & 1409.61 & 3.86 & 0.125 \\ 5 & -702.36 & 1414.88 & 9.13 & 0.009 \\ 4 & -706.01 & 1420.13 & 14.38 & 0.001 \\ 4 & -706.56 & 1421.24 & 15.49 & 0.000 \\ 5 & -705.58 & 1421.34 & 15.59 & 0.000 \\ 2 & -715.29 & 1434.62 & 28.87 & 0.000\end{array}$


Acadian Flycatcher

Additive with regional temperature

Additive with both temperatures

Cross-scale interaction

Global

Additive with landscape temperature

Base

Within-scale interaction

Both interactions

Intercept only

$\begin{array}{rrrrr}5 & -1008.30 & 2026.76 & 0.00 & 0.548 \\ 6 & -1008.26 & 2028.76 & 2.00 & 0.202 \\ 6 & -1008.30 & 2028.83 & 2.07 & 0.195 \\ 8 & -1008.24 & 2032.89 & 6.13 & 0.026 \\ 5 & -1011.94 & 2034.05 & 7.29 & 0.014 \\ 3 & -1014.45 & 2034.97 & 8.20 & 0.009 \\ 6 & -1011.94 & 2036.12 & 9.35 & 0.005 \\ 7 & -1030.33 & 2074.97 & 48.21 & 0.000 \\ 2 & -1037.02 & 2078.07 & 51.31 & 0.000\end{array}$

Hairy Woodpecker

Within-scale interaction

Global

Additive with landscape temperature

Additive with both temperatures

Additive with regional temperature

Cross-scale interaction

Base

Both interactions

Intercept only

White-breasted Nuthatch

Additive with both temperatures

Additive with regional temperature

$\begin{array}{lrrrr}6 & -552.32 & 1116.87 & 0.00 & 0.296 \\ 8 & -550.52 & 1117.42 & 0.56 & 0.224 \\ 5 & -553.90 & 1117.96 & 1.10 & 0.171 \\ 6 & -552.96 & 1118.14 & 1.28 & 0.156 \\ 5 & -554.45 & 1119.06 & 2.20 & 0.099 \\ 6 & -554.15 & 1120.51 & 3.65 & 0.048 \\ 3 & -559.21 & 1124.49 & 7.62 & 0.007 \\ 7 & -559.49 & 1133.27 & 16.41 & 0.000 \\ 2 & -578.63 & 1161.30 & 44.43 & 0.000 \\ & & & & \\ & & & & \\ 8 & -992.19 & 2000.76 & 0.00 & 0.383 \\ 7 & -993.72 & 2001.74 & 0.98 & 0.234\end{array}$


Additive with landscape temperature

Cross-scale interaction

Within-scale interaction

Global

Base

Both interactions

Intercept only

Yellow-breasted Chat

Within-scale interaction

Global

Both interactions

Additive with landscape temperature

Additive with both temperatures

Additive with regional temperature

Cross-scale interaction

Base

Intercept only

Ruby-throated Hummingbird

Within-scale interaction

Both interactions

Additive with landscape temperature Additive with both temperatures

Additive with regional temperature

Cross-scale interaction

$\begin{array}{rrrrr}7 & -994.05 & 2002.40 & 1.65 & 0.168 \\ 8 & -993.70 & 2003.78 & 3.02 & 0.084 \\ 8 & -993.88 & 2004.14 & 3.38 & 0.071 \\ 10 & -991.95 & 2004.48 & 3.72 & 0.060 \\ 5 & -1010.54 & 2031.25 & 30.49 & 0.000 \\ 7 & -1049.42 & 2113.13 & 112.37 & 0.000 \\ 2 & -1115.17 & 2234.38 & 233.62 & 0.000\end{array}$

$\begin{array}{rrrrr}8 & -1440.29 & 2896.96 & 0.00 & 0.805 \\ 10 & -1439.82 & 2900.21 & 3.26 & 0.158 \\ 7 & -1445.31 & 2904.91 & 7.95 & 0.015 \\ 7 & -1445.36 & 2905.02 & 8.06 & 0.014 \\ 8 & -1444.98 & 2906.34 & 9.39 & 0.007 \\ 7 & -1458.24 & 2930.78 & 33.83 & 0.000 \\ 8 & -1457.43 & 2931.24 & 34.29 & 0.000 \\ 5 & -1476.36 & 2962.88 & 65.92 & 0.000 \\ 2 & -1532.07 & 3068.16 & 171.21 & 0.000\end{array}$

$\begin{array}{rrrrr}5 & -808.75 & 1627.66 & 0.00 & 0.632 \\ 7 & -807.30 & 1628.89 & 1.24 & 0.340 \\ 4 & -813.53 & 1635.17 & 7.52 & 0.015 \\ 5 & -813.52 & 1637.20 & 9.55 & 0.005 \\ 4 & -814.76 & 1637.62 & 9.96 & 0.004 \\ 5 & -813.90 & 1637.95 & 10.29 & 0.004\end{array}$


Intercept only

Northern Mockingbird

Additive with landscape temperature

Additive with regional temperature

Additive with both temperatures

Within-scale interaction

Cross-scale interaction

Global

Base

Both interactions

Intercept only

Brown-headed Cowbird

Cross-scale interaction

Within-scale interaction

Both interactions

Intercept only

Additive with regional temperature

Additive with landscape temperature

Additive with both temperatures
2

$-820.16$

1644.36

16.70

0.000

$7 \quad-1900.72$

$3815.74 \quad 0.00$

0.352

$7 \quad-1901.08$

3816.45

0.71

0.247

$8 \quad-1900.65$

3817.69

1.95

0.133

$8 \quad-1900.69$

3817.76

2.02

0.129

$8 \quad-1900.94$

3818.26

2.52

0.100

$10 \quad-1899.80$

3820.18

4.44

0.038

$5 \quad-1908.35$

3826.86

11.12

0.001

$7 \quad-1917.69$

3849.68

33.94

0.000

$2-1967.48$

3939.00

123.26

0.000

$5 \quad-1724.07$

3458.31

0.00

0.656

$5 \quad-1725.73$

3461.63

3.32

0.125

$7 \quad-1723.86$

3462.02

3.71

0.103

$2-1729.42$

3462.87

4.56

0.067

$4 \quad-1728.54$

3465.18

6.87

0.021

$\begin{array}{lll}4 & -1728.54 & 3465.18\end{array}$

$\begin{array}{lll}5 & -1728.53 \quad 3467.22\end{array}$

6.87

8.92

0.021

0.008

$\dagger$ See Table 3 in the main text for definitions of the names of competing models. The best-supported model among a set of competing models was the model with the lowest AIC c value. Models with uninformative parameters were not considered as the second-bestsupported model. For three species (Kentucky Warbler, Ruby-throated Hummingbird, and Brown-headed Cowbird) there were only seven competing models because no covariates were selected during the first stage of the analysis. 
$\$ K=$ Effective number of parameters. This number includes the intercept, number of explanatory variables (including interactions terms), and the error term.

$\S$ Amount by which the $\mathrm{AIC}_{\mathrm{c}}$ for the second-best-supported model exceeded the $\mathrm{AIC}_{\mathrm{c}}$ for the best-supported model.

Models with uninformative parameters were included in this table. 
Table A1.2. Statistics for the best-supported regression models relating relative abundance for eight bird species to explanatory variables.

\begin{tabular}{|c|c|c|c|c|c|c|c|c|}
\hline $\begin{array}{l}\text { Socioeconomic } \\
\text { variable }\end{array}$ & Explanatory variable ${ }^{\ddagger}$ & Coefficient & SE & $\begin{array}{l}85 \% \text { CI for } \\
\text { coefficient }\end{array}$ & $\begin{array}{l}R^{2} \mathrm{COR} \\
(\%)^{\S}\end{array}$ & $\begin{array}{l}\text { MAE fitted } \\
\text { (predicted) }\end{array}$ & $\Delta \mathrm{AIC}_{\mathrm{c}} \rrbracket$ & VIF \\
\hline \multirow[t]{18}{*}{ Percent female } & Kentucky Warbler & & & & & & & \\
\hline & Intercept & 0.61 & 0.10 & $0.47-0.75$ & 13.0 & $3.40(3.52)$ & & \\
\hline & LndMaxTemp & 0.92 & 0.12 & $0.73-1.12$ & & & 40.7 & 1.5 \\
\hline & SpatEig2 \# & -0.56 & 0.10 & $-0.72--0.41$ & & & 31.0 & 1.3 \\
\hline & SpatEig8 & -0.52 & 0.09 & $-0.65--0.39$ & & & 28.9 & 1.1 \\
\hline & SpatEig73 & 0.40 & 0.09 & $0.27-0.53$ & & & 18.5 & 1.0 \\
\hline & SpatEig9 & 0.54 & 0.11 & $0.35-0.72$ & & & 14.2 & 1.0 \\
\hline & SpatEig12 & 0.28 & 0.09 & $0.15-0.40$ & & & 8.4 & 1.0 \\
\hline & SpatEig42 & -0.27 & 0.09 & $-0.39--0.15$ & & & 8.4 & 1.0 \\
\hline & SpatEig15 & 0.30 & 0.09 & $0.16-0.42$ & & & 7.6 & 1.0 \\
\hline & PercFemale & -0.18 & 0.09 & $-0.33--0.03$ & & & 0.9 & 1.0 \\
\hline & Acadian Flycatcher & & & & & & & \\
\hline & Intercept & 1.72 & 0.07 & $1.61-1.83$ & 28.3 & $6.99(7.17)$ & & \\
\hline & LndPercDec & 1.07 & 0.10 & $0.92-1.22$ & & & 92.66 & 1.8 \\
\hline & SpatEig10 & -0.49 & 0.08 & $-0.62--0.36$ & & & 27.41 & 1.1 \\
\hline & RegMaxTemp & 0.44 & 0.10 & $0.30-0.59$ & & & 17.82 & 1.6 \\
\hline & SpatEig3 & -0.27 & 0.07 & $-0.39--0.15$ & & & 10.73 & 1.0 \\
\hline & PercFemale & -0.06 & 0.08 & $-0.17-0.05$ & & & -1.39 & 1.1 \\
\hline
\end{tabular}


Hairy Woodpecker

Intercept
LndPercDec
LndMaxTemp
IntLndTemFem
PercFemale

White-breasted Nuthatch

Intercept
LndPercDec
RegWinTemp
SpatEig39
SpatEig4
SpatEig1
RegSprPrec
RegMaxTemp
LndMaxTemp
Yellow-breasted Chat
Intercept
SpatEig16
SpatEig18
LndMaxTemp
SpatEig1
LndPercDev
SpatEig11

$\begin{array}{rcc}-0.04 & 0.08 & -0.15-0.08 \\ 0.37 & 0.09 & 0.24-0.49 \\ -0.26 & 0.09 & -0.40--0.11 \\ -0.13 & 0.07 & -0.24--0.01 \\ 0.02 & 0.08 & -0.09-0.14\end{array}$

$17.7 \quad 1.18(1.20)$

$\begin{array}{rr}14.41 & 1.5 \\ 6.72 & 1.4 \\ 0.52 & 1.0 \\ -1.40 & 1.1\end{array}$

$\begin{array}{rcc}1.38 & 0.06 & 1.30-1.46 \\ 0.64 & 0.07 & 0.54-0.73 \\ -0.64 & 0.14 & -0.84--0.43 \\ 0.22 & 0.05 & 0.14-0.30 \\ -0.17 & 0.05 & -0.24--0.09 \\ -0.16 & 0.06 & -0.24--0.09 \\ 0.11 & 0.06 & 0.02-0.20 \\ 0.21 & 0.18 & -0.04-0.47 \\ -0.12 & 0.12 & -0.31-0.06\end{array}$

$39.4 \quad 4.27(4.42)$

$\begin{array}{rr}75.19 & 1.7 \\ 17.23 & 6.0 \\ 15.19 & 1.1 \\ 8.96 & 1.2 \\ 7.35 & 1.3 \\ 1.23 & 1.4 \\ -0.67 & 10.4 \\ -1.16 & 4.8\end{array}$

$\begin{array}{rrc}2.42 & 0.06 & 2.34-2.50 \\ 0.58 & 0.09 & 0.44-0.71 \\ 0.31 & 0.06 & 0.23-0.40 \\ 0.93 & 0.16 & 0.69-1.16 \\ -0.47 & 0.09 & -0.59--0.35 \\ -0.42 & 0.09 & -0.55--0.29 \\ -0.24 & 0.05 & -0.32--0.16\end{array}$

$39.1 \quad 14.95(15.60)$

$\begin{array}{ll}35.24 & 1.3 \\ 28.10 & 1.1 \\ 27.78 & 7.6 \\ 27.53 & 1.3 \\ 17.39 & 1.1 \\ 15.05 & 1.1\end{array}$




SpatEig48
LndWinTemp
SpatEig37
RegPercMix
PercFemale
Ruby-throated Humming
Intercept
SpatEig14
SpatEig13
SpatEig36
LndMaxTemp
SpatEig27
PercFemale
Northern Mockingbird
Intercept
SpatEig13
SpatEig49
SpatEig37
SpatEig47
LndWinTemp
SpatEig1
SpatEig40
SpatEig21
SpatEig16

$\begin{array}{rrr}-0.31 & 0.05 & -0.42--0.20 \\ -0.25 & 0.16 & -0.49--0.01 \\ 0.07 & 0.05 & -0.01-0.16 \\ 0.03 & 0.07 & -0.08-0.13 \\ 0.00 & 0.05 & -0.08-0.08\end{array}$

Ruby-throated Hummingbird

$\begin{array}{rrr}0.76 & 0.06 & 0.67-0.84 \\ 0.39 & 0.07 & 0.30-0.50 \\ 0.26 & 0.06 & 0.17-0.35 \\ 0.20 & 0.05 & 0.13-0.27 \\ -0.21 & 0.06 & -0.30--0.13 \\ -0.20 & 0.05 & -0.28--0.12 \\ 0.10 & 0.06 & 0.02-0.18\end{array}$




SpatEig12
SpatEig36
SpatEig5
SpatEig4
LndPercDec
SpatEig82
SpatEig54
SpatEig23
SpatEig26
RegArea
PercFemale
LndMaxTemp

Brown-headed Cowbird

Intercept

SpatEig45

SpatEig17

PercFemale

SpatEig11

SpatEig20

IntRegTempFem

RegMaxTemp

Percent college

$\begin{array}{rcc}-0.21 & 0.04 & -0.27--0.14 \\ -0.21 & 0.04 & -0.29--0.14 \\ -0.18 & 0.04 & -0.25--0.12 \\ -0.16 & 0.04 & -0.23--0.10 \\ -0.24 & 0.06 & -0.33--0.14 \\ -0.12 & 0.04 & -0.18--0.07 \\ 0.16 & 0.04 & 0.09-0.23 \\ 0.10 & 0.04 & 0.05-0.16 \\ -0.11 & 0.04 & -0.18--0.05 \\ 0.09 & 0.06 & 0.01-0.17 \\ -0.03 & 0.04 & -0.10-0.04 \\ -0.05 & 0.12 & -0.23-0.12\end{array}$

18.29

15.64

15.52

13.60

10.61

10.23

10.07

4.95

4.60

0.09

$-1.90$

$-2.07$

$18.5 \quad 19.08(19.52)$

$\begin{array}{rcc}3.41 & 0.04 & 3.35-3.47 \\ 0.32 & 0.04 & 0.25-0.39 \\ -0.17 & 0.04 & -0.23--0.12 \\ -0.14 & 0.04 & -0.20--0.08 \\ 0.16 & 0.04 & 0.10-0.23 \\ -0.14 & 0.04 & -0.21--0.08 \\ 0.11 & 0.04 & 0.05-0.17 \\ -0.02 & 0.04 & -0.09-0.05\end{array}$

0.62

0.10

$0.48-0.77$

0.70

0.12

$0.50-0.90$
1.2

1.1

1.2

1.0

2.0

1.0

1.1

1.0

1.0

2.0

1.1

9.2

Intercept

LndMaxTemp 


SpatEig73
SpatEig9
PercCollege
SpatEig12
SpatEig2
SpatEig8
SpatEig11
SpatEig42
IntLndTemCol

Acadian Flycatcher

Intercept

LndPercDec

SpatEig10

RegMaxTemp

SpatEig3

PercCollege

Hairy Woodpecker

Intercept

LndPercDec

LndMaxTemp

PercCollege

White-breasted Nuthatch

Intercept

$\begin{array}{rcc}0.40 & 0.09 & 0.28-0.53 \\ 0.53 & 0.11 & 0.36-0.71 \\ -0.40 & 0.12 & -0.57--0.23 \\ 0.31 & 0.09 & 0.19-0.43 \\ -0.40 & 0.10 & -0.57--0.24 \\ -0.34 & 0.09 & -0.47--0.21 \\ -0.30 & 0.09 & -0.42--0.18 \\ -0.22 & 0.09 & -0.34--0.10 \\ 0.32 & 0.14 & 0.12-0.52\end{array}$

20.41

15.90

15.15

12.33

12.08

11.68

10.16

5.08

3.43

$28.8 \quad 7.00(7.18)$

$\begin{array}{rcc}1.72 & 0.07 & 1.61-1.83 \\ 1.10 & 0.10 & 0.94-1.26 \\ -0.50 & 0.08 & -0.63--0.36 \\ 0.50 & 0.10 & 0.34-0.66 \\ -0.26 & 0.07 & -0.39--0.15 \\ 0.08 & 0.08 & -0.03-0.18\end{array}$

91.19

27.97

18.18

10.11

$-0.98$

1.9

1.9

$\begin{array}{rrr}-0.02 & 0.08 & -0.13-0.09 \\ 0.41 & 0.09 & 0.28-0.54 \\ -0.23 & 0.10 & -0.38--0.07 \\ 0.08 & 0.09 & -0.04-0.20\end{array}$

17.

$1.17(1.19)$

16.78

1.5

2.41

$-1.15$

1.6

1.2 


LndPercDec
PercCollege
SpatEig4
RegWinTemp
SpatEig7
RegSprPrec
LndMaxTemp
RegMaxTemp
Yellow-breasted Chat
Intercept
LndMaxTemp
SpatEig16
SpatEig18
SpatEig48
SpatEig11
LndPercDev
SpatEig1
PercCollege
SpatEig34
SpatEig37
IntLndTempCol
LndWinTemp
RegPercMix

$\begin{array}{rcc}0.73 & 0.07 & 0.63-0.83 \\ 0.25 & 0.05 & 0.18-0.33 \\ -0.17 & 0.05 & -0.25--0.10 \\ -0.50 & 0.14 & -0.71--0.28 \\ -0.12 & 0.06 & -0.21--0.03 \\ 0.12 & 0.06 & 0.03-0.21 \\ -0.17 & 0.12 & -0.35--5.6 \mathrm{E}-04 \\ 0.24 & 0.18 & -0.01-0.49\end{array}$

$\begin{array}{rr}95.30 & 1.8 \\ 21.81 & 1.2 \\ 8.86 & 1.2 \\ 8.81 & 5.9 \\ 1.87 & 1.2 \\ 1.66 & 1.4 \\ -0.02 & 4.3 \\ -0.23 & 10.1\end{array}$

$\begin{array}{rrr}2.42 & 0.06 & 2.34-2.51 \\ 0.86 & 0.16 & 0.64-1.09 \\ 0.48 & 0.08 & 0.35-0.62 \\ 0.29 & 0.06 & 0.20-0.38 \\ -0.32 & 0.05 & -0.42--0.22 \\ -0.24 & 0.05 & -0.32--0.16 \\ -0.37 & 0.10 & -0.50--0.23 \\ -0.34 & 0.08 & -0.47--0.21 \\ -0.23 & 0.07 & -0.34--0.12 \\ 0.19 & 0.05 & 0.11-0.27 \\ 0.13 & 0.05 & 0.05-0.22 \\ 0.14 & 0.08 & 0.02-0.26 \\ -0.11 & 0.16 & -0.34-0.12 \\ 0.01 & 0.07 & -0.09-0.11\end{array}$

$43.9 \quad 14.66(15.33)$

$\begin{array}{rr}28.76 & 7.8 \\ 24.84 & 1.4 \\ 22.10 & 1.1 \\ 19.05 & 1.0 \\ 15.95 & 1.1 \\ 11.83 & 1.2 \\ 11.53 & 1.3 \\ 9.80 & 1.2 \\ 8.07 & 1.0 \\ 2.70 & 1.1 \\ 0.69 & 1.2 \\ -1.67 & 9.1 \\ -2.15 & 1.9\end{array}$


Ruby-throated Hummingbird

Intercept
SpatEig14
PercCollege
LndMaxTemp
SpatEig13
SpatEig36
Northern Mockingbird
Intercept
SpatEig37
SpatEig49
SpatEig47
SpatEig13
SpatEig21
SpatEig16
SpatEig40
LndWinTemp
PercCollege
SpatEig36
LndPercDec
SpatEig5
SpatEig43
SpatEig12
SpatEig4
SpatEig54

$\begin{array}{rrc}0.74 & 0.06 & 0.66-0.82 \\ 0.37 & 0.07 & 0.27-0.47 \\ -0.31 & 0.07 & -0.41--0.22 \\ -0.28 & 0.06 & -0.37--0.19 \\ 0.26 & 0.06 & 0.17-0.34 \\ 0.18 & 0.05 & 0.11-0.25\end{array}$

$17.5 \quad 1.92(1.96)$

$30.29 \quad 1.0$

$19.05 \quad 1.1$

$18.27 \quad 1.2$

$16.63 \quad 1.1$

$11.49 \quad 1.0$

$\begin{array}{rlc}3.71 & 0.04 & 3.65-3.77 \\ -0.34 & 0.04 & -0.42--0.27 \\ 0.34 & 0.05 & 0.26-0.43 \\ -0.38 & 0.06 & -0.47--0.29 \\ -0.27 & 0.04 & -0.34--0.21 \\ -0.25 & 0.04 & -0.31--0.19 \\ -0.37 & 0.06 & -0.47--0.28 \\ -0.27 & 0.04 & -0.34--0.20 \\ 0.73 & 0.12 & 0.53-0.92 \\ 0.21 & 0.04 & 0.14-0.27 \\ -0.22 & 0.04 & -0.29--0.15 \\ -0.27 & 0.06 & -0.36--0.17 \\ -0.17 & 0.04 & -0.23--0.11 \\ -0.18 & 0.04 & -0.25--0.11 \\ -0.17 & 0.04 & -0.24--0.10 \\ -0.15 & 0.04 & -0.21--0.08 \\ 0.15 & 0.04 & 0.09-0.22\end{array}$

$47.2 \quad 28.37(30.74)$

$\begin{array}{rr}40.87 & 1.2 \\ 39.40 & 1.4 \\ 38.98 & 1.5 \\ 37.43 & 1.2 \\ 30.49 & 1.1 \\ 28.37 & 1.5 \\ 27.41 & 1.1 \\ 25.32 & 8.8 \\ 21.13 & 1.2 \\ 18.66 & 1.1 \\ 14.10 & 2.0 \\ 13.60 & 1.2 \\ 13.11 & 1.0 \\ 11.64 & 1.2 \\ 10.13 & 1.0 \\ 9.24 & 1.1\end{array}$




\begin{tabular}{|c|c|c|c|c|c|c|c|c|}
\hline & SpatEig19 & -0.12 & 0.04 & $-0.18--0.07$ & & & 7.33 & 1.0 \\
\hline & SpatEig26 & -0.11 & 0.04 & $-0.18--0.05$ & & & 4.44 & 1.0 \\
\hline & RegArea & 0.14 & 0.06 & $0.06-0.22$ & & & 3.55 & 2.0 \\
\hline & SpatEig23 & 0.09 & 0.04 & $0.04-0.15$ & & & 3.51 & 1.0 \\
\hline & LndMaxTemp & -0.17 & 0.12 & $-0.34--2.8 \mathrm{E}-03$ & & & -0.12 & 8.1 \\
\hline & Brown-headed Cowbird & & & & & & & \\
\hline & Intercept & 3.39 & 0.04 & $3.33-3.45$ & 18.8 & $18.80(19.11)$ & & \\
\hline & SpatEig45 & 0.33 & 0.04 & $0.26-0.40$ & & & 41.00 & 1.0 \\
\hline & SpatEig5 & 0.19 & 0.04 & $0.13-0.24$ & & & 18.39 & 1.0 \\
\hline & SpatEig17 & -0.17 & 0.04 & $-0.22--0.11$ & & & 17.48 & 1.0 \\
\hline & SpatEig11 & 0.18 & 0.04 & $0.12-0.25$ & & & 14.83 & 1.0 \\
\hline & SpatEig20 & -0.14 & 0.04 & $-0.20--0.08$ & & & 8.90 & 1.0 \\
\hline Median age & Kentucky Warbler & & & & & & & \\
\hline & Intercept & 0.65 & 0.10 & $0.51-0.79$ & 12.6 & $3.39(3.52)$ & & \\
\hline & LndMaxTemp & 0.93 & 0.12 & $0.74-1.13$ & & & 42.75 & 1.5 \\
\hline & SpatEig2 & -0.55 & 0.10 & $-0.72--0.40$ & & & 29.29 & 1.3 \\
\hline & SpatEig8 & -0.52 & 0.10 & $-0.65--0.38$ & & & 27.68 & 1.2 \\
\hline & SpatEig73 & 0.39 & 0.10 & $0.26-0.52$ & & & 17.23 & 1.0 \\
\hline & SpatEig9 & 0.53 & 0.11 & $0.34-0.72$ & & & 13.49 & 1.1 \\
\hline & SpatEig15 & 0.31 & 0.09 & $0.18-0.44$ & & & 8.58 & 1.0 \\
\hline & SpatEig42 & -0.27 & 0.09 & $-0.39--0.15$ & & & 8.39 & 1.0 \\
\hline & SpatEig12 & 0.27 & 0.09 & $0.14-0.40$ & & & 7.20 & 1.0 \\
\hline & IntLndTempAge & 0.09 & 0.10 & $-0.06-0.24$ & & & -1.46 & 1.1 \\
\hline & MedianAge & -0.03 & 0.10 & $-0.19-0.13$ & & & -1.46 & 1.1 \\
\hline
\end{tabular}


Acadian Flycatcher

Intercept
LndPercDec
SpatEig10
RegMaxTemp
SpatEig3
MedianAge

$\begin{array}{rcc}1.72 & 0.07 & 1.61-1.82 \\ 1.04 & 0.10 & 0.90-1.19 \\ -0.50 & 0.08 & -0.63--0.37 \\ 0.46 & 0.10 & 0.31-0.60 \\ -0.25 & 0.07 & -0.38--0.13 \\ 0.13 & 0.08 & 0.01-0.24\end{array}$

$27.9 \quad 7.09(7.27)$

$88.99 \quad 1.8$

$28.73 \quad 1.1$

$18.45 \quad 1.6$

$8.76 \quad 1.0$

$0.37 \quad 1.1$

Hairy Woodpecker

Intercept

$\begin{array}{lll}-0.02 & 0.08 & -0.13-0.09\end{array}$

$\begin{array}{lll}0.40 & 0.09 & 0.27-0.53\end{array}$

LndPercDec

LndMaxTemp

MedianAge

$-0.28 \quad 0.09 \quad-0.42--0.13$

$\begin{array}{lll}-0.06 & 0.08 & -0.18-0.06\end{array}$

$15.6 \quad 1.18(1.20)$

$16.50 \quad 1.5$

$5.44 \quad 1.4$

White-breasted Nuthatch

Intercept
LndPercDec
RegWinTemp
SpatEig39
SpatEig4
SpatEig1
RegSprPrec
RegMaxTemp
LndMaxTemp
MedianAge

\begin{tabular}{|c|c|c|c|c|c|}
\hline 1.38 & 0.06 & $1.30-1.46$ & 39.2 & $4.28(4.44)$ & \\
\hline 0.64 & 0.07 & $0.54-0.74$ & & 74.16 & 1.8 \\
\hline-0.66 & 0.14 & $-0.85--0.46$ & & 19.06 & 5.8 \\
\hline 0.22 & 0.05 & $0.14-0.30$ & & 15.04 & 1.1 \\
\hline-0.17 & 0.05 & $-0.24--0.09$ & & 8.76 & 1.2 \\
\hline-0.16 & 0.05 & $-0.24--0.09$ & & 7.60 & 1.3 \\
\hline 0.11 & 0.06 & $0.02-0.20$ & & 1.23 & 1.4 \\
\hline 0.23 & 0.18 & $-0.02-0.48$ & & -0.30 & 9.9 \\
\hline-0.13 & 0.12 & $-0.31-0.06$ & & -1.12 & 4.7 \\
\hline-0.02 & 0.06 & $-0.11-0.06$ & & -1.96 & 1.1 \\
\hline
\end{tabular}


Yellow-breasted Chat

Intercept
SpatEig16
SpatEig1
LndMaxTemp
SpatEig18
LndPercDev
SpatEig11
SpatEig48
IntLndTempAge
LndWinTemp
SpatEig37
MedianAge
RegPercMix

$\begin{array}{rll}2.44 & 0.06 & 2.36-2.52 \\ 0.57 & 0.09 & 0.43-0.70 \\ -0.48 & 0.09 & -0.60--0.36 \\ 0.90 & 0.16 & 0.66-1.14 \\ 0.31 & 0.06 & 0.23-0.40 \\ -0.40 & 0.09 & -0.53--0.27 \\ -0.24 & 0.05 & -0.32--0.16 \\ -0.31 & 0.05 & -0.42--0.2 \\ 0.09 & 0.06 & -4.5 \mathrm{E}-03-0.18 \\ -0.22 & 0.17 & -0.46-0.01 \\ 0.07 & 0.05 & -0.01-0.16 \\ 0.02 & 0.06 & -0.07-0.10 \\ 0.04 & 0.07 & -0.07-0.14\end{array}$

$40.5 \quad 14.95(15.66)$

$33.97 \quad 1.4$

$28.81 \quad 1.3$

$28.80 \quad 7.9$

$27.88 \quad 1.1$

$15.86 \quad 1.2$

$15.11 \quad 1.1$

$14.83 \quad 1.0$

$-0.29 \quad 1.1$

$\begin{array}{ll}-0.33 & 8.9\end{array}$

$-0.70 \quad 1.1$

$-1.54 \quad 1.2$

$\begin{array}{ll}-1.88 & 1.9\end{array}$

Ruby-throated Hummingbird

\begin{tabular}{|c|c|c|c|c|c|c|}
\hline Intercept & 0.75 & 0.06 & $0.67-0.83$ & 17.0 & & \\
\hline SpatEig14 & 0.38 & 0.07 & $0.29-0.48$ & & 33.22 & 1.0 \\
\hline SpatEig36 & 0.21 & 0.05 & $0.14-0.28$ & & 16.65 & 1.0 \\
\hline SpatEig13 & 0.25 & 0.06 & $0.16-0.33$ & & 14.85 & 1.1 \\
\hline SpatEig27 & -0.18 & 0.05 & $-0.27--0.10$ & & 8.45 & 1.0 \\
\hline LndMaxTemp & -0.19 & 0.06 & $-0.27--0.10$ & & 7.06 & 1.1 \\
\hline MedianAge & 0.11 & 0.06 & $0.03-0.19$ & & 1.82 & 1.0 \\
\hline SpatEig32 & 0.10 & 0.05 & $0.02-0.18$ & & 1.51 & 1.0 \\
\hline
\end{tabular}


Northern Mockingbird

\begin{tabular}{|c|c|c|c|c|c|c|c|}
\hline Intercept & 3.74 & 0.04 & $3.68-3.80$ & 36.2 & $31.47(33.85)$ & & \\
\hline SpatEig37 & -0.35 & 0.05 & $-0.43--0.28$ & & & 39.52 & 1.2 \\
\hline SpatEig13 & -0.28 & 0.04 & $-0.35--0.21$ & & & 33.62 & 1.2 \\
\hline LndWinTemp & 0.85 & 0.13 & $0.65-1.04$ & & & 33.56 & 8.8 \\
\hline SpatEig49 & 0.30 & 0.05 & $0.22-0.38$ & & & 28.32 & 1.1 \\
\hline SpatEig47 & -0.32 & 0.05 & $-0.41--0.24$ & & & 27.29 & 1.2 \\
\hline SpatEig1 & -0.22 & 0.05 & $-0.29--0.16$ & & & 23.10 & 1.3 \\
\hline SpatEig21 & -0.21 & 0.04 & $-0.27--0.15$ & & & 19.84 & 1.1 \\
\hline SpatEig40 & -0.24 & 0.04 & $-0.33--0.16$ & & & 16.74 & 1.1 \\
\hline SpatEig4 & -0.16 & 0.04 & $-0.22--0.10$ & & & 15.90 & 1.1 \\
\hline SpatEig16 & -0.28 & 0.06 & $-0.37--0.18$ & & & 14.84 & 1.5 \\
\hline SpatEig12 & -0.20 & 0.05 & $-0.27--0.13$ & & & 14.49 & 1.3 \\
\hline SpatEig36 & -0.18 & 0.04 & $-0.25--0.11$ & & & 11.05 & 1.1 \\
\hline MedianAge & -0.14 & 0.05 & $-0.21--0.07$ & & & 5.79 & 1.2 \\
\hline SpatEig39 & 0.12 & 0.04 & $0.05-0.18$ & & & 4.34 & 1.2 \\
\hline SpatEig23 & 0.10 & 0.04 & $0.04-0.15$ & & & 3.76 & 1.0 \\
\hline SpatEig26 & -0.10 & 0.04 & $-0.17--0.04$ & & & 3.10 & 1.0 \\
\hline LndPercDec & -0.11 & 0.06 & $-0.21--0.02$ & & & 0.85 & 1.9 \\
\hline RegArea & 0.04 & 0.06 & $-0.05-0.13$ & & & -1.89 & 2.2 \\
\hline LndMaxTemp & -0.07 & 0.13 & $-0.25-0.11$ & & & -1.91 & 8.9 \\
\hline \multicolumn{8}{|c|}{ Brown-headed Cowbird } \\
\hline Intercept & 3.42 & 0.04 & $3.37-3.48$ & 18.2 & $19.22(19.74)$ & & \\
\hline SpatEig45 & 0.33 & 0.04 & $0.26-0.41$ & & & 38.30 & 1.0 \\
\hline SpatEig5 & 0.19 & 0.04 & $0.14-0.25$ & & & 19.29 & 1.1 \\
\hline
\end{tabular}


SpatEig17

MedianAge

RegMaxTemp

IntRegTempAge

SpatEig20

Median income

$\begin{array}{rcc}-0.17 & 0.04 & -0.23--0.11 \\ -0.12 & 0.04 & -0.18--0.06 \\ -0.10 & 0.04 & -0.16--0.03 \\ 0.16 & 0.04 & 0.10-0.23 \\ -0.16 & 0.04 & -0.23--0.09\end{array}$

$\begin{array}{rcc}0.94 & 0.11 & 0.78-1.19 \\ -0.31 & 0.15 & -0.52--0.19 \\ 0.57 & 0.11 & 0.39-0.75 \\ -0.35 & 0.09 & -0.47--0.24 \\ 0.50 & 0.12 & 0.29-0.71 \\ 0.78 & 0.17 & 0.51-1.05 \\ 0.33 & 0.10 & 0.20-0.47 \\ -0.31 & 0.10 & -0.49--0.15\end{array}$

IntLndTempInc

SpatEig12

SpatEig2

Acadian Flycatcher

Intercept

1.73

1.23

$-0.55$

0.64

0.21

$$
\begin{array}{lc}
0.08 & 1.62-1.84 \\
0.10 & 1.07-1.41 \\
0.08 & -0.67--0.43 \\
0.11 & 0.47-0.82 \\
0.08 & 0.10-0.31
\end{array}
$$

Hairy Woodpecker

Intercept

LndPercDec $\begin{array}{lll}0.06 & 0.09 & -0.06-0.18\end{array}$

$\begin{array}{lll}0.38 & 0.10 & 0.24-0.53\end{array}$
18.13

13.61

13.41

11.18

8.26

$11.0 \quad 3.30(3.39)$

30.58

23.45

17.58

16.63

14.30

11.61

6.40

1.3

1.0

1.0

1.6

1.2

1.0

1.1

1.1

1.0

1.0

1.1

1.2

$30.1 \quad 7.01(7.13)$

$99.88 \quad 2.0$

$45.31 \quad 1.1$

$27.19 \quad 2.1$

$\begin{array}{ll}7.09 & 1.3\end{array}$

$17.1 \quad 1.16(1.18)$

$12.43 \quad 1.8$ 


LndMaxTemp
MedianInc
IntLndTemInc
White-breasted Nuthatch
Intercept
LndPercDec
MedianInc
RegWinTemp
SpatEig4
RegSprPrec
RegMaxTemp
LndMaxTemp
Yellow-breasted Chat
Intercept
LndMaxTemp
MedianInc
SpatEig48
SpatEig16
SpatEig11
SpatEig18
SpatEig34
IntLndTempInc
SpatEig40
SpatEig10

White-breasted Nuthatch

$\begin{array}{rrc}1.38 & 0.05 & 1.30-1.46 \\ 0.73 & 0.07 & 0.63-0.83 \\ 0.27 & 0.06 & 0.19-0.35 \\ -0.53 & 0.13 & -0.72--0.34 \\ -0.16 & 0.05 & -0.24--0.09 \\ 0.15 & 0.06 & 0.06-0.23 \\ 0.22 & 0.17 & -0.02-0.46 \\ -0.12 & 0.12 & -0.30-0.06\end{array}$

$\begin{array}{rr}57.21 & 7.0 \\ 38.92 & 1.3 \\ 28.59 & 1.1 \\ 28.22 & 1.4 \\ 16.93 & 1.1 \\ 14.31 & 1.1 \\ 13.95 & 1.1 \\ 13.09 & 1.3 \\ 7.09 & 1.0 \\ 5.46 & 1.1\end{array}$




LndPercDev
SpatEig37
SpatEig4
LndWinTemp
RegPercMix

Ruby-throated Hummingbird

Intercept
SpatEig14
MedianInc
LndMaxTemp
IntLndTempInc
Northern Mockingbird
Intercept
SpatEig37
SpatEig47
SpatEig13
SpatEig49
LndWinTemp
SpatEig21
SpatEig40
MedianInc
SpatEig16
SpatEig36
SpatEig12

$\begin{array}{rcc}-0.26 & 0.10 & -0.40--0.12 \\ 0.16 & 0.05 & 0.07-0.24 \\ 0.10 & 0.05 & 0.03-0.18 \\ -0.26 & 0.16 & -0.48--0.04 \\ -0.03 & 0.07 & -0.13-0.07\end{array}$

4.59

$\begin{array}{rcc}0.90 & 0.06 & 0.81-1.00 \\ 0.31 & 0.06 & 0.21-0.40 \\ -0.15 & 0.08 & -0.26--0.04 \\ -0.14 & 0.06 & -0.23--0.04 \\ 0.33 & 0.09 & 0.19-0.47\end{array}$

$11.1 \quad 1.90(1.93)$

$\begin{array}{rr}21.31 & 1.0 \\ 19.33 & 1.3 \\ 17.37 & 1.3 \\ 9.89 & 1.2\end{array}$

$\begin{array}{rlc}3.71 & 0.04 & 3.65-3.77 \\ -0.37 & 0.04 & -0.45--0.29 \\ -0.38 & 0.06 & -0.47--0.29 \\ -0.28 & 0.04 & -0.34--0.21 \\ 0.32 & 0.05 & 0.24-0.41 \\ 0.79 & 0.12 & 0.60-0.99 \\ -0.25 & 0.04 & -0.31--0.19 \\ -0.25 & 0.04 & -0.33--0.18 \\ 0.22 & 0.05 & 0.16-0.29 \\ -0.33 & 0.06 & -0.43--0.24 \\ -0.22 & 0.04 & -0.29--0.15 \\ -0.19 & 0.04 & -0.25--0.13\end{array}$

$47.75 \quad 1.2$

$39.47 \quad 1.5$

$39.22 \quad 1.2$

$35.03 \quad 1.4$

$31.17 \quad 8.8$

$30.82 \quad 1.1$

$24.64 \quad 1.1$

$23.15 \quad 1.4$

$22.39 \quad 1.5$

$19.60 \quad 1.1$

$15.84 \quad 1.2$ 


\begin{tabular}{|c|c|c|c|c|c|c|c|}
\hline SpatEig5 & -0.18 & 0.04 & $-0.24--0.11$ & & & 15.62 & 1.2 \\
\hline SpatEig43 & -0.17 & 0.04 & $-0.23--0.10$ & & & 11.90 & 1.0 \\
\hline SpatEig4 & -0.15 & 0.04 & $-0.21--0.09$ & & & 11.41 & 1.0 \\
\hline SpatEig82 & -0.13 & 0.04 & $-0.18--0.08$ & & & 10.67 & 1.0 \\
\hline SpatEig54 & 0.16 & 0.04 & $0.10-0.23$ & & & 10.54 & 1.1 \\
\hline LndPercDec & -0.22 & 0.06 & $-0.31--0.12$ & & & 8.59 & 2.2 \\
\hline SpatEig23 & 0.11 & 0.04 & $0.06-0.17$ & & & 6.05 & 1.0 \\
\hline SpatEig26 & -0.12 & 0.04 & $-0.18--0.06$ & & & 5.27 & 1.0 \\
\hline RegArea & 0.14 & 0.06 & $0.06-0.23$ & & & 3.79 & 2.1 \\
\hline LndMaxTemp & -0.13 & 0.12 & $-0.30-0.04$ & & & -0.97 & 8.2 \\
\hline \multicolumn{8}{|c|}{ Brown-headed Cowbird } \\
\hline Intercept & 3.36 & 0.04 & $3.29-3.42$ & 19.8 & $18.61(19.09)$ & & \\
\hline SpatEig45 & 0.32 & 0.04 & $0.25-0.39$ & & & 41.29 & 1.0 \\
\hline SpatEig5 & 0.18 & 0.04 & $0.12-0.24$ & & & 16.78 & 1.1 \\
\hline SpatEig17 & -0.16 & 0.04 & $-0.22--0.10$ & & & 15.62 & 1.0 \\
\hline SpatEig11 & 0.19 & 0.04 & $0.12-0.26$ & & & 14.58 & 1.2 \\
\hline SpatEig20 & -0.14 & 0.04 & $-0.21--0.08$ & & & 8.17 & 1.1 \\
\hline MedianInc & 0.06 & 0.05 & $-0.01-0.13$ & & & 4.42 & 1.3 \\
\hline IntRegTempInc & -0.09 & 0.05 & $-0.16--0.02$ & & & 0.98 & 1.2 \\
\hline RegMaxTemp & 0.01 & 0.05 & $-0.06-0.08$ & & & -1.00 & 1.3 \\
\hline
\end{tabular}

$\dagger$ The best-supported model among a set of competing models was the model with the lowest AIC $\mathrm{c}$ value. There were 32 sets of competing models, one for each combination of 8 species and 4 socioeconomic variables.

$\$$ See Table 2 in the main text for definitions of explanatory variables. 
$\S R^{2}$ COR was the squared correlation between observed and predicted relative abundance (Cameron and Trivedi 2013).

I Mean absolute error (MAE) of predictions for fitted model; MAE (predicted) is for leave-one-out cross validation.

" $\triangle \mathrm{AIC}_{\mathrm{c}}$ is the difference in $\mathrm{AIC}_{\mathrm{c}}$ values between the best-supported model and the reduced model in which the variable of interest was removed (Coppes et al. 2017). Within a model, variables with larger $\Delta \mathrm{AIC}_{\mathrm{c}}$ values were more influential than were those with smaller $\triangle \mathrm{AIC}_{\mathrm{c}}$ values; negative $\triangle \mathrm{AIC}_{\mathrm{c}}$ values indicate that the reduced model had a better fit than did the best model, implying that the associated variable was not influential.

\# SpatEig = spatial eigenvector. 


\section{LITERATURE CITED}

Billerman, S. M., B. K. Keeny, P. Rodewald, and T. S. Schulenberg. (Eds). 2020. Birds of the World. Cornell Lab of Ornithology, Ithaca, New York, USA. [online] URL:

https://birdsoftheworld.org/bow/home

BirdLife International, and Handbook of the Birds of the World. 2016. Bird species distribution maps of the world. Version 6.0. http://datazone.birdlife.org/species/requestdis

Buckland, S. T., S. J. Marsden, and R. E. Green. 2008. Estimating bird abundance: making methods work. Bird Conservation International 18:91-108.

https://doi.org/10.1017/S0959270908000294

Cameron, A. C., and P. K. Trivedi. 2013. Regression analysis of count data 2 nd ed. Cambridge University Press, New York, NY, USA.

Canty, A., and B. Ripley. 2017. boot: Bootstrap R (S-Plus) functions. R package version 1.3-20. [online] URL: https://CRAN.R-project.org/package=boot

Carver, E. 2009. Birding in the United States: a demographic and economic analysis. Addendum to the 2006 National Survey of Fishing, Hunting, and Wildlife-Associated Recreation. U.S. Fish and Wildlife Service, Arlington, Virginia, USA.

Chuang, T.-F., and Y.-H. Chang. 2014. Comparison of physical characteristics between Rana latouchtii and Rana adenopleura using grey system theory and Artificial Neural Network. Ecological Engineering 68:223-232. https://doi.org/10.1016/j.ecoleng.2014.03.038

Commission for Environmental Cooperation. 1997. Ecological regions of North America: towards a common perspective. Commission for Environmental Cooperation, Montreal, Quebec, Canada. [online] URL: http://www3.cec.org/islandora/en/item/1701-ecological-regions-northamerica-toward-common-perspective/

Coppes, J., J. Ehrlacher, D. Thiel, R. Suchant, and V. Braunisch. 2017. Outdoor recreation causes effective habitat reduction in capercaillie Tetrao urogallus: a major threat for geographically restricted populations. Journal of Avian Biology 48:1583-1594.

https://doi.org/10.1111/jav.01239

Downes, C. M., M.-A. R. Hudson, A. C. Smith, and C. M. Francis. 2016. The Breeding Bird Survey at 50: scientists and birders working together for bird conservation. Avian Conservation and Ecology 11(1):8. https://doi.org/10.5751/ACE-00855-110108

Drapeau, P., A. Leduc, J.-F. Giroux, J.-P. L. Savard, Y. Bergeron, and W. L. Vickery. 2000. Landscape-scale disturbances and changes in bird communities of boreal mixed-wood forests. 
Ecological Monographs 70:423-444. https://doi.org/10.1890/00129615(2000)070[0423:LSDACI]2.0.CO;2

Ehrlich, P. R., D. S. Dobkin, and D. Wheye. 1988. The birder's handbook: a field guide to the natural history of North American birds. Simon \& Schuster, New York, USA.

ESRI. 2012. ArcGIS Desktop 10.1. Environmental Systems Research Institute, Redlands, California, USA.

Farnsworth, G., G. A. Londono, J. U. Martin, K. C. Derrickson, and R. Breitwisch. 2020. Northern Mockingbird (Mimus polyglottos) version 1.0. in A. F. Poole, editor. Birds of the World. Cornell Lab of Ornithology, Ithaca, New York, USA.

https://doi.org/10.2173/bow.normmoc.01

Forsman, J. T., and M. Mönkkönen. 2003. The role of climate in limiting European resident bird populations. Journal of Biogeography 30:55-70. https://doi.org/10.1046/j.13652699.2003.00812.x

Fraterrigo, J. M., and J. A. Wiens. 2005. Bird communities of the Colorado Rocky Mountains along a gradient of exurban development. Landscape and Urban Planning 71:263-275. https://doi.org/10.1016/j.landurbplan.2004.03.008

Freemark, K. E., and B. Collins. 1992. Landscape ecology of birds breeding in temperate forest fragments. Pages 443-454 in J. M. I. Hagan and D. W. Johnston, editors. Ecology and conservation of Neotropical migrant landbirds. Smithsonian Institution Press, Washington, DC, USA.

Gutzwiller, K. J., S. K. Riffell, and C. H. Flather. 2015. Avian abundance thresholds, humanaltered landscapes, and the challenge of assemblage-level conservation. Landscape Ecology 30:2095-2110. https://doi.org/10.1007/s10980-015-0233-1

Hamner, B., and M. Frasco. 2018. Metrics: evaluation metrics for machine learning. R package version 0.1.4. [online] URL: https://CRAN.R-project.org/package=Metrics

Harrell, F. E. Jr. 2001. Regression modeling strategies: with applications to linear models, logistic regression, and survival analysis. Springer, New York, USA.

Heisler-White, J. L., A. K. Knapp, and E. F. Kelly. 2008. Increasing precipitation event size increases aboveground net primary productivity in a semi-arid grassland. Oecologia 158:129140. https://doi.org/10.1007/s00442-008-1116-9

Hilbe, J. M. 2014. Modeling count data. Cambridge University Press, New York, USA. 
Holmes, R. T., and T. W. Sherry. 2001. Thirty-year bird population trends in an unfragmented temperate deciduous forest: importance of habitat change. The Auk 118:589-609. https://doi.org/10.1642/0004-8038(2001)118[0589:TYBPTI]2.0.CO;2

Howard, C., P. A. Stephens, J. W. Pearce-Higgins, R. D. Gregory, and S. G. Willis. 2015. The drivers of avian abundance: patterns in the relative importance of climate and land use. Global Ecology and Biogeography 24:1249-1260. https://doi.org/10.1111/geb.12377

Illán, J. G., C. D. Thomas, J. A. Jones, W.-K. Wong, S. M. Shirley, and M. G. Betts. 2014. Precipitation and winter temperature predict long-term range-scale abundance changes in Western North American birds. Global Change Biology 20:3351-3364. https://doi.org/10.1111/gcb.12642

Jones, J., P. J. Doran, and R. T. Holmes. 2003. Climate and food synchronize regional forest bird abundances. Ecology 84:3024-3032. https://doi.org/10.1890/02-0639

Kaspari, M. 2001. Taxonomic level, trophic biology and the regulation of local abundance. Global Ecology and Biogeography 10:229-244. https://doi.org/10.1046/j.1466$\underline{822 X .2001 .00214 . X}$

Kaspari, M., S. O’Donnell, and J. R. Kercher. 2000. Energy, density, and constraints to species richness: ant assemblages along a productivity gradient. American Naturalist 155:280-293. https://doi.org/10.1086/303313

Kendall, W. L., B. G. Peterjohn, and J. R. Sauer. 1996. First-time observer effects in the North American Breeding Bird Survey. The Auk 113:823-829. https://doi.org/10.2307/4088860

Lemoine, N., and K. Bohning-Gaese. 2003. Potential impact of global climate change on species richness of long-distance migrants. Conservation Biology 17:577-586.

https://doi.org/10.1046/j.1523-1739.2003.01389.x

MRLC. 2016. National Land Cover Database 2011 (NLCD 2011). Multi-Resolution Land Characteristics Consortium [online] URL: https:/www.mrlc.gov/data

Murray, K. B., F. Di Muro, A. Finn, and P. Popkowski Leszczyc. 2010. The effect of weather on consumer spending. Journal of Retailing and Consumer Services 17:512-520.

https://doi.org/10.1016/j.jretconser.2010.08.006

Neter, J., W. Wasserman, and M. H. Kutner. 1989. Applied linear regression models, 2nd ed. Irwin Inc., Homewood, Illinois, USA. 
Nichols, J. D., J. E. Hines, J. R. Sauer, J. E. Fallon, and P. J. Heglund. 2000. A double-observer approach for estimating detection probability and abundance from point counts. The Auk 117:393-408. https://doi.org/10.2307/4089721

Omernik, J. M., and G. E. Griffith. 2014. Ecoregions of the conterminous United States: evolution of a hierarchical spatial framework. Environmental Management 54:1249-1266. https://doi.org/10.1007/s00267-014-0364-1

PRISM Climate Group. 2016. Climate Data. PRISM Climate Group, Oregon State University. [online] URL: http://www.prism.oregonstate.edu/

R Core Team. 2019. R: A language and environment for statistical computing. version 3.6.1. $\mathrm{R}$ Foundation for Statistical Computing, Vienna, Austria. [online] URL: https://www.r-project.org/

Raich, J. W., A. E. Russell, K. Kitayama, W. J. Parton, and P. M. Vitousek. 2006. Temperature influences carbon accumulation in moist tropical forests. Ecology 87:76-87.

https://doi.org/10.1890/05-0023

Rangel, T. F., J. A. F. Diniz-Filho, and L. M. Bini. 2010. SAM: a comprehensive application for spatial analysis in macroecology. Ecography 33:46-50. https://doi.org/10.1111/j.1600-

0587.2009.06299.x

Sæther, B.-E., S. Engen, and W. J. Sutherland. 2004. Climate influences on avian population dynamics. Pages 185-209 in A. P. Møller, W. Fiedler, and P. Berthold, editors. Birds and climate change. Elsevier, Amsterdam, Netherlands.

Sauer, J. R., J. E. Fallon, and R. Johnson. 2003. Use of North American Breeding Bird Survey data to estimate population change for Bird Conservation Regions. Journal of Wildlife Management 67:372-389. https://doi.org/10.2307/3802778

Schuttler, S. G., A. E. Sorensen, R. C. Jordan, C. Cooper, and A. Shwartz. 2018. Bridging the nature gap: can citizen science reverse the extinction of experience? Frontiers in Ecology and the Environment 16:405-411. https://doi.org/10.1002/fee.1826

Sillett, T. S., R. T. Holmes, and T. W. Sherry. 2000. Impacts of a global climate cycle on population dynamics of a migratory songbird. Science 288:2040-2042.

https://doi.org/10.1126/science.288.5473.2040

Smith, A. C., L. Fahrig, and C. M. Francis. 2011. Landscape size affects the relative importance of habitat amount, habitat fragmentation, and matrix quality on forest birds. Ecography 34:103113. https://doi.org/10.1111/j.1600-0587.2010.06201.x 
Soga, M., K. Gaston, Y. Yamaura, K. Kurisu, and K. Hanaki. 2016. Both direct and vicarious experiences of nature affect children's willingness to conserve biodiversity. International Journal of Environmental Research and Public Health 13:529.

https://doi.org/10.3390/ijerph13060529

Sólymos, P., S. Lele, and E. Bayne. 2012. Conditional likelihood approach for analyzing single visit abundance survey data in the presence of zero inflation and detection error. Environmetrics 23:197-205. https://doi.org/10.1002/env.1149

Sutherland, G. D., A. S. Harestad, K. Price, and K. P. Lertzman. 2000. Scaling of natal dispersal distances in terrestrial birds and mammals. Conservation Ecology 4:16 [online] URL: https://www.jstor.org/stable/26271738?seq=1

Theodori, G. L., and A. E. Luloff. 2002. Position on environmental issues and engagement in proenvironmental behaviors. Society \& Natural Resources 15:471-482. https://doi.org/10.1080/08941920290069128

U.S. Census Bureau. 2009. A compass for understanding and using American Community Survey data: what researchers need to know. U.S. Government Printing Office, Washington, DC, USA.

U.S. Census Bureau. 2015. 2009-13 American Community Survey 5-year estimates. [online] URL: https://www.census.gov/programs-surveys/acs/data/summary-file.2013.html.

U.S. Census Bureau. 2016. TIGER/Line shapefiles. [online] URL:

https://www.census.gov/geo/maps-data/data/tiger-line.html.

U.S. Department of Interior, U.S. Fish and Wildlife Service, U.S. Department of Commerce, and U.S. Census Bureau. 2018. 2016 National Survey of Fishing, Hunting, and Wildlife-Associated Recreation. U.S. Fish and Wildlife Service, Washington, DC, USA.

U.S. Environmental Protection Agency. 2017a. Level III and IV Ecoregions of the Continental United States. [online] URL: https://www.epa.gov/eco-research/level-iii-and-iv-ecoregionscontinental-united-states.

U.S. Environmental Protection Agency. 2017b. Ecoregions of North America. [online] URL: https://www.epa.gov/eco-research/ecoregions-north-america.

U.S. Geological Survey Patuxent Wildlife Research Center, and Canadian Wildlife Service. 1998. Instructions for conducting the North American Breeding Bird Survey. [online] URL: https://www.pwrc.usgs.gov/bbs/participate/instructions.html.

Van de Vliert, E., X. Huang, and P. M. Parker. 2004. Do colder and hotter climates make richer societies more, but poorer societies less, happy and altruistic? Journal of Environmental Psychology 24:17-30. https://doi.org/10.1016/S0272-4944(03)00021-5 
Weber, E. P. 2000. A new vanguard for the environment: grass-roots ecosystem management as a new environmental movement. Society \& Natural Resources 13:237-259.

https://doi.org/10.1080/089419200279081

Wellstead, A. M., R. C. Stedman, and J. R. Parkins. 2003. Understanding the concept of representation within the context of local forest management decision making. Forest Policy and Economics 5:1-11. https://doi.org/10.1016/S1389-9341(02)00031-X

Xu, W., Y. Hou, Y. S. Hung, and Y. Zou. 2013. A comparative analysis of Spearman's rho and Kendall's tau in normal and contaminated normal models. Signal Processing 93:261-276. https://doi.org/10.1016/j.sigpro.2012.08.005

Zhang, W., E. Goodale, and J. Chen. 2014. How contact with nature affects children's biophilia, biophobia and conservation attitude in China. Biological Conservation 177:109-116.

https://doi.org/10.1016/j.biocon.2014.06.011

Zuckerberg, B., D. N. Bonter, W. M. Hochachka, W. D. Koenig, A. T. DeGaetano, and J. L. Dickinson. 2011. Climatic constraints on wintering bird distributions are modified by urbanization and weather. Journal of Animal Ecology 80:403-413.

https://doi.org/10.1111/j.1365-2656.2010.01780.x

Zuur, A. F., E. N. Ieno, and C. S. Elphick. 2010. A protocol for data exploration to avoid common statistical problems. Methods in Ecology and Evolution 1:3-14.

https://doi.org/10.1111/j.2041-210X.2009.00001.X 
Appendix 2. Kendall's tau b correlation matrices for candidate explanatory variables for each of the eight study species.

Please click here to download file 'appendix2.xlsx'. 